\title{
Chancelloriids of the Cambrian Burgess Shale
}

\author{
Stefan Bengtson and Desmond Collins
}

\begin{abstract}
The cactus-like chancelloriids from the Middle Cambrian Burgess Shale are revised on the basis of Walcott's (1920) original collections and new material containing several hundred specimens collected by Royal Ontario Museum field expeditions from 1975 to 2000. Walcott's interpretation of chancelloriids as sponges was based on a misinterpretation of the dermal coelosclerites as embedded sponge-type spicules, an interpretation that further led to the lumping of three distinct taxa into one species, Chancelloria eros Walcott, 1920. The other two taxa are herein separated from C. eros and described as Allonnia tintinopsis n.sp. and Archiasterella coriacea n.sp., all belonging to the Family Chancelloriidae Walcott, 1920. Chancelloriids were sedentary animals, anchored to shells or lumps of debris in the muddy bottom, or to sponges, or to other chancelloriids. They had a radially symmetrical body and an apical orifice surrounded by a palisade of modified sclerites. Well-preserved integuments in Al. tintinopsis and Ar. coriacea do not show any ostium-like openings. Neither is there any evidence for internal organs, such as a gut. Partly narrowed specimens suggest that the body periodically contracted from the attached end to expel waste material from the body cavity. Chancelloriids were close in organization to cnidarians but shared the character of coelosclerites with the bilaterian halkieriids and siphogonuchitids. The taxon Coeloscleritophora is most likely paraphyletic.
\end{abstract}

Stefan Bengtson, Department of Palaeobiology and Nordic Center for Earth Evolution, Swedish Museum of Natural History, Box 50007, SE-104 05 Stockholm, Sweden; stefan.bengtson@nrm.se Desmond Collins, 501-437 Roncesvalles Ave., Toronto, Ontario M6R 3B9, Canada; suzanne.collins029@sympatico.ca

Keywords: Cambrian; Burgess Shale; Chancelloriida; Coeloscleritophora; Metazoa; new species

\section{INTRODUCTION}

\section{History of Work}

Of the many kinds of fossil organisms originally described from the Burgess Shale by Charles
Doolittle Walcott, chancelloriids are among the most enigmatic. The genus Chancelloria was introduced by Walcott in his monograph on sponges (Walcott, 1920). At the time, a sponge affinity seemed uncontroversial for these sack-like organ-

http://zoobank.org/4FD984D1-8E0C-4051-9DC9-46B085D5EF22

PE Article Number: 18.1.6A

Copyright: Paleontological Society February 2015

Submission: 4 June 2014. Acceptance: 19 December 2014

Bengtson, Stefan and Collins, Desmond. 2015. Chancelloriids of the Cambrian Burgess Shale. Palaeontologia Electronica 18.1.6A: 167.

palaeo-electronica.org/content/2015/1031-chancelloriids 
isms covered with composite aggregates of sharp spines, somewhat reminiscent of cacti. Chancelloriids have turned out to be very common and widespread Cambrian fossils - their dissociated spines have been found in multitudes in microfossil samples from all continents. Whole-body preservation of chancelloriids, as in the Burgess Shale, is known also from other conservation lagerstätten, such as the Middle Cambrian Wheeler and Marjum Formations in Utah (Rigby, 1978; Gunther and Gunther, 1981; Janussen et al., 2002), the Middle Cambrian Kaili Formation in Guizhou, China (Zhao et al., 2005), the Lower-Middle Cambrian Mount Cap Formation in Northwest Territories, Canada (Harvey and Butterfield, 2011), the Lower Cambrian Yu'anshan Member of the Heilinpu Formation, Chengjiang, China (Chen et al., 1996; Hou et al., 1999; Bengtson and Hou, 2001; Janussen et al., 2002; Dornbos et al., 2005; Kloss et al., 2009), the Lower Cambrian Wulongqing Formation in Yunnan, China (Hu et al., 2010), the Lower Cambrian Balang Formation in Hunan, China (Liu and Lei, 2013), and the Lower Cambrian Sekwi Formation in Northwest Territories, Canada (Randell et al., 2005). Such preservation is generally superior for the purpose of understanding the construction and mode of life of the organisms. The structure of individual sclerites, however, has been taken to indicate that their mode of formation was fundamentally different from that of sponge spicules (Goryanskij, 1973; Bengtson and Missarzhevsky, 1981), and that these skeletal structures are therefore not homologous. The issue of whether chancelloriids are sponges or a different kind of organism has been open ever since.

Burgess Shale sponges have been the subject of three monographs. Walcott's 1920 publication has been superseded by two modern monographs (Rigby, 1986; Rigby and Collins, 2004), but because of the probable non-sponge nature of chancelloriids they were left out of this latter context. The present monograph is intended to remedy the situation and presents for the first time since Walcott a comprehensive analysis of the chancelloriids in the Burgess Shale. The foundation for this work is the collections in the Royal Ontario Museum (ROM) obtained through field expeditions led by Desmond Collins during 18 field seasons between 1975 and 2000. We have also restudied the original Walcott collections at the US National Museum (USNM) in Washington, D.C.

The taxonomy of chancelloriids has developed into a plethora of names mostly based on the shape or structure of isolated sclerites; only a few taxa are known from whole-body preservation or natural associations of sclerites. In the present monograph, we do not address this complex issue, but deal only with taxa known from whole-body preservation, these providing a sounder basis for taxonomy than individual sclerites. We do not thereby imply that sclerite-based studies are without taxonomic value - such studies indeed have led to the recognition of two distinct world-wide genera, Allonnia Doré and Reid, 1965, and Archiasterella Sdzuy, 1969, that were in Walcott's (1920) monograph hidden under the single specific designation Chancelloria eros. Most of the specieslevel taxonomy based on single sclerites, co-occurrences of sclerites, or even clusters of sclerites has turned out to be nearly non-applicable to specimens outside the type series. Morphological variability in large sclerite assemblages united by structural features and repeated co-occurrences may lead to the establishment of recognizable taxa (Bengtson et al., 1990; Moore et al., 2014). Previous studies of complete scleritomes with uniform sclerite composition (Rigby, 1978; Bengtson and Hou, 2001) have inspired optimism regarding the possibility of working taxonomically with disarticulated sclerite assemblages (Moore et al., 2014). However, the extensive Burgess Shale material documented herein demonstrates that, whereas some taxa indeed have very uniform sclerite assemblages, others show a considerable variability both between individuals and within scleritomes. This circumstance renders taxonomy based on disarticulated sclerites unstable at best.

In addition to the descriptive sections in this monograph, we discuss in detail earlier published observations and ideas pertaining to the biological nature and affinities of chancelloriids, and present our interpretations of the anatomy, mode of life, and evolutionary significance of these truly problematic fossil animals.

\section{Material, Methods and Terminology}

The International Code of Zoological Nomenclature $(I C Z N)$ referred to is the $4^{\text {th }}$ Edition (London 1999, also available online at www.nhm.ac.uk/ hosted-sites/iczn/code/).

Location of Material. The specimens illustrated herein are housed under their museum numbers at the Royal Ontario Museum, Toronto, Ontario (ROM numbers) and the National Museum of Natural History, Smithsonian Institution, Washington, D.C. (USNM numbers).

Methods. The photographic images were taken using different methods depending on the preser- 
vation of the material and on which specific aspects needed to be enhanced. The figure captions indicate whether the specimens were figured under water (wet) or dry (dry) and whether or not epipolarization (pol) was used to eliminate direct reflections. The latter method has been particularly successful with Burgess Shale preservation (Boyle, 1992; Bengtson, 2000).

Terminology. The following terms apply to chancelloriid bodies, scleritomes, and sclerites as specified.

Abapical part - proximal (lower) part of chancelloriid body.

Apical part - distal (upper) part of chancelloriid body.

Apical orifice - opening in the apical end of the chancelloriid body.

Apical tuft - circle of spine-shaped sclerites surrounding the apical orifice.

Ascending ray - the ray (central in Chancelloria, marginal in Allonnia and Archiasterella) that starts out at a high angle to the body wall. (In Archiasterella this is equivalent to the "basal ray" of Randell et al., 2005; and the "principal ray" of Moore et al., 2014.)

Basal disk - the part of a chancelloriid sclerite in which the rays are joined.

Basal surface - the surface of a chancelloriid sclerite or ray that carries the foramen/foramina.

Central ray - a ray in a Chancelloria sclerite, the basal surface of which is totally surrounded by the basal surfaces of other rays.

Coelosclerite - sclerite consisting of an aragonitic shell around an inner cavity occupied by organic tissue and opening to the outside via a basal foramen. Characteristic of chancelloriids, halkieriids, siphogonuchitids, and others, collectively known as coeloscleritophorans.

Foramen - basal opening of coeloscleritophoran (single) sclerite or ray.

Integument - outer layer of chancelloriid body, consisting of soft, flexible skin, and mineralized sclerites. It is presumed to have comprised an epidermis and a cuticle.

Lateral ray - one of the two side rays that lie approximately flush with the body wall or form an acute angle with it in the sclerites of Allonnia and Archiasterella.
Length [of body] - distance from the apical end (excluding protruding tuft of spines) to the abapical end.

Marginal ray - a ray in a chancelloriid sclerite, the basal surface of which has a free edge.

Median ray - the ray in an Archiasterella sclerite that lies in the plane of ray symmetry and is flush with the body wall or forms an acute angle with it.

Platelets - elements, about $50 \mu \mathrm{m}$ in size, usually imbricating, in coeloscleritophoran integument.

Ray - individual element of composite chancelloriid sclerite.

Ray formula - notation showing the number of marginal vs. central rays in a chancelloriid sclerite (Qian and Bengtson, 1989, modified after Sdzuy, 1969). Examples: A 3+0 sclerite has three marginal and no central ray; $5-7+1$ sclerites have five to seven marginal and one central ray.

Root bulb - anchoring structure binding coarse grains and debris in sediment.

Sclerite - individual element of scleritome. May be composite or single.

Scleritome - composite skeleton consisting of sclerites.

Skin - soft integument between sclerites.

Stalk - constriction, probably temporal, in the abapical end of the chancelloriid body.

Width [of body] - Preserved maximum width of body, excluding protruding sclerites, if any.

\section{Geologic and Ecologic Setting}

Sediments of the Burgess Shale Formation (Fletcher and Collins, 1998) accumulated in the marine basin west of the submarine cliff, now called the Cathedral Escarpment, marking the western edge of the continental platform off the west coast, in late Middle Cambrian time. The animals of the Burgess Shale lived on, or above, the muddy seafloor some 20-100 m away from the Cathedral Escarpment. The seafloor immediately adjacent to the Escarpment had more silt, presumably eroding off the cliff, and few animals lived there. The depth of the water in Burgess Shale time has been estimated to have been about 100 m (Conway Morris, 1998, p. 111), becoming somewhat less as the basin filled up. The presence of algae, such as Marpolia and Margaretia, indicates that the animals lived within or near the photic zone. 
The Burgess Shale animals found fossil on Fossil Ridge had lived in front of the Escarpment in a succession of communities that were periodically buried by mud flows, more or less in place (Caron and Jackson, 2008).

\section{Chancelloriid Distribution}

The main chancelloriid collecting sites, including Walcott's Phyllopod Bed Quarry, are within an $80 \mathrm{~m}$ thickness of the Burgess Shale Formation abutting the Cathedral Escarpment on Fossil Ridge (Rigby and Collins, 2004, text-figure 6), and in the Trilobite Beds on Mount Stephen (Rigby and Collins, 2004, text-figure 4). Chancelloriids occur intermittently throughout the Burgess Shale Formation.

Chancelloriid specimens were found in five groups, as shown in the field collecting lists. On Fossil Ridge, starting with the oldest: (1) The Greater Phyllopod Bed; (2) the Raymond Quarry; and (3) the Collins Quarries. The oldest common occurrence (4) is in the Trilobite Beds on Mount Stephen. Lastly, (5) a few chancelloriids were found in Monarch Cirque, $60 \mathrm{~km}$ to the east of Fossil Ridge (Rigby and Collins, 2004, text-figure 8).

Provenience for the figured specimens is given in the figure captions as a two-letter prefix (explained in the accounts below of the collecting sites), followed by (if applicable) the distance in centimeters above or below a reference level. Thus "BW -130" refers to a level $130 \mathrm{~cm}$ below the base of Walcott's Phyllopod Bed in the Walcott Quarry.

(1) Greater Phyllopod Bed. The Greater Phyllopod Bed occurs wholly within the Walcott Quarry Member (Fletcher and Collins, 1998). It is composed of Walcott's $2 \mathrm{~m}$ thick Phyllopod Bed at the top, underlain by $5 \mathrm{~m}$ of fossil-bearing shale down to the top of the underlying Wash (limestone) Member. The zero datum used during excavation was the base of Walcott's Phyllopod Bed (BW).

Moving up section from the BW minus $5 \mathrm{~m}$, the lowermost chancelloriid was found at the $3.7 \mathrm{~m}$ level below BW. At the $3.2 \mathrm{~m}$ level, nine chancelloriids were found, including all three genera, Chancelloria, Allonnia, and Archiasterella. Two Chancelloria were found $5 \mathrm{~m}$ higher. From $3.1 \mathrm{~m}$ below BW, right up to BW, the base of the Phyllopod Bed, the chancelloriids are nearly all Archiasterella. At the level with the most chancelloriids, BW -130, with 32 specimens, all except one, a Chancelloria, are Archiasterella. Few chancelloriids were found in the Phyllopod Bed itself, and these also are Archiasterella. Walcott collected a couple of Allonnia specimens from 35k, the Walcott Quarry locality.
(2) Raymond Quarry Beds (RQ). This is wholly within the Raymond Quarry Shale Member (Fletcher and Collins, 1998), 20-25 m above the base of the Phyllopod Bed.

In three seasons, 1991, 1992, and 1993 (Devereux, 2001), 297 chancelloriid specimens were collected from the Raymond Quarry. They were concentrated in the lower half of the fossiliferous section, from the base at $8.1 \mathrm{~m}$, up to $10.5 \mathrm{~m}$, with a minor development at the $12.0 \mathrm{~m}$ level. The major occurrence was between the $8.9 \mathrm{~m}$ and 9.2 $\mathrm{m}$ levels, where a total of 112 chancelloriid specimens were collected. Nearly all are Allonnia, except for three Chancelloria and one Archiasterella. Devereux (2001, p. 74) also observed that "the chancellorids are unique in the Raymond Quarry for their preferred close proximity to the Cathedral Escarpment. In situ specimens appear to be restricted to distances between $30-35 \mathrm{~m}$ from the Escarpment, but no complete chancelloriids were found closer than $23 \mathrm{~m}$."

Samples collected from Raymond Quarry talus are marked "RT".

(3) Collins Quarries. Levels EZ and UE, 50-60 m above the base of the Phyllopod Bed. This is within the Emerald Lake Oncolite Member (Fletcher and Collins, 1998).

There are 35 chancelloriids collected from the Collins Quarry EZ and UE levels. The few identified so far are all Allonnia, except for a single Archiasterella (ROM49567) indicating a continuation from the Raymond Quarry beds.

(4) Mount Stephen Trilobite Beds (ST). Stratigraphically, the Mount Stephen Trilobite Beds occur near the base of the Campsite Cliff Shale Member, low in the Burgess Shale Formation (Fletcher and Collins, 1998). The name, Trilobite Beds, is really a misnomer - the site is a deep pile of loose shale slabs. Consequently, the fossils all occur on slabs of various sizes. Many of the fossils present are trilobite moults, lacking the free cheeks, and disarticulated claws of the dinocarid Anomalocaris, indicating that they accumulated over a long interval of little or no sedimentation. Most of the chancelloriids are Chancelloria, with fewer specimens of Archiasterella and a single Allonnia.

(5) Monarch Cirque, Kootenay National Park, 60 km east of Fossil Ridge. In 1996, a small number of chancelloriids (Allonnia and Chancelloria) were found in Monarch Cirque. All of the fossils collected from both sides of Monarch Cirque are from talus. The most diagnostic fossil present is the trilobite Ogygopsis klotzi, indicating that the rock member 
yielding the talus specimens is probably low in the Burgess Shale Formation, in the Campsite Cliff Shale Member, at approximately the same level as the Mt. Stephen Trilobite Beds.

\section{RESTUDY OF WALCOTT'S SPECIMENS}

Walcott (1920) illustrated eight specimens (preserved soft bodies or sclerite associations) of chancelloriids from the Burgess Shale Formation in the Walcott Quarry and in the Trilobite Beds on Mount Stephen. All of these he referred to Chancelloria eros Walcott, 1920. By comparing Walcott's illustrations with isolated chancelloriid sclerites from microfossil samples, Goryanskij (1973) concluded that Walcott's material was more diverse than his taxonomy suggested. Our restudy of Walcott's specimens, housed in the National Museum of Natural History (cf. also Qian and Bengtson, 1989; Bengtson et al., 1990), confirms that they represent three distinctly different genera and species, Chancelloria eros Walcott, 1920, Allonnia tintinopsis n.sp., and Archiasterella coriacea n.sp. Four of Walcott's specimens are illustrated in Figures 1-4.

These three species are also the species represented in the ROM collections that form the principal basis for the present study. Walcott's specimens (Chancelloria eros: Figure 1; Allonnia tintinopsis: Figures 2, 3; Archiasterella coriacea: Figure 4) are described in the systematic section together with the ROM material.

Walcott's mistaken treatment of his diverse material as monospecific can be ascribed to his view of Chancelloria eros as a sponge and particularly to his interpretation of the chancelloriid body wall. All three Burgess chancelloriid species are at least sometimes preserved with body tissues as dark and/or shiny films. In Allonnia tintinopsis and Archiasterella coriacea this feature is particularly prominent, with indications that the body surface was thrown into folds as a result of collapse and compression of the body. Walcott (1920, p. 327) interpreted these structures as evidence of a "tough ectosome and dense choanosome," adding that spicules [sclerites] were "distributed irregularly in the outer dermal layer (ectosome), also in an intermediate layer and an inner layer (choanosome)." The subsequent discussion of the morphology of the "spicules" makes it clear that the three-layered structure of the body wall was based on a misconception. Walcott considered the apparent differences in number and attitude of "spicule" rays to be artifical, resulting from different degrees of burial of the "spicules" in different body layers.
Depending on the preservation, sclerite shape may be difficult to discern, either because the sclerites are poorly preserved or because they are so crowded in the integument that only the distal parts of the rays are visible. This is not the case, however, in most of Walcott's specimens. As shown in the present study, Burgess Shale chancelloriids have sclerites with the ray formula $3-4+0 /$ 5-7+1 (Chancelloria), 3+0 (Allonnia), and 4+0 (Archiasterella). These ray formulas, as well as the sclerite shapes characteristic of C. eros, Al. tintinopsis, and Ar. coriacea, respectively, are clearly visible in all three species in Walcott's collection (Figures 1.3; 2.2, 2.3; 3.2, 3.3; 4.2). Furthermore, the up-versus-down orientation of the sclerites on the shale surfaces and the respective superposition of sclerites with opposite orientation (Figure 1.3) leave no doubt that the central ray in the $C$. eros $N+1$ sclerites was directed outwards, away from the body, rather than being embedded in the sponge soft tissue, as assumed by Walcott. A similar orientation of the protruding ray in Allonnia and Archiasterella sclerites, i.e., pointing away from the body surface, is evident in the material described herein.

\section{SYSTEMATIC PALAEONTOLOGY}

Remarks on Higher-Order Taxonomy. Janussen et al. (2002) referred chancelloriids to the Phylum Epitheliozoa Ax, 1995. Ax's concept of the taxon, however, was not a phylum but a clade that includes all eumetazoans, which is much more encompassing than a phylum in any accepted sense. We concur that the chancelloriids belong to the Epitheliozoa in the sense of Sperling et al. (2007), i.e., the clade including all eumetazoans plus the homoscleromorph sponges. For reasons expounded on in the discussion of chancelloriid affinities, we do not assign the group to any of the currently recognized epitheliozoan phyla.

Remarks on Species-Level Taxonomy. A large number of chancelloriid species have been established on isolated sclerites. Some of these are based on type material with distinct morphologies or structural features and may be recognizable as such, but the great majority of published species are simply not recognizable outside the type series. Whole-body preservation, such as in the Burgess Shale, adds a number of characters, such as scleritome composition and variability, nature of integument, nature of apical tuft. However, such preservation is not optimal for the preservation of fine structural details and 3D morphology of sclerites. It is therefore difficult or even impossible to 

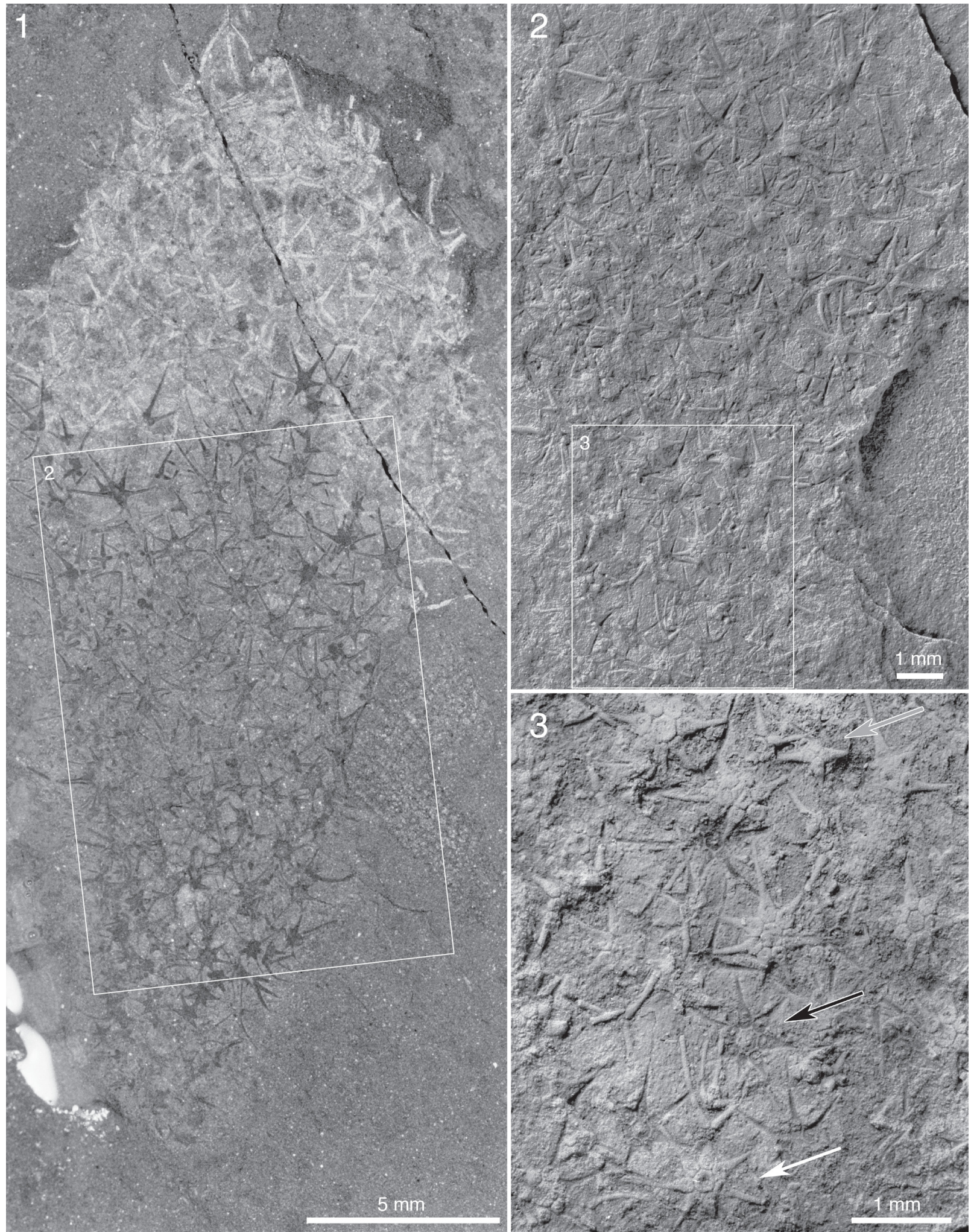

FIGURE 1. Chancelloria eros Walcott, 1920, lectotype, USNM 66524. Figured by Walcott (1920) as pls 86:2 and 88:1f. 1. Wet. 2. Dry, coated with ammonium chloride. Detail of 1 (position marked by frame). 3. Dry, coated with ammonium chloride. Detail of 2 (position marked by frame). Top arrow (grey): $4+0$ sclerite. Middle arrow (black): $7+1$ sclerite, preserved in negative relief (ascending ray towards the viewer). Bottom arrow (white): $7+1$ sclerite, preserved in positive relief (ascending ray pointing away from the viewer). 


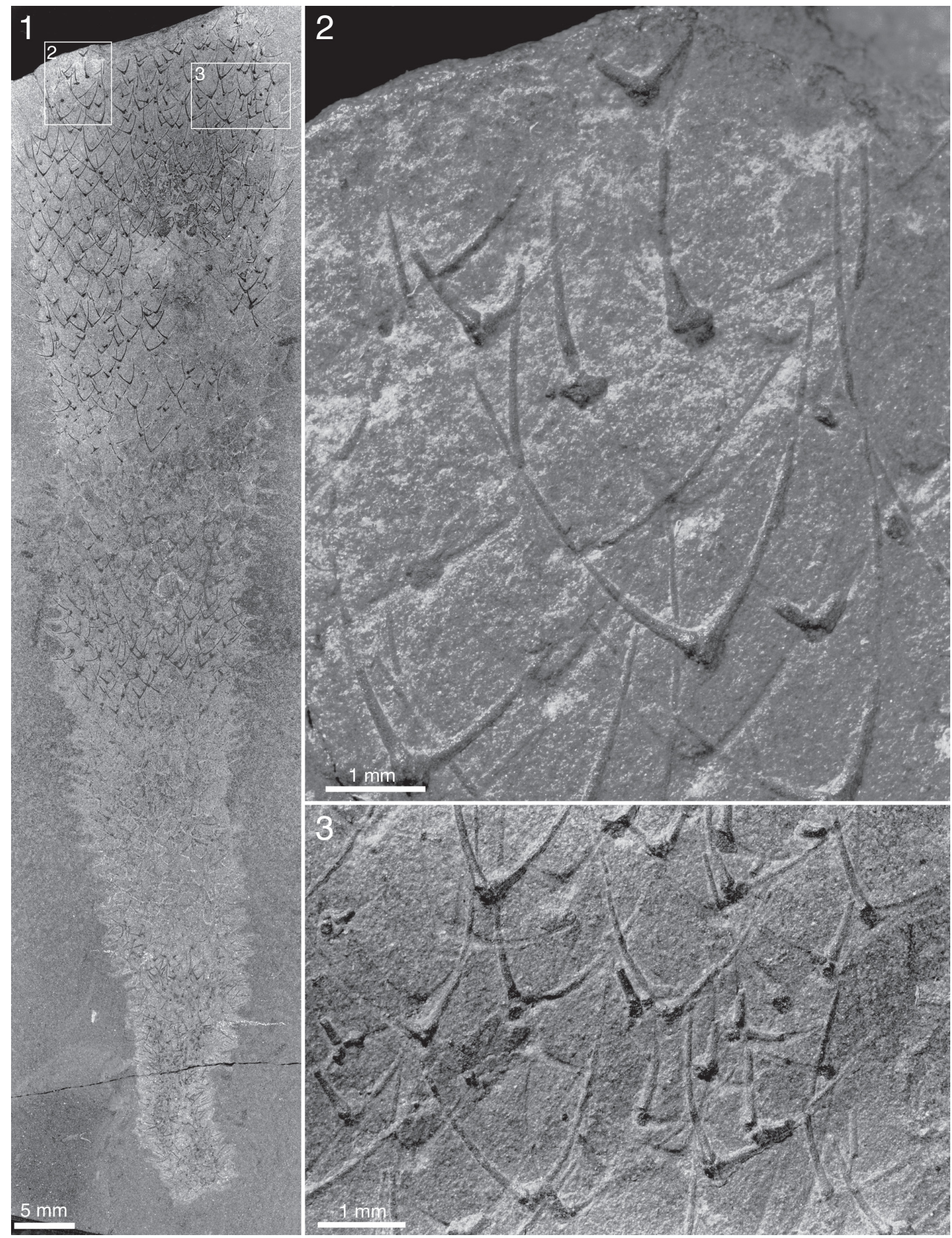

FIGURE 2. Allonnia tintinopsis n.sp., USNM 66526 (specimen figured as Chancelloria eros by Walcott, 1920, pl. 88:1, 1a, and by Briggs et al., 1994, figure 176). 1. Wet. 2, 3. Details of 1 (positions marked by frames), dry. 


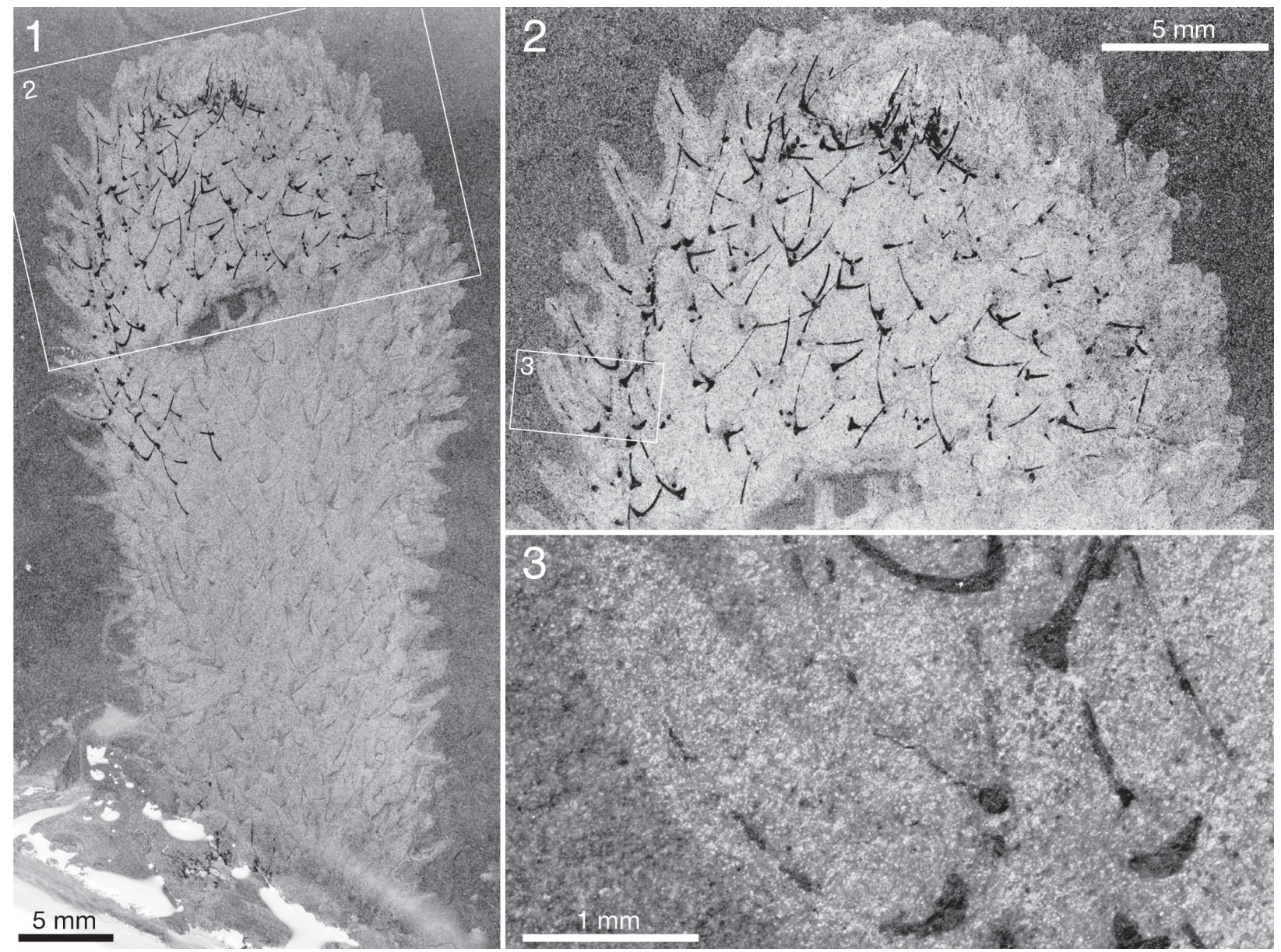

FIGURE 3. Allonnia tintinopsis n.sp., USNM 66528, upper part of body (specimen figured as Chancelloria eros by Walcott, 1920, pl. 88:1d, 1e). 1. Wet. 2. Detail of 1 (position marked by frame), wet. 3. Detail of 2 (position marked by frame), wet.

relate taxa established on whole-body material to those based on even well-preserved individual sclerites. An example of this is the type species of Allonnia, Al. tripodophora Doré and Reid, 1965. The species is based on isolated sclerites that are difficult to distinguish from those of Al. phrixothrix Bengtson and Hou, 2001 or Al. tintinopsis n.sp., known from whole-body preservation (but see Moore et al., 2014, for a possible distinction based on fine details of sclerite symmetry). We therefore choose to include in the synonymy lists only taxa based on whole-body specimens, treating the sclerite-based taxa as potential sciotaxa (cf. Bengtson, 1985). A revision of published sclerite-based taxa, identifying those that should be regarded as nomina dubia, is needed but is outside the scope of the present paper. Janussen et al. (2002) recommended that no further chancelloriid species be erected on the basis of isolated sclerites. Although we concur that sclerite-based taxonomy of chancelloriids is difficult to reconcile with that based on whole bodies in Burgess-Shale-type preservation, there are good examples of three-dimensionally preserved sclerite associations with taxonomically useful characters that may serve to characterize composite scleritomes (Bengtson et al., 1990; Moore et al., 2010, 2014). A moratorium on sclerite-based taxonomy would therefore be counterproductive to the study of chancelloriid diversity and evolution.

\section{Order CHANCELLORIIDA Walcott, 1920}

Remark. The family name Chancelloriidae Walcott 1920 was elevated to order rank by Sdzuy (1969), who argued for the retention of Walcott as the author of the taxon. We choose to follow Sdzuy with regard to authorship. Missarzhevsky (1989) named a new order Chancelloriida, having apparently overlooked Sdzuy's action. The order has subsequently been cited as Chancelloriida Missarzhevsky, 1989 (e.g., Elicki, 2011), but it is clearly a junior homonym of Walcott's order name. 

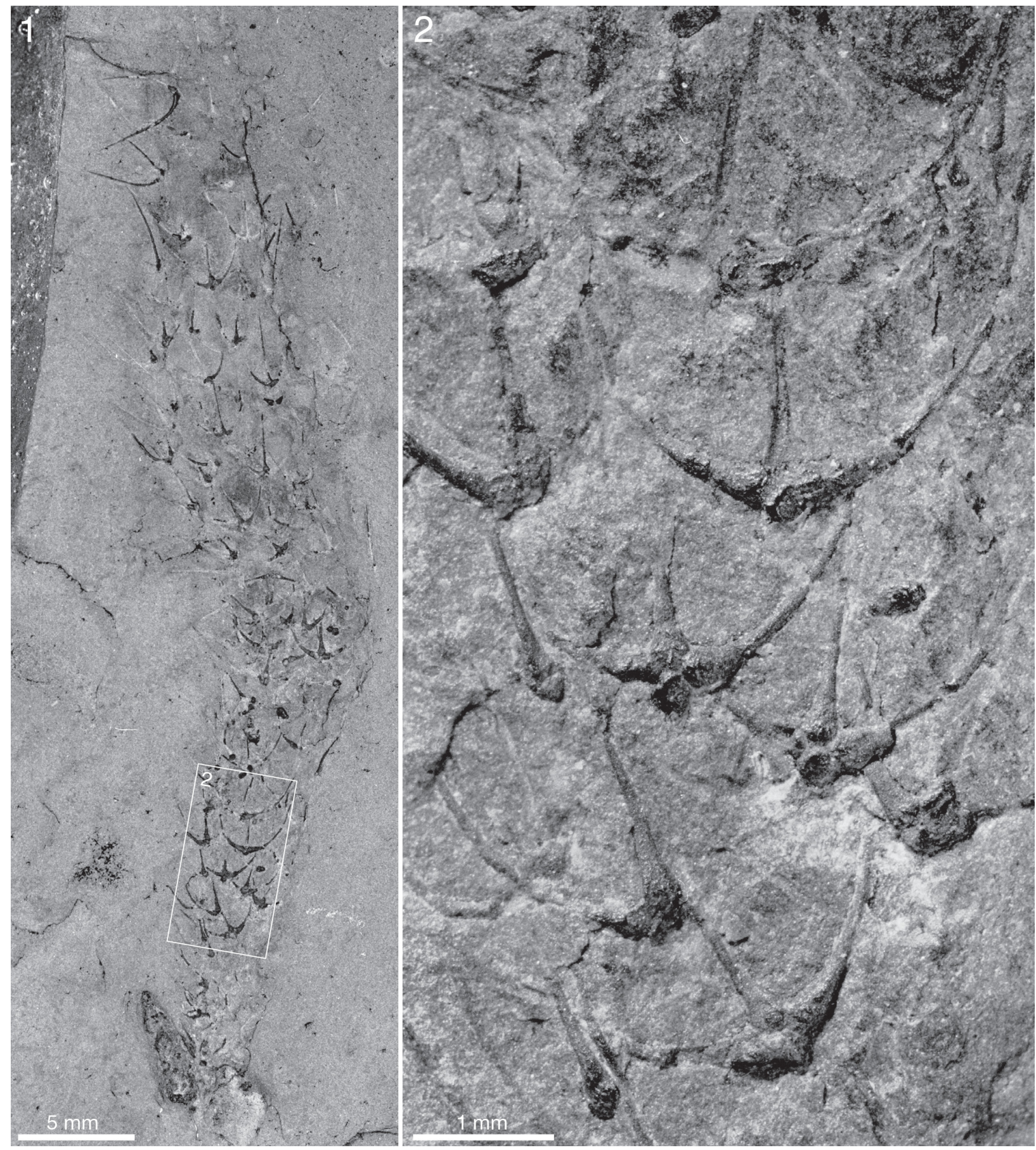

FIGURE 4. Archiasterella coriacea n.sp. USNM 66527 (specimen figured as Chancelloria eros by Walcott,1920, pl. 88:1c, and de Laubenfels, 1955, figure 76). 1. Dry. 2. Detail of 1 (position marked by frame), dry.

\section{Family CHANCELLORIIDAE Walcott 1920}

\section{Genera Known from Scleritome Preservation.} Chancelloria Walcott, 1920, Allonnia Doré and Reid, 1965, Archiasterella Sdzuy, 1969.

Diagnosis. Sessile marine animals with radially symmetrical, baglike body, broadening upwards from attachment. Integument flexible, sometimes with fine, rectangularly or rhombically arranged platelets or spines, $\sim 0.1 \mathrm{~mm}$ long, directed towards the apex. Armour consisting of spiny coelosclerites, which are usually composite, consisting of individual rays joined at base but having separate internal cavities and foramina; cross-section of rays nearly circular, except where bases are 
joined; foramen restricted. Sclerites rhombically or irregularly arranged; at the apex concentrated into an apical tuft consisting of modified spine-shaped sclerites surrounding a central apical orifice. (Modified after Bengtson et al., 1990.)

Spelling of Name. The spellings "Chancelloridae" and "Chancelloriidae" both occur in the modern literature (e.g., Janussen et al., 2002; Moore et al., 2010). Walcott (1920) based the family name Chancelloridae on the type and only genus Chancelloria. Following ICZN (32.5.3.1) a family-group name must be corrected if (before 1999) the stem of the generic name was not properly formed from its Latin suffix (ICZN 29.3.1). The stem of "Chancelloria" (genitive "Chancelloriae") is "Chancellori-", which combined with the family suffix "-idae" gives "Chancelloriidae"; thus the family should be referred to as Chancelloriidae Walcott, 1920. In the 1955 Treatise on Invertebrate Paleontology, de Laubenfels (1955) erected a "Family Chancelloriidae de Laubenfels, nov.," again with Chancelloria Walcott, 1920, as the only genus. Chancelloriidae de Laubenfels, 1955, is therefore both a junior homonym and a junior objective synonym of Chancellori[i]dae Walcott, 1920.

\section{Genus CHANCELLORIA Walcott, 1920}

Type Species. Chancelloria eros Walcott, 1920. Species Known from Scleritome Preservation. Chancelloria eros Walcott, 1920, Chancelloria cruceana Rusconi, 1954 (see Beresi and Rigby, 2013), Chancelloria pentacta Rigby, 1978.

Diagnosis. Chancelloriids with scleritome dominated by star-shaped $N+1$ sclerites. $4+0$ sclerites and (rarely) $3+0$ sclerites may be present.

Chancelloria eros Walcott, 1920

Figures $1 ; 5-11 ; 12$ (part); 13; 14.2; 15

Chancelloria eros new species (Walcott, 1920, partim; pls 86:2, 2a, 2b, ?2c, 88:1f, non pl. 88:1, 1ae).

Chancelloria eros Walcott, 1920 (Goryanskij, 1973, p. 43).

Chancelloria eros Walcott, 1920 (Rigby, 1978, pl. 2:3).

Chancelloria (Bengtson, 2000; figure 12, partim).

?Chancelloria cf. eros Walcott, 1920 (Randell et al., 2005, figure 6).

Lectotype. USNM 66524. Walcott 1920, pls 86:2, 88:1f. Figure 1 herein. Designation by Goryanskij (1973).

Remarks. This species, with its characteristic "rosettes" of star-shaped sclerites, has become the epitome of the chancelloriids, and so Goryanskij's (1973) choice of USNM 66524 as lectotype for
Chancelloria eros, among the disparate material figured by Walcott, was appropriate even though he did not have access to the material. The species, in fact, differs considerably from the other Burgess Shale chancelloriids, not only in its generally rosette-like sclerites but also in incorporating a variety of sclerite forms within its scleritome.

Diagnosis. Chancelloria species with main sclerites varying from $5+1$ to $8+1$, the most common forms being $6-7+1$. Auxilliary $4+0$ sclerites present, sometimes also $3+0$ sclerites. Sclerite size variable, their arrangement in the scleritome irregular. Tuft inconspicuous.

Description. The lectotype, USNM 66524 (Figure 1 ), has not previously been figured in its completeness. The original illustration (Walcott, 1920, pls $86: 2$, 88:1f) showed only a central patch of sclerites, and so the species has become known as an assemblage of sclerites rather than as a body fossil. In fact, the specimen is almost complete and shows a well-defined club-shaped body (Figure 1.1), $29 \mathrm{~mm}$ long and $11 \mathrm{~mm}$ wide at its broadest part. The body narrows gradually to a width of 2.8 $\mathrm{mm}$ near the abapical end, but the end appears to be incompletely preserved. A bunch of $2 \mathrm{~mm}$ long spines at the apex may represent the apical tuft (Figure 1.1, top).

The sclerites are preserved in flattened relief in the proximal $2 / 3$ of the specimen; in the apical part of the body they appear like "ghosts" without relief. The basal surface is seen either in positive (Figure 1.3, white arrow) or in negative (Figure 1.3, black arrow) relief. These differences in mode of preservation relate to the orientation of the sclerites: the shale is always parted along the basal surface of the sclerite (rather than along the opposite surface carrying the spiny protrusions). This shows that the central ray protrudes away from the body surface, i.e. in the opposite direction to that of Walcott's sponge-based interpretation. The outward direction of the spines is also apparent from their preservation in profile at the edges of the specimen (Figure 1.1).

There is no clear regularity in the distribution of the sclerites in the body wall, but the sclerite density is roughly uniform along the body. The common sclerite forms are $6+1$ and $7+1$, with a basal-disk width of $0.45-0.51 \mathrm{~mm}$. They present a bilateral symmetry owing to the fact that the adapical rays have a larger base than the abapical ones (see, for example, the large sclerite above the black arrow in Figure 1.3). The abapical rays also appear shorter, which may be due to the fact that their distal parts protrude from the body surface 


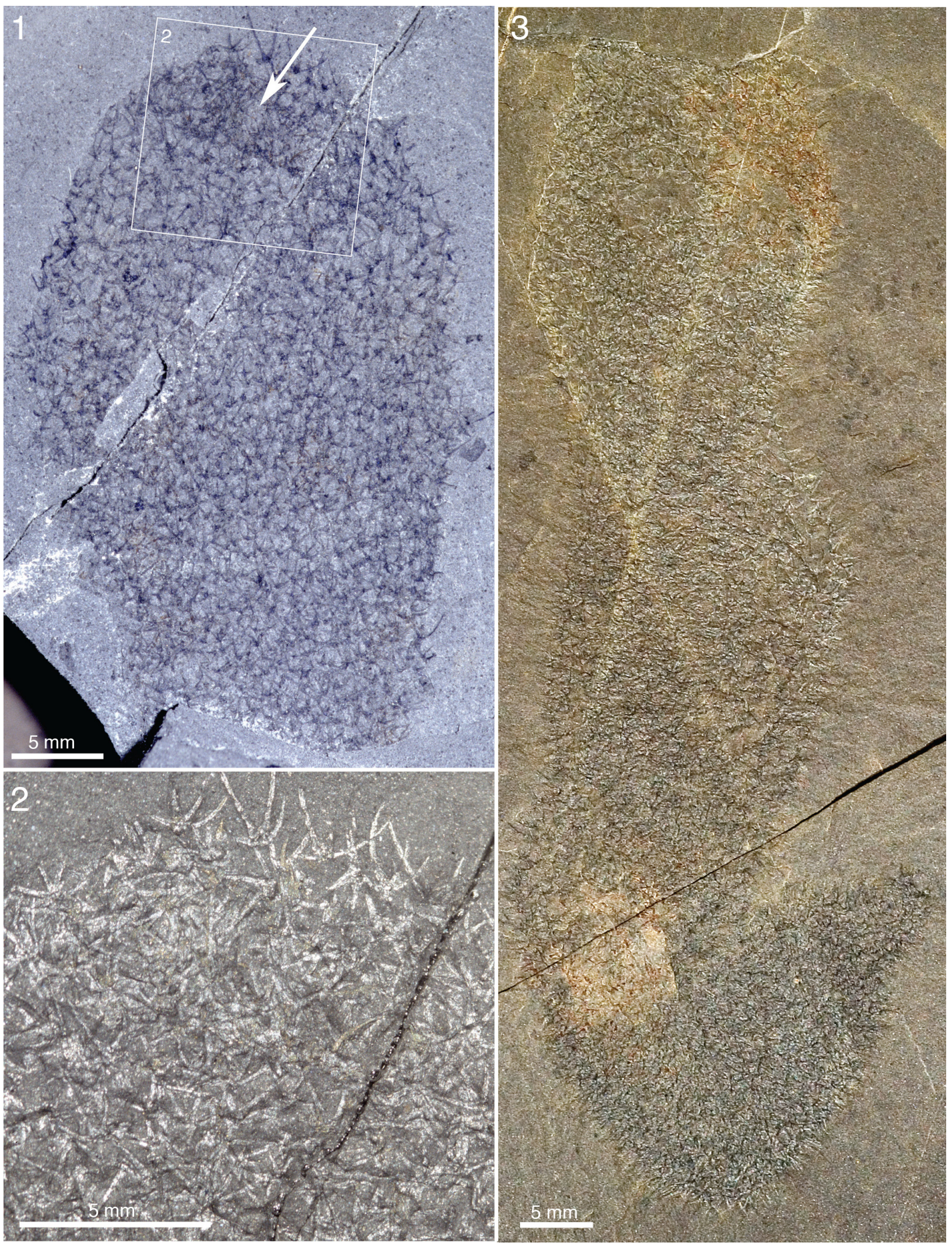

FIGURE 5. Chancelloria eros Walcott, 1920. 1. ROM 62538, ST talus, wet. Arrow points to empty area that may represent an apical orifice. 2. Detail of 1 (position marked by frame), wet. 3. ROM 62535A, BW -300, dry. 

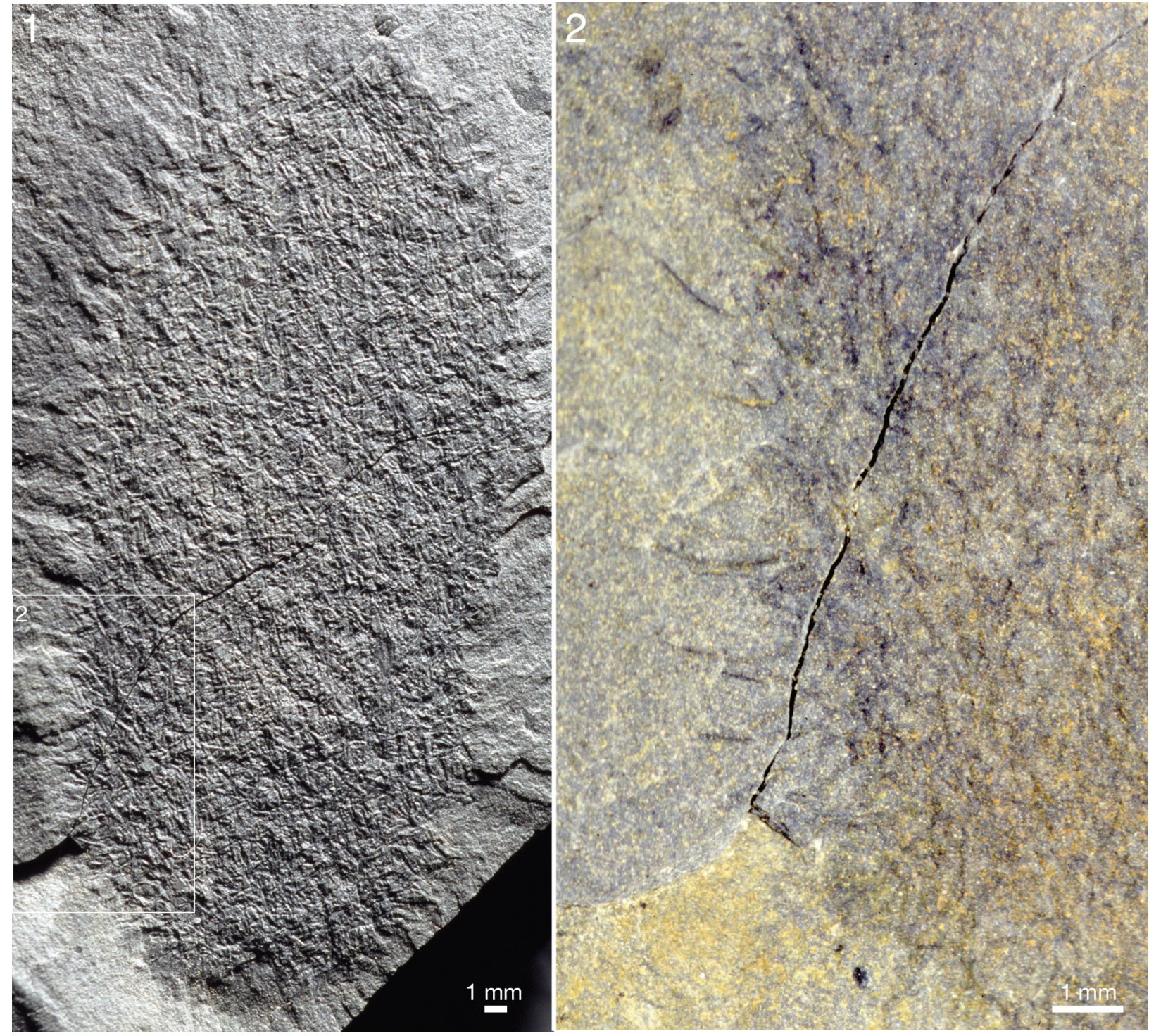

FIGURE 6. Chancelloria eros Walcott, 1920. ROM 62539, BW -320. 1. Dry. 2. Detail of 1 (position marked by frame), wet.

and are somewhat recurved in the adapical direction The sclerites preserved in profile at the specimen edges suggest that the adapical rays are straight or somewhat recurved outwards, whereas the central rays protrude perpendicularly from the body surface and, like the abapical rays, tend to be recurved in the adapical direction (Figures 1.1; 6.2; 7.3; 10; and 13).

In addition, smaller, cross-shaped $4+0$ sclerites are scattered throughout the scleritome (e.g., Figure 1.3, grey arrow), though they are smaller and less common than the N+1 sclerites. Their rays are at right angle to each other in the plane of the body wall; it has not been possible to observe the degree of protrusion and recurving from the body wall.

Complete or nearly complete specimens in the ROM collection conform to the club-shaped body outline of the lectotype, but there is considerable variation in length/width ratio. Figure 5.3 shows a large specimen preserved almost in its entirety. The body is roughly cylindrical, up to 20 $\mathrm{mm}$ in width. The preserved outline undulates somewhat - a narrow constriction near the apex gives a body width of $13 \mathrm{~mm}$, but otherwise the width is constantly about $20 \mathrm{~mm}$ except in the abapical region, which narrows to a stalk about 4 $\mathrm{mm}$ wide. The initial $2 \mathrm{~cm}$ is bent upwards to form a $45^{\circ}$ angle with the main body; this may be a folding 

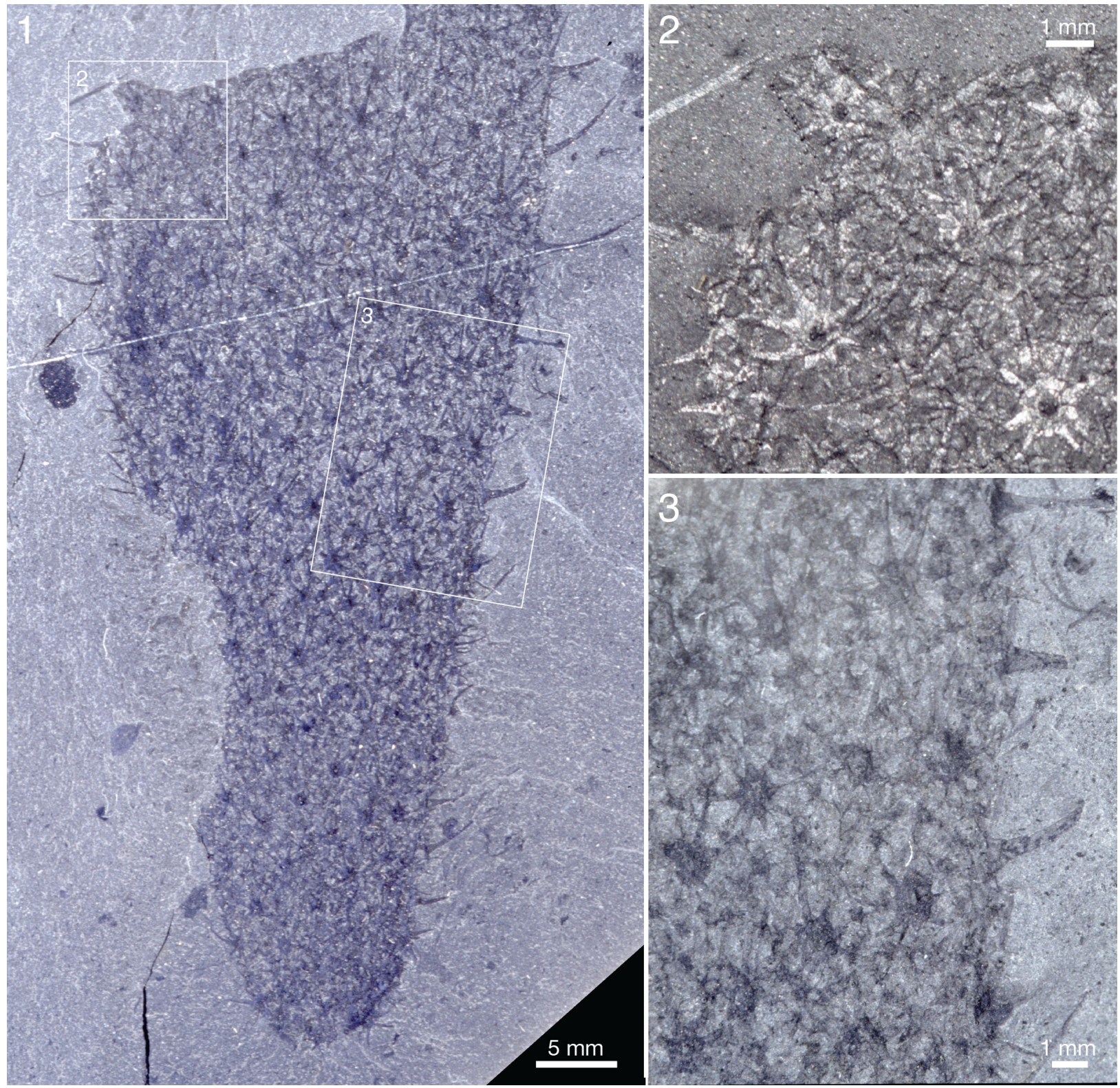

FIGURE 7. Chancelloria eros Walcott, 1920. ROM 62588B, BW -320. 1. Dry. 2. Detail of 1 (position marked by frame), dry. 3. Detail of 1 (position marked by frame), wet.

due to collapse of the body. If the body were unfolded, the total length would be about $100 \mathrm{~mm}$. The apical end is flat, although this may be an effect of its being cut off by a crack in the rock. This specimen has a dense scleritome, and the shape of individual sclerites is difficult to make out, because of the preservation.

The specimen in Figure 5.1 and 5.2 is slightly wider $(23 \mathrm{~mm})$ than the one in 5.3 , but only the apical part is preserved. The apical end is evenly rounded and has a small region of denser sclerite matter around an empty area (Figure 5.1, arrow), which may represent an apical tuft and orifice.
Although sclerite rays are distinctly visible throughout the scleritome, individual sclerites are often difficult to make out. Discernible ones are of the 5+1 and $6+1$ types, and the width of the basal disk ranges from 0.38 to $0.64 \mathrm{~mm}$.

The specimen in Figure 6 shows a short, slightly tapering body, $45 \mathrm{~mm}$ long and $19 \mathrm{~mm}$ wide, rounded at both ends. The structure of the sclerites is poorly discernible, but sclerite rays are visible throughout the body. The direction of the ascending rays in profile (Figure 6.2) and the slight taper of the body unambiguously define the apicalabapical polarity. The apical end has a tuft-like 


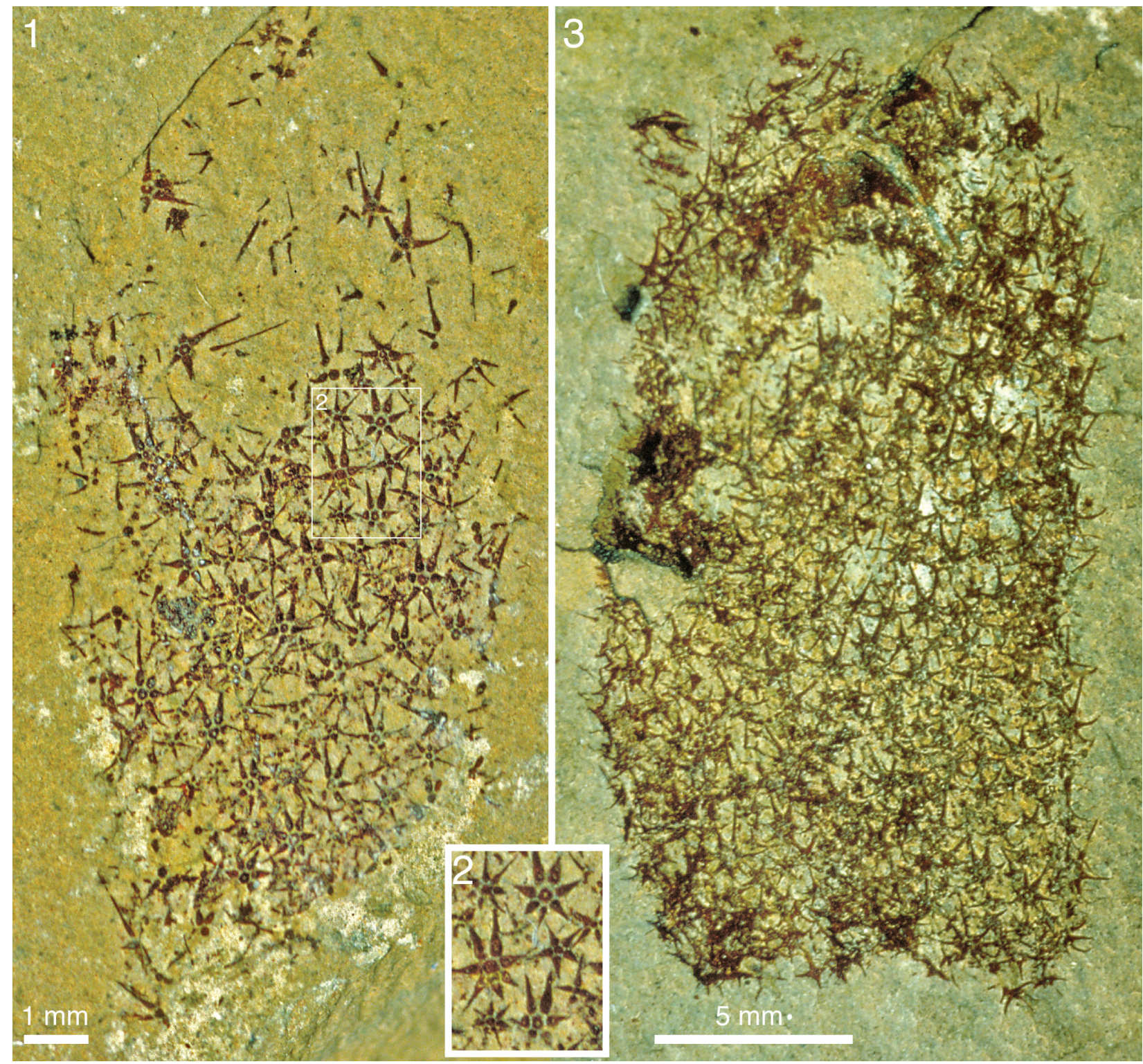

FIGURE 8. Chancelloria eros Walcott, 1920. 1, 2. ROM 49580, ST. 1. Dry. 2. Detail of 1 (position marked by frame), dry. 3. ROM 62590, ST, dry.

structure. There is no evidence of a stalk at the attached end.

The specimen in Figure 7 has a preserved length of $66 \mathrm{~mm}$ and a greatest measurable width of $27 \mathrm{~mm}$; it still appears to be widening toward the broken-off apical part. The body tapers evenly to a rounded abapical end, without any evidence of a stalk. The sclerites are large, indistinctly preserved, of 7+1 and $8+1$ type, having basal disks up to 1.2 $\mathrm{mm}$ in diameter and ascending spines up to $7 \mathrm{~mm}$ in length.

The two specimens from the Trilobite Beds in Figure 8 have the abapical parts missing, but the remaining body outline conforms to the usual club shape. No trace of the soft integument is visible, but the sclerites and their individual rays are distinctly outlined. The discernible ray formulas in both are $4+0$ and $5-7+1$. In ROM 49580 (Figure $8.1,8.2$ ) the width of the basal disks ranges from 0.13 to $0.43 \mathrm{~mm}$. This is a substantial range, but there is no evidence of separate size orders of sclerites, and the preserved scleritomes do not have any regular arrangement. In ROM 62590 (Figure 8.3) the sclerites are less well-preserved and cannot be measured exactly, but the size range and (lack of) scleritome organization is similar to that of ROM 49580. ROM 62590 has a circular opening, $2.5 \mathrm{~mm}$ in diameter, in the sclerite 


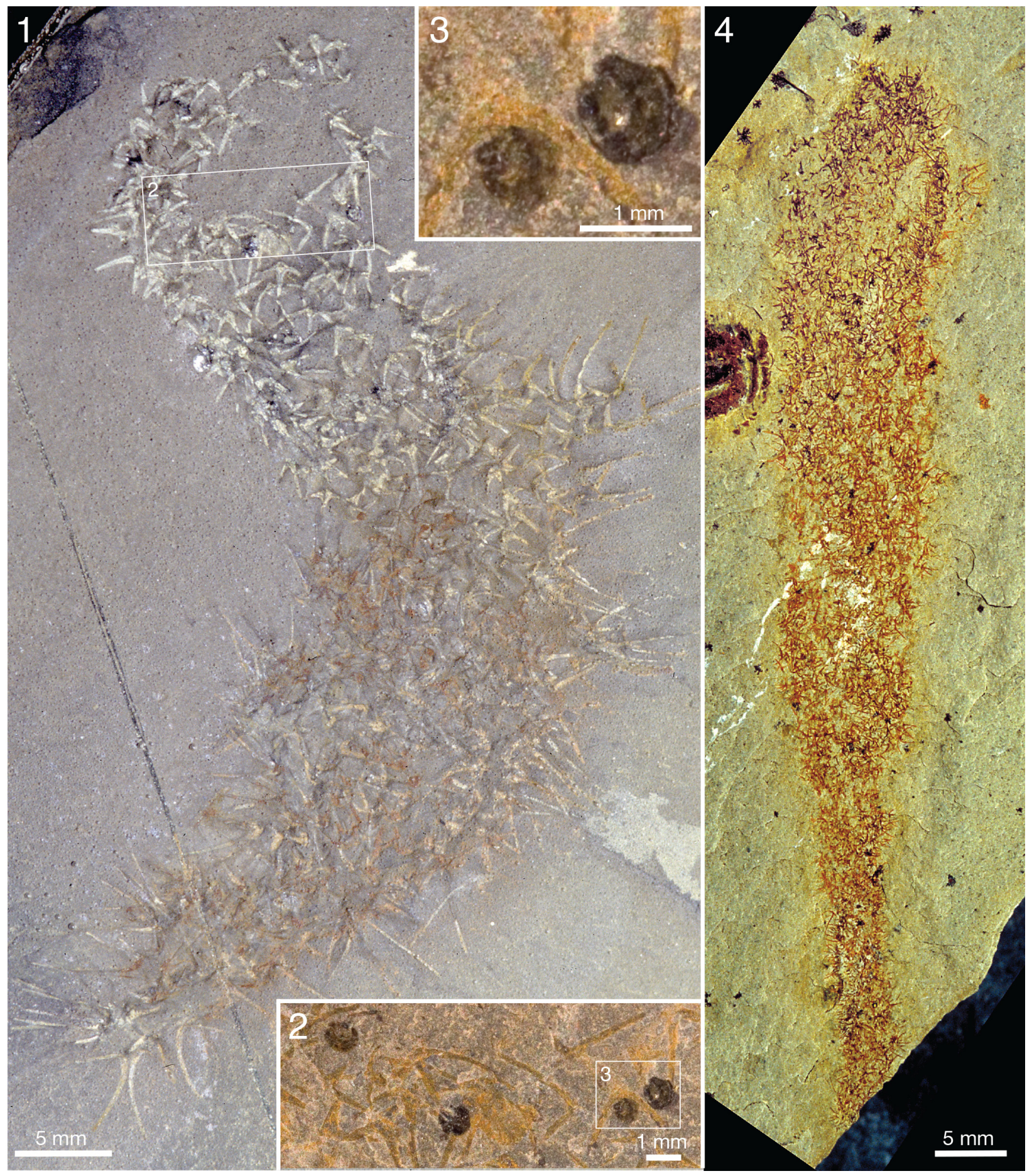

FIGURE 9. Chancelloria eros Walcott, 1920. 1-3. ROM 57604, BW -130. Specimens of the lingulate brachiopod Acrothyra gregaria appear to be attached to the spines of the Chancelloria. The brachiopods are concentrated to what is interpreted as the apical part of the chancelloriid body. 1. Wet. 2. Detail of 1 (position marked by frame), dry. 3. Detail of 2 (position marked by frame), dry. 4. ROM 63055, ST, dry.

mass about $5 \mathrm{~mm}$ from the preserved apical edge of the specimen. The regularity of the opening suggests that it might represent the apical orifice, but the interpretation is problematic because there is no other indication that the specimen has been obliquely preserved, and the sclerites surrounding the opening do not show any particular modification. Furthermore, other, less regular gaps in the 


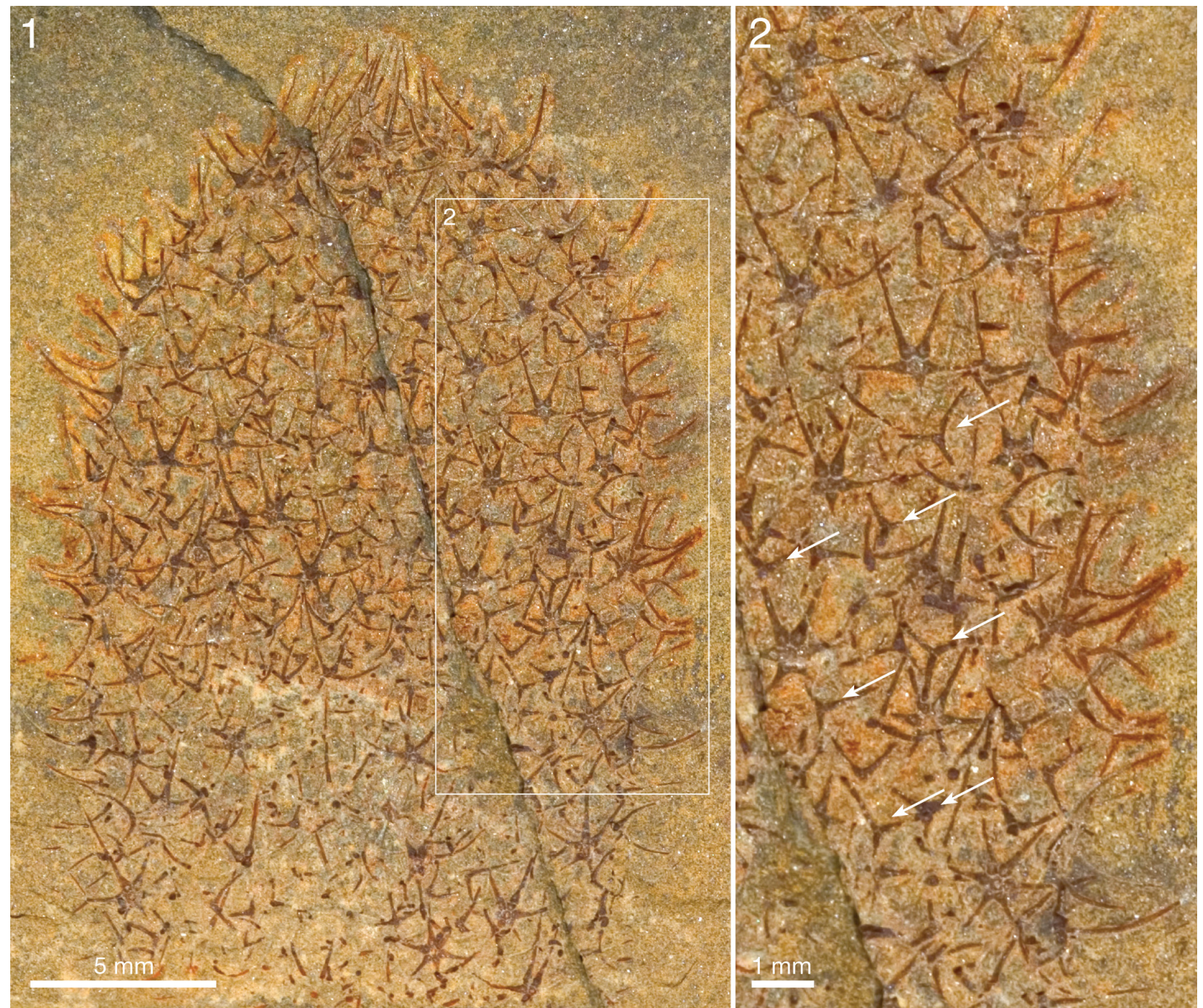

FIGURE 10. Chancelloria eros Walcott, 1920. ROM 62534, RT. 1. Wet. 2. Detail of 1 (position marked by frame), wet. Note the common presence of 3+0 Allonnia-type sclerites (arrows) in a scleritome dominated by 5-7+1 Chancelloriatype sclerites.

scleritome indicate that the integument may be ruptured. As none of the other specimens shows the same structure we regard the circular opening in this specimen as an artifact of preservation.

The specimen in Figure 9.1-9.3 is mainly cylindrical, and the directionality of the sclerite rays is ambiguous, making it difficult to determine the axial polarity of the body. The end where it tapers to a narrow point (lower left in the picture) is tentatively interpreted as abapical. Specimens of the lingulate brachiopod Acrothyra gregaria occur among the spines in the apical part of the body (Figure 9.2, 9.3). Although no definitive attachment structure is observed, it is likely that they were attached to the spines of the chancelloriid, as the immediately surrounding matrix is otherwise free of them.
Figure 9.4 shows a specimen, also from the Trilobite Beds, with a club-shaped body that is considerably narrower than most of the other specimens. It is $74 \mathrm{~mm}$ long and at its widest $13 \mathrm{~mm}$ wide, narrowing slightly towards a well-developed stalk, 3-4 mm wide and more than $15 \mathrm{~mm}$ long. The sclerites are tightly spaced, forming a jumbled mass both in the stalk and in the more apical parts of the body.

There is considerable variability in the scleritome composition of Chancelloria eros as delimited in the present study. Although the preservational mode frequently makes it difficult to discern the shape and ray formula of most sclerites, the available material contains examples of scleritomes closely adhering to that of the lecto- 

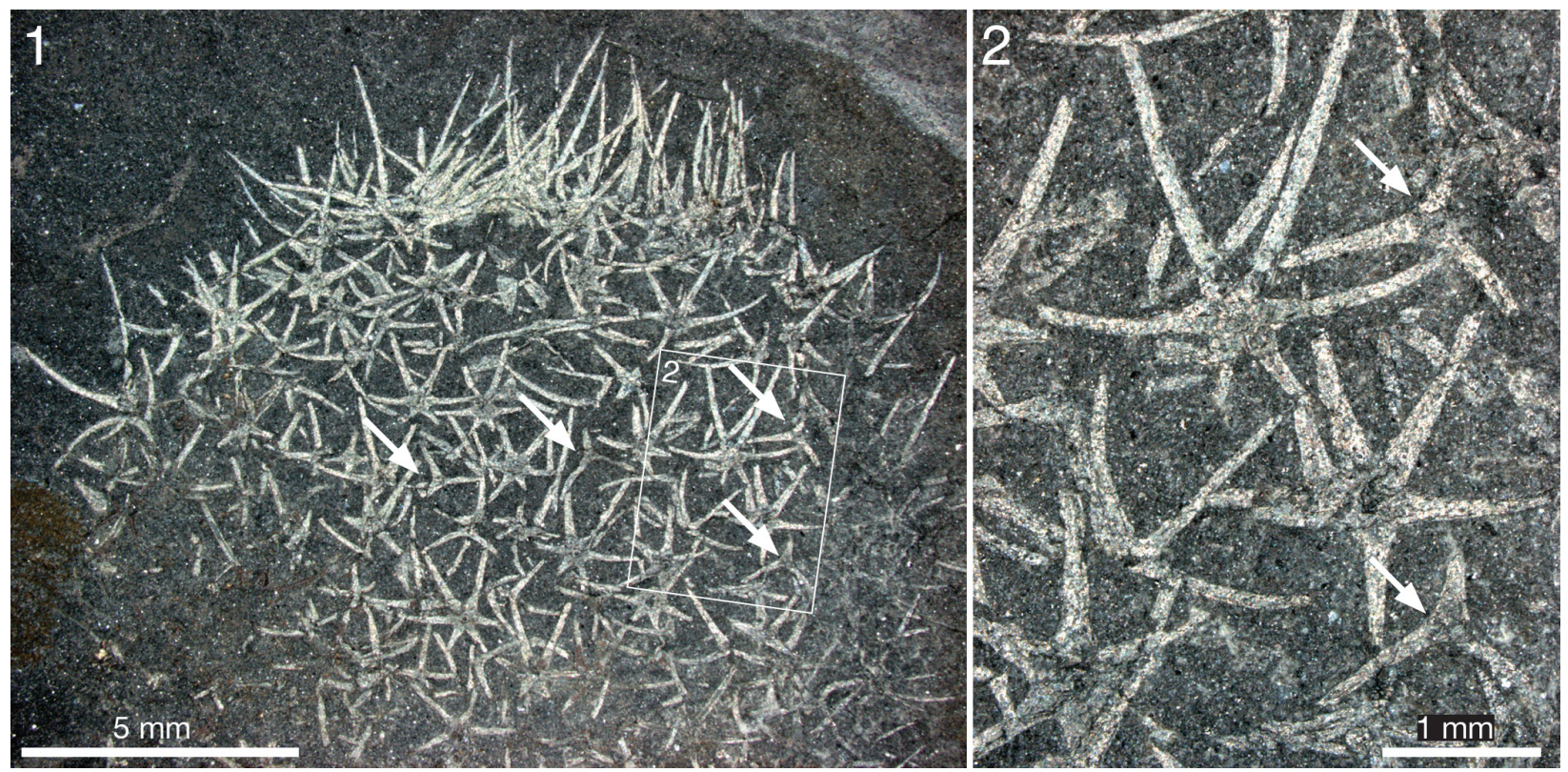

FIGURE 11. Chancelloria eros Walcott, 1920. ROM 49599A, RQ 8.0. Arrows point to examples of 3+0 sclerites. 1. Dry. 2. Detail of 1 (position marked by frame), dry.

type, as well as those that deviate from this pattern. The specimen in Figure 7 is dominated by $8+1$ and $7+1$ sclerites. The one in Figure 10 has a more complex scleritome, in that $5+1$ and $6+1$ sclerites, in addition to the $4+0$ sclerites present in the lectotype, are accompanied by $3+0$ sclerites of a morphology that is difficult to distinguish from that of Allonnia tintinopsis sclerites. A similar scleritome is seen also in the incomplete specimen of Figure 11. The sclerites are flat, preserved as shiny films, but otherwise they show the morphology well. In addition to $5+1$ and $6+1$ sclerites with a basal-disk diameter of $0.47-0.53 \mathrm{~mm}$, there are $3+0$ sclerites (arrows in Figure 11) similar to those of Al. tintinopsis. The Chancelloria $3+0$ sclerites are more flat and star-shaped, however, with rays diverging at $120^{\circ}$, not raising themselves much from the plane of the base. (In Allonnia, all three rays are bent towards the apex.) These specimens also have prominent apical tufts (Figures 10.1; 11.1), much like those that are frequently seen in Al. tintinopsis.

The Chancelloria eros specimen in Figure 12.4 (right) and 12.6 has a similar association of sclerites, with common $3+0$ and $4+0$ amidst starshaped $6+1$ and $5+1$ sclerites. In this case, however, the presence of the $3+0$ sclerites may be due to the superposition on a specimen of Al. tintinopsis.

The specimens from Mount Stephen shown in Figures 13 and 14 preserve the slender spines particularly well and allow an estimate of how ray length changes along the body. Both specimens in Figure 13 show expansion from a narrow stalk-like portion with densely packed, smaller sclerites, to a wider apical portion with more widely spaced, larger sclerites. In Figure 13.1, the basal-disk diameter in the lowermost $12 \mathrm{~mm}$ of the preserved body is $0.47-0.53 \mathrm{~mm}$ and in the remaining portion $0.53-0.78 \mathrm{~mm}$. The rays protruding from the right side of the body in this specimen are predominantly central, ascending rays. Although it is seldom possible to determine whether the whole length of the ray is preserved, the shape and tapering suggest that some of them are at least nearly complete, so at least a minimal length of the ray can be obtained. In the abapical portion, up to 12 $\mathrm{mm}$ from the preserved end of the body, the longest ray is at least $3.9 \mathrm{~mm}$, whereas the apical portion of the body $22-30 \mathrm{~mm}$ from the abapical end has rays up to at least $6.6 \mathrm{~mm}$ long. The same trend is seen in Figure 13.2 and in the incompletely preserved specimens in Figure 14. The specimen in Figure 14.1 has fairly well-preserved sclerites that allow the recognition of 5-6+1 and (questionably) 4+0 sclerites, whereas the one in Figure 14.2 mostly presents isolated rays, which does not allow assignments to a ray formula.

A life reconstruction of Chancelloria eros is shown in Figure 15.

The specimen shown in Figure 14.3-14.5 is unique among the material of Chancelloria used in this investigation in that its sclerites are strictly lim- 

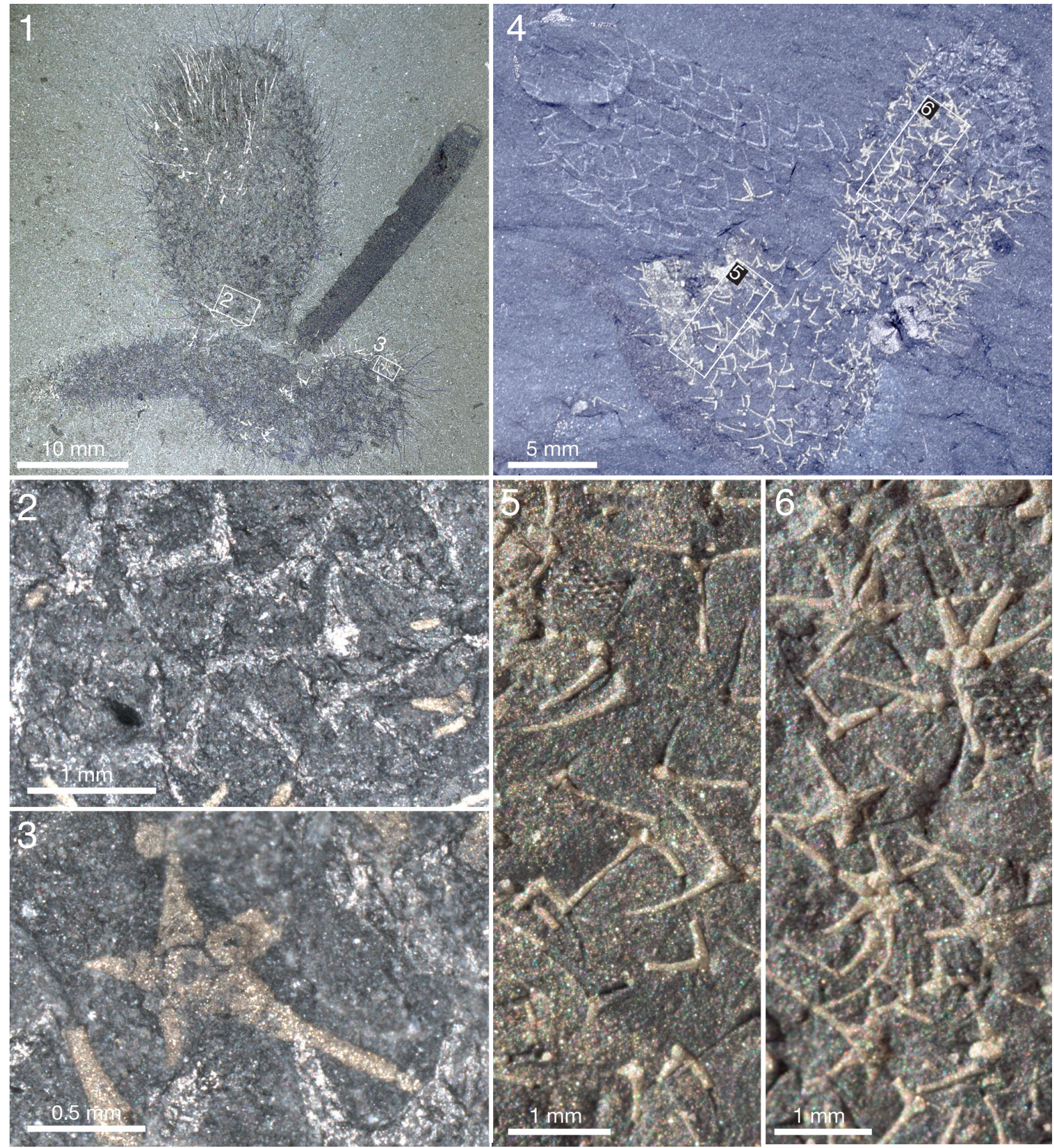

FIGURE 12. Allonnia tintinopsis n.sp. intergrown with or superimposed on Chancelloria eros Walcott, 1920. 1-3. ROM 49605(2) (intergrown with a specimen of Vauxia), RQ 9.2. 1. Same as figure 12B in Bengtson, 2000; see that paper for details on settings. 2, 3. Details of 1 (positions marked by frames), dry. 4-6. ROM 62537B, RQ 8.4. 4. Wet. 5, 6. Details of 4 (positions marked by frames), dry. Net-like patches are fragments of Micromitra shells.

ited to the $6+1$ formula, with a narrow size range (basal-disk diameter $0.27-0.31 \mathrm{~mm}$ ) and furthermore, seem to be more regularly arranged (see Figure 14.5, lower right) than in the other specimens. For this reason, we refer to this specimen as Chancelloria cf. eros.
Discussion. Rigby (1978, pl. 2:3) figured a sclerite assemblage from the Middle Cambrian Wheeler Shale in the Wheeler Amphitheatre, Utah, as $C$. eros. Because of the disordered arrangement of the sclerites, he interpreted it as a somewhat disorganized cluster, perhaps even a scatological accu- 

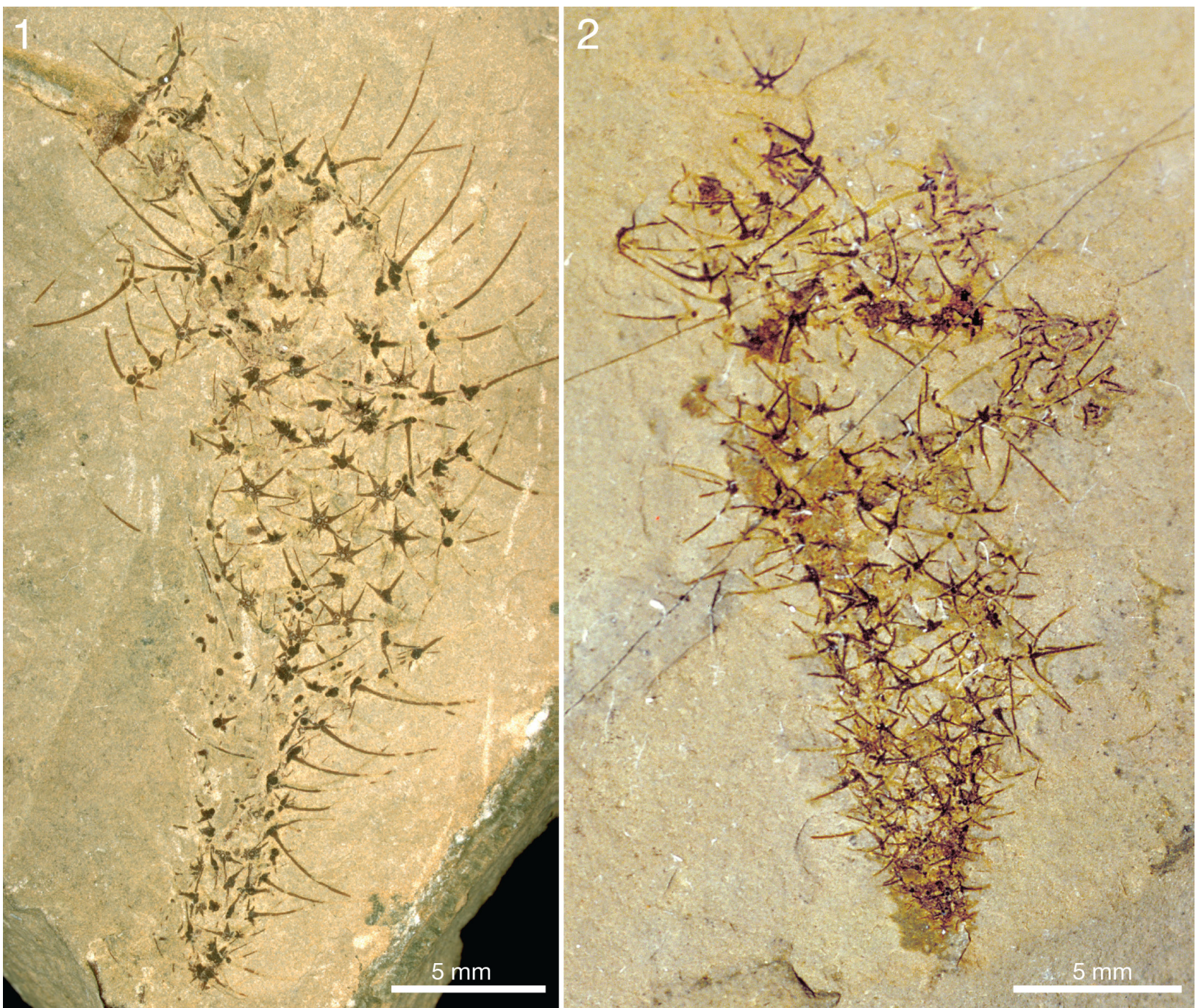

FIGURE 13. Chancelloria eros Walcott, 1920. 1. ROM 49578, ST, dry. 2. ROM 43126, ST, dry.

mulation. In addition to $6+1$ sclerites (he actually wrote "six tangential rays and one or two vertical, proximal-distal, rays", but the presence of a proximal, inner, ray was not documented and seems to have been based on his concept of Chancelloria as a heteractinid sponge), Rigby also identified $4+0$ sclerites.

The presence of $4+0$ sclerites, as in the lectotype (also observed in ROM 49580 and ROM 62590 , Figure 8 ), thus seems well established as a general character of Chancelloria eros. In addition, $3+0$ sclerites in the $C$. eros scleritome have been observed in ROM 62534 (Figure 10), ROM 49599 (Figure 11), and possibly in ROM 62537 (Figure 12.4-12.6).

Whole-body specimens attributed to Chancelloria eros were described by Janussen et al. (2002) from the Wheeler Shale. These have $6-8+1$ sclerites, but no observed $4+0$ forms. The sclerites are also more regularly arranged than in $C$. eros and are of consistent size. The Wheeler specimen figured by Bengtson (2000) as Chancelloria, without species assignment, also belongs to this form. Given the differences from the Burgess Shale $C$. eros, it is likely that these Wheeler forms (but not the one figured by Rigby, 1978, pl. 2:3) belong to a hitherto unnamed species, which may also include ROM 49576 (Figure 14.3-14.5).

In our material identified as Chancelloria eros there are a number of specimens with poor sclerite preservation (Figures $5.3 ; 6 ; 9.4 ; 14.2$ ). As our recognition of the species technically hinges on the composition and variability of the scleritome, a definitive identification of these specimens is not possible. However, with the exception of ROM 49576 (Figure 14.3-14.5), we have not seen any evidence of additional Chancelloria species present in the Burgess Shale material. We therefore 

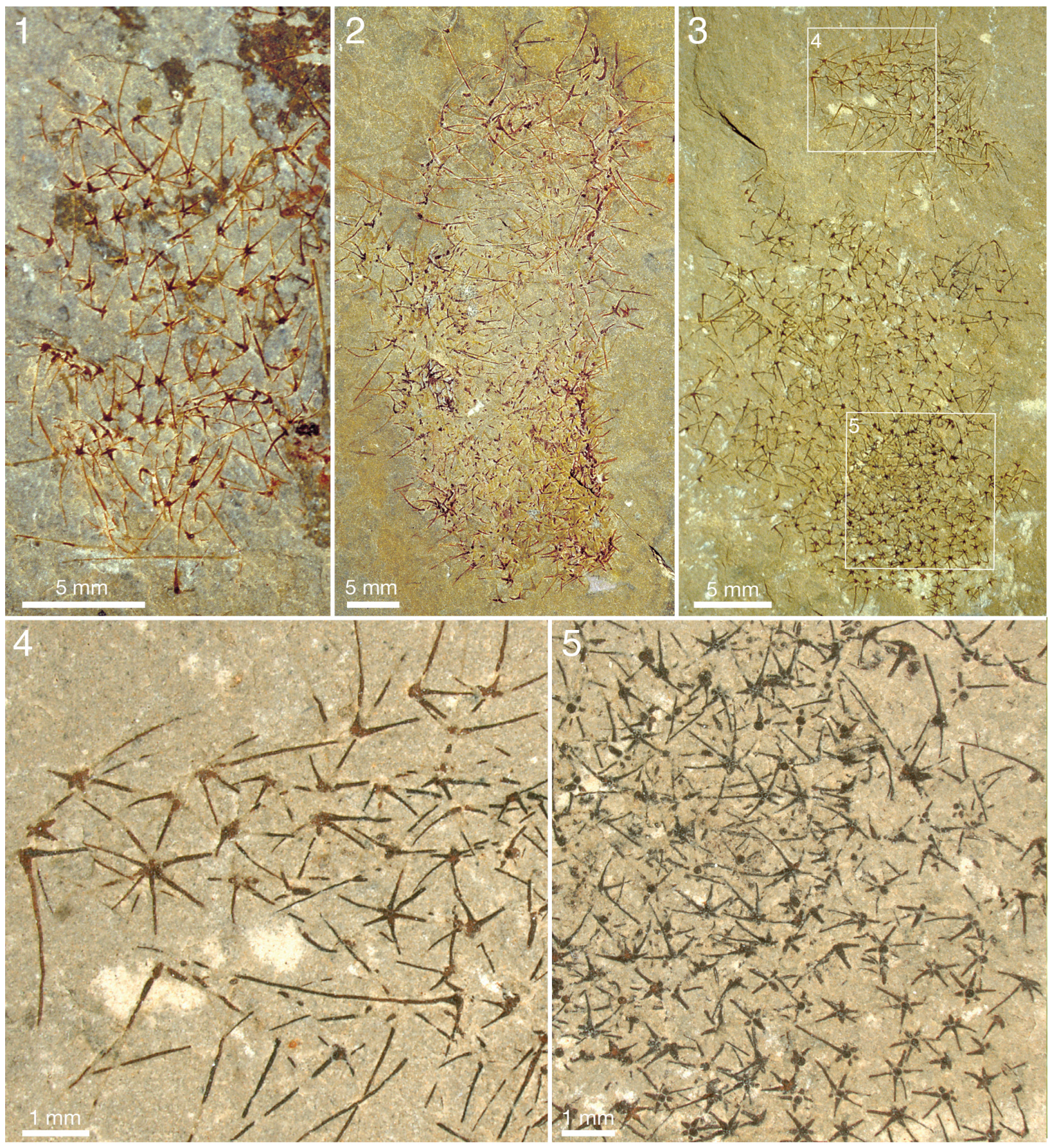

FIGURE 14. Chancelloria eros Walcott, 1920 (1, 2), and C. cf. eros (3-5), ST. 1. ROM 49574, dry. 2. ROM 49572, dry. 3-5. ROM 49576, dry. Items 4 and 5 show details of the upper and lower portions, respectively, of 3.

choose not to use open nomenclature for these specimens.

Genus ALLONNIA Doré and Reid, 1965

Type Species. Allonnia tripodophora Doré and Reid, 1965 (based on isolated sclerites).

Species Known from Scleritome Preservation. Allonnia phrixothrix Bengtson and Hou, 2001 (junior synonym: Allonnia junyuani Janussen et al. 2002); Allonnia tintinopsis n.sp.

Diagnosis. Chancelloriids with $3+0$ sclerites having long, apically directed rays. Modified sclerites around the apical orifice form a palisade-like tuft.

Remarks. The type species, Allonnia tripodophora Doré and Reid, 1965, was based on isolated sclerites from the Lower Cambrian of Carteret (Manche, 


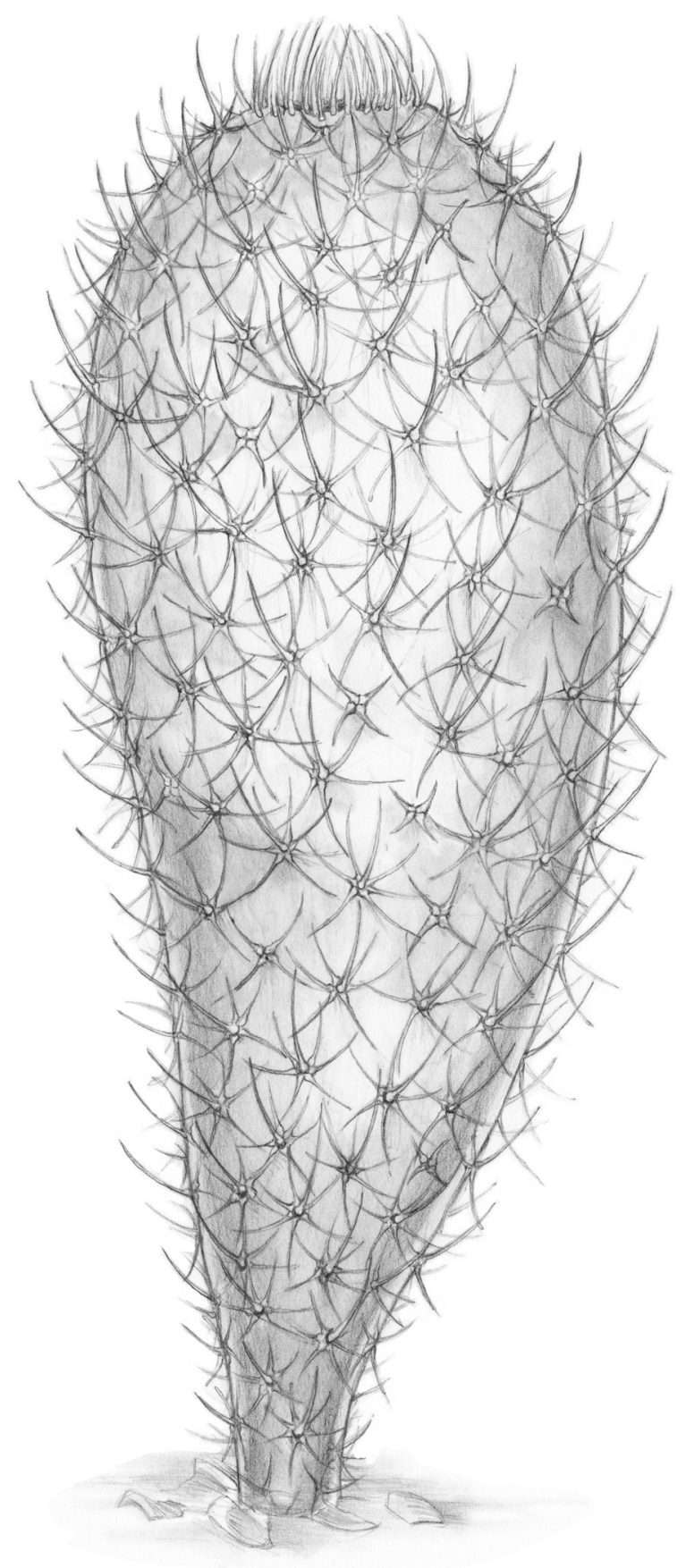

FIGURE 15. Life reconstruction of Chancelloria eros, Walcott, 1920. Artwork Pollyanna von Knorring.

Normandy). As discussed above, the sclerites are difficult to distinguish morphologically from those of species known from whole-body preservation in shales. Moore et al. (2014) noted that sclerites of Al. tripodophora may have had all three rays protruding from the body surface, which might set them apart from more bilaterally symmetrical scler- ites of Al. phrixothrix (and, by implication, those of Al. tintinopsis), the latter having one strongly protruding ray (the ascending ray) and two (lateral) rays closer to the body surface. They established a sclerite-based species, Archiasterella charma, dominated by $3+0$ sclerites, and implied that $A I$. phrixtothrix should possibly be reassigned to Archiasterella. We leave this proposal open and acknowledge that further studies of the variability and distribution of sclerites in assemblages and full-body preservation will be necessary to resolve the taxonomic issue.

Allonnia junyuani Janussen et al., 2002 was established on material from the same section as Al. phrixothrix Bengtson and Hou, 2001. Janussen et al. (2002) discussed two forms previously figured by Chen et al. (1996) as Form A and Form B. They stated that $A l$. junyuani "definitely represents" Form A, and chose as holotype the specimen figured by Chen et al. (1996, p. 91) as "Type A, new Chancellorid gen. et sp. nov." They further included in the species the "Chancelloriid, genus, species uncertain" figured by Hou et al. (1999, p. 155, figure 225) and used this specimen to reconstruct the body plan of $A l$. junyuani. The specimen is the holotype of Al. phrixothrix. Consequently, Al. junyuani Janussen et al., 2002 is a junior synonym of $A l$. phrixothrix Bengtson and Hou, 2001.

Kloss et al. (2009) discussed the validity of the names and concluded that "it is possible that only Form $\mathrm{B}$ is $A[I]$. junyuani, whereas Form $\mathrm{A}$ is simply a synonym for $A[I]$. phrixothrix." As the holotype of Al. junyuani according to its original authors belongs to Form A (Janussen et al., 2002), the conclusion that the species are different is untenable.

Allonnia tintinopsis n.sp.

Figures 2; 3; 12 (part); 17-30; 31.1-31.3; 32-37

http://zoobank.org/NomenclaturalActs/52051170-F28B4A48-9DD8-B76979C3AD5A

Chancelloria eros new species (Walcott, 1920, partim; pl. 88:1, 1a, 1b, 1d, 1e).

Chancelloria eros Walcott, 1920 (Briggs et al., 1994; figure 176).

Chancelloria (Bengtson, 2000; figure 1A; figure 12, partim).

Derivation of the Name. From Tintin, the comicbook hero of Hergé (Georges Remi), and Greek opsis, like, alluding to the pronounced apical tuft of this species.

Holotype. ROM 62527[1] (Figure 16.1, right; 16.2, 16.3).

Figured Paratypes. USNM 66526, 66528. ROM 49573, 49582, 49584, 49587, 49588, 49589, 

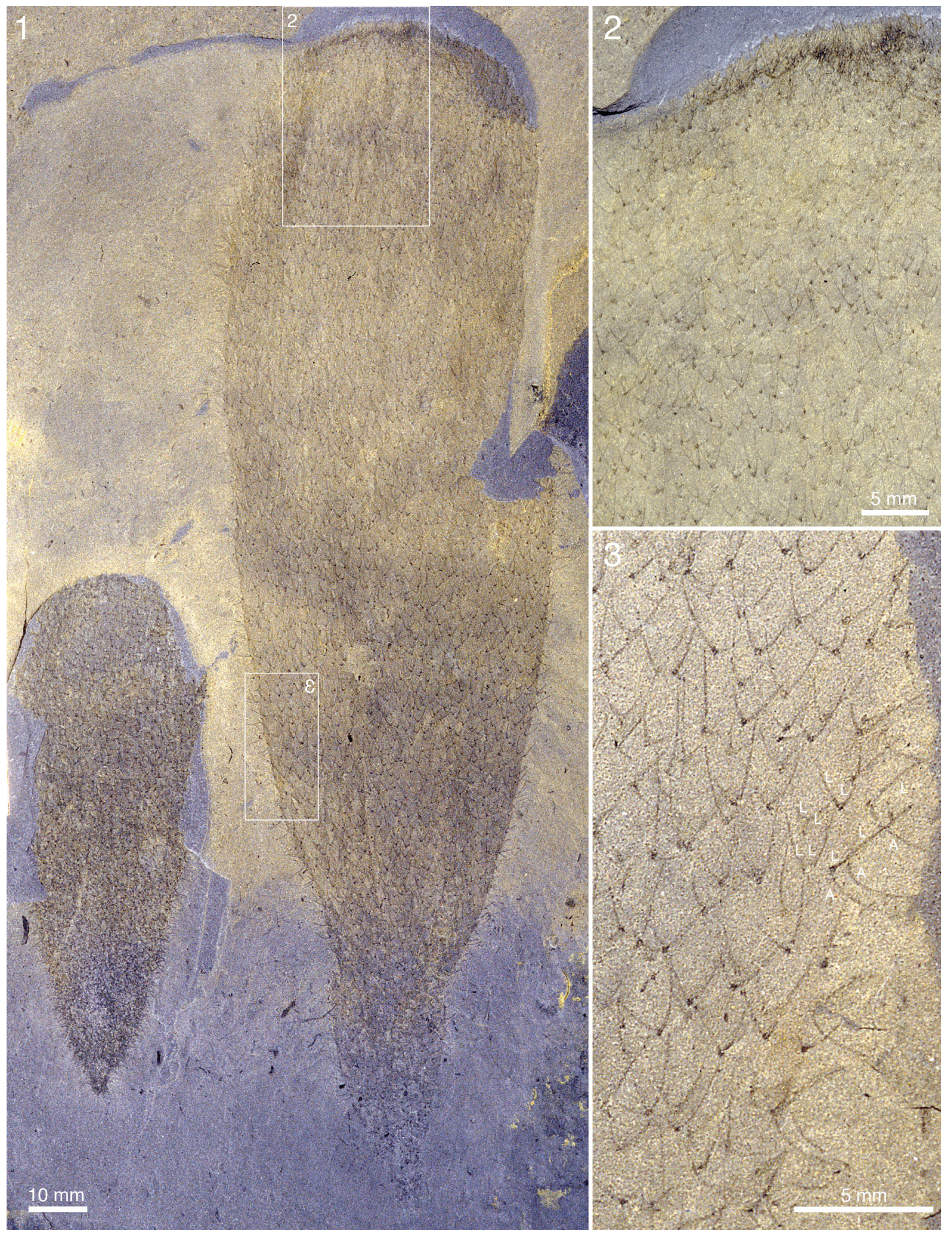

FIGURE 16. Allonnia tintinopsis n.sp., ROM 62527, part $(1,2)$ and counterpart (3), BW -110. 1. The larger specimen to the right in 1 is the holotype (ROM 62527[1]). 2. Holotype, detail of apical part (position marked in 1), with tuft. 3. Detail of lower part of body of holotype (counterpart; position on part marked in 1), showing morphology and arrangement of sclerites. Small letters at mid right denote lateral $(L)$ and ascending $(A)$ rays of selected sclerites. All pictures taken wet. 

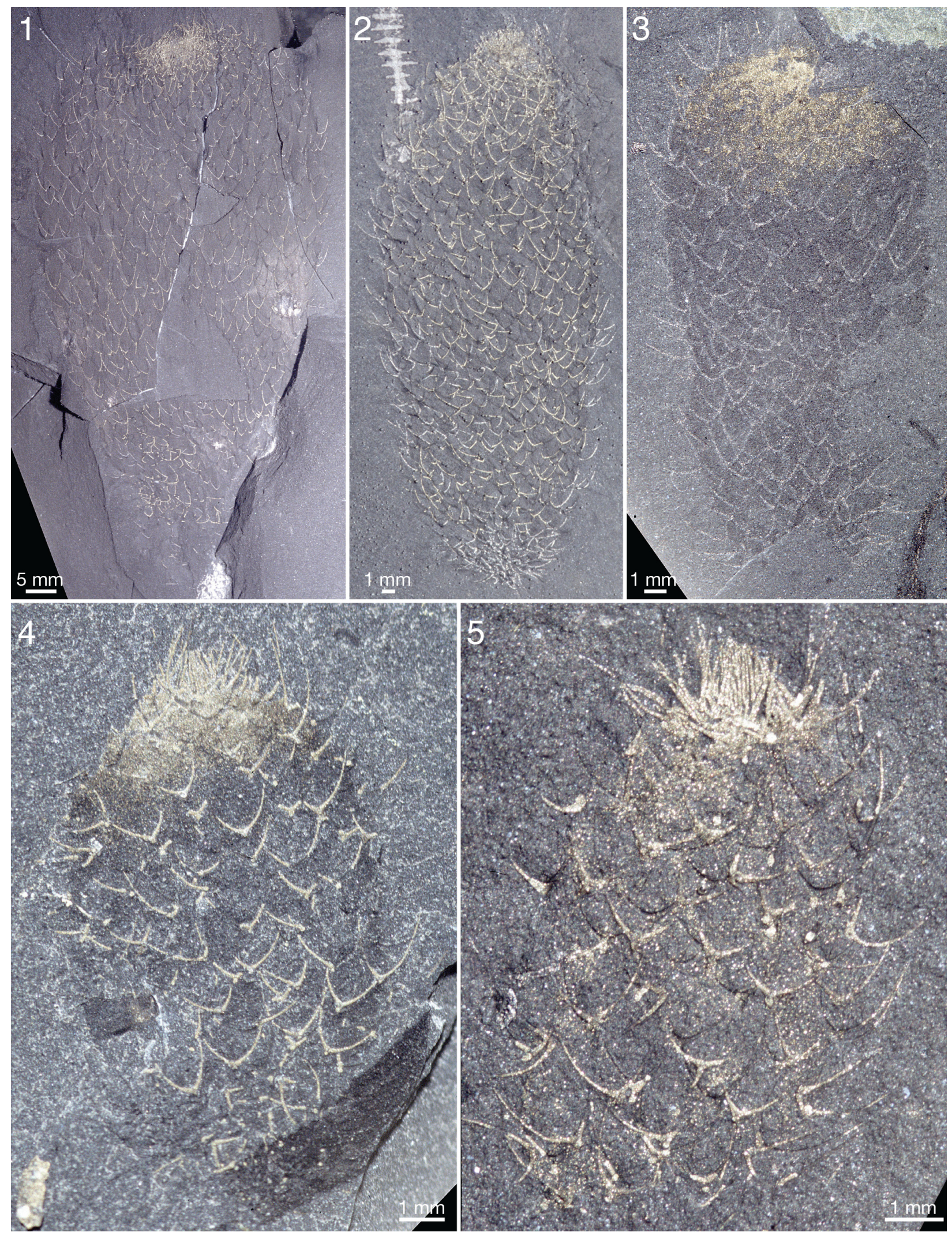

FIGURE 17. Allonnia tintinopsis n.sp. Apical tufts and concentration gradient of pyrite. 1. ROM 62524A (also in Figure 21.1), RQ 8.7, wet. 2. ROM 62516B, RQ 8.8, wet. 3. ROM 62519B, RQ 8.2, wet. 4. ROM 62586, wet. 5. ROM 62517, $\mathrm{RQ}$ 8.8, wet. 


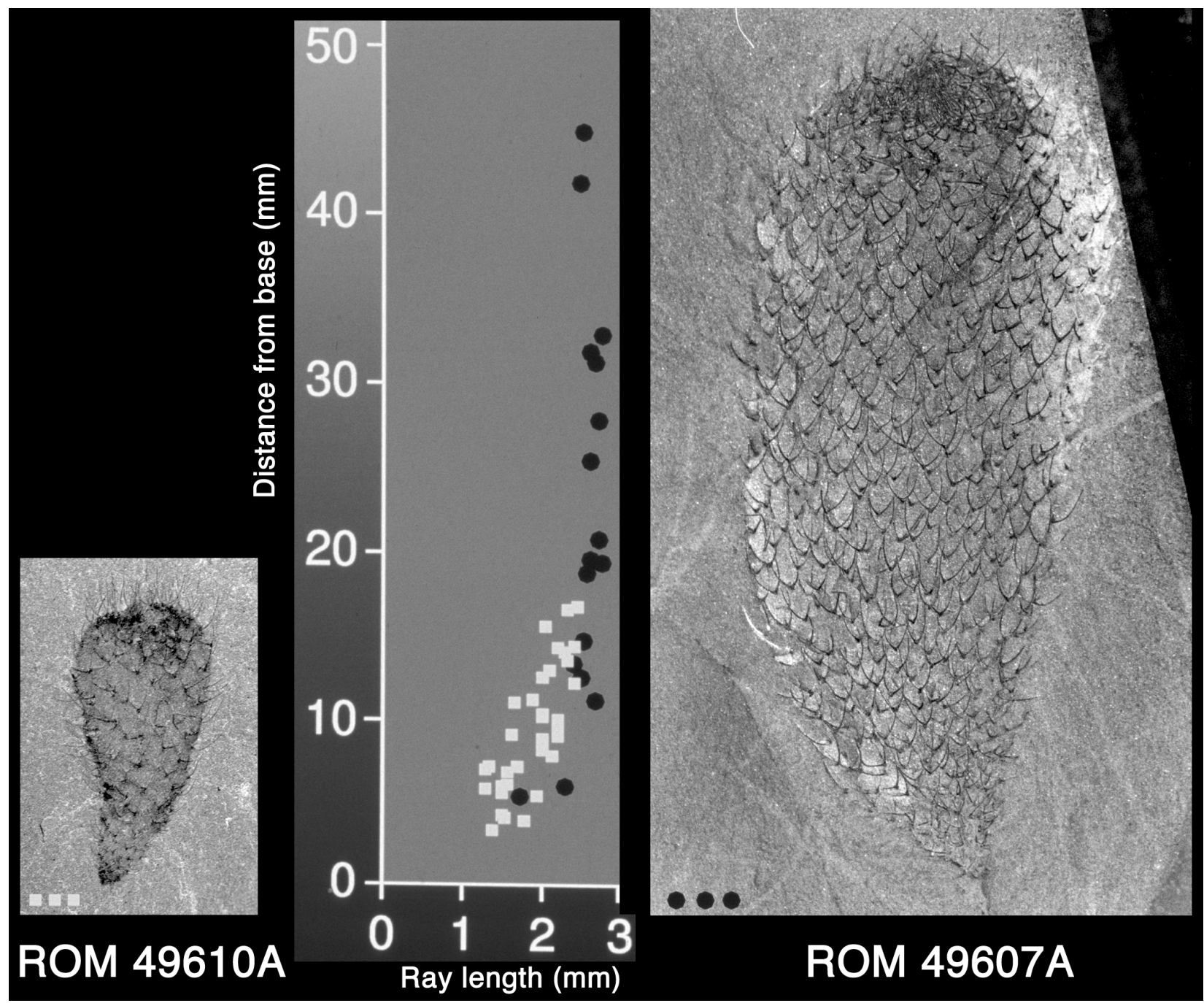

FIGURE 18. Ray length against distance from base in Allonnia tintinopsis n.sp. ROM 49610A, RQ 11.4 (left; white squares) and ROM 49607A, RQ 10.7 (right; black circles).

49596, 49600, 49601, 49602, 49603, 49605 , 49606, 49607, 49608, 49609, 49610, 49612, 49614, 49615, 49616, 49620, 49621, 57574, $62514,62515,62516,62517,62518,62519$, $62520,62521,62523,62524,62525,62526$, 62527[2], 62536, 62537, 62585, 62586, 62587, 62591.

Diagnosis. Species of Allonnia with slender, regularly dispersed $3+0$ sclerites and pronounced apical tuft formed by modified body sclerites. Ray length of fully developed body sclerites $3-3.8 \mathrm{~mm}$; basal width of rays about $200 \mu \mathrm{m}$. Abapical end of body commonly anchored to skeletal debris, to sponges, or to other chancelloriids.

Description. This is the most common chancelloriid in the Burgess Shale, characterized by a strictly regulated scleritome with exclusively $3+0$ body sclerites and a prominent palisade of spines (the apical tuft) around the apical orifice. The body is usually club-shaped, with the widest part near the apex and abapically tapering to a point or a prolonged stalk.

Two of Walcott's (1920) figured syntypes of Chancelloria eros belong to this species, namely his pl. 88:1, 1a (USNM 66526; Figure 2 herein) and pl. 88:1d, 1e (USNM 66528; Figure 3 herein).

The holotype (Figure 16.1, right; 16.2, 16.3) is a large specimen, about $200 \mathrm{~mm}$ long and $55 \mathrm{~mm}$ wide. The body contour is clearly outlined by an integument that forms a film, darker than the surrounding matrix. The abapical part appears incomplete but forms a cylindrical stalk more than $30 \mathrm{~mm}$ long and ca $18 \mathrm{~mm}$ wide. The sclerites are distinctly preserved, with a uniform size and shape across the whole body: each one has three slender rays, two lateral and one ascending, each up to 3.8 

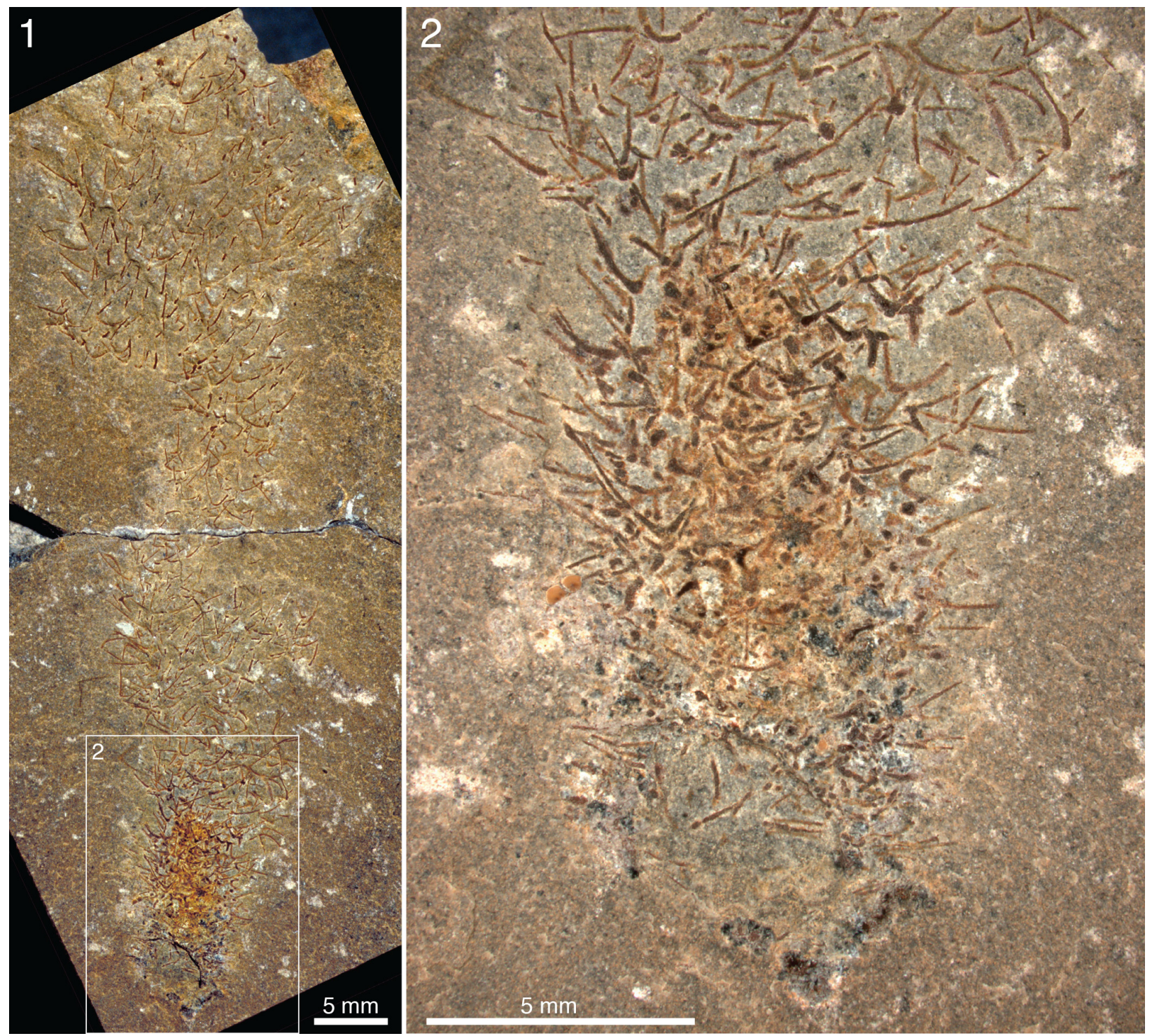

FIGURE 19. Allonnia tintinopsis n.sp. with stalk-like constriction. ROM 49573, ST. 1. Complete specimen, dry. 2. Detail of 1 (position marked by frame), dry, showing lower part of stalk with densely packed sclerites and debris.

$\mathrm{mm}$ long and basally up to about $200 \mu \mathrm{m}$ wide (Figure 16.3). They have the typical lyre shape seen in most shale-preserved specimens. This shape is due to the selective preservation of the curved lateral rays vs. the ascending ray, which is usually seen only where the sclerites are laterally compressed at the edges of the flattened specimen (Figure 16.3, right). The lateral rays form a mutual angle of ca $70^{\circ}$ and curve somewhat toward each other in the plane formed by the two rays. The plane of the rays forms a $0^{\circ}-35^{\circ}$ angle to the body surface. The ascending rays diverge basally at $80^{\circ}-120^{\circ}$ from the plane of the lateral rays, and then curve toward the apical end of the body. The sclerites are semiregularly distributed over the body surface in a rhombic pattern, at intervals of about 1.5-3 $\mathrm{mm}$ in the wider parts of the body; in the narrower abapical portion the sclerites are more densely positioned. The apically facing body surface shows a denser palisade of sclerites, and centrally there is an $8 \mathrm{~mm}$ wide region characterized by an aggregation of thin, parallel outwardfacing rays (Figure 16.2). This clearly corresponds to the tuft seen in most specimens (see below).

A second specimen (Figure 16.1, left) is preserved side-by-side with the holotype. It is $88 \mathrm{~mm}$ long and $32 \mathrm{~mm}$ wide. Its body shape is similar to that of the holotype, but there is no discernible stalk; instead, the abapical end appears to narrow to a point. The apical end is not exposed. The 

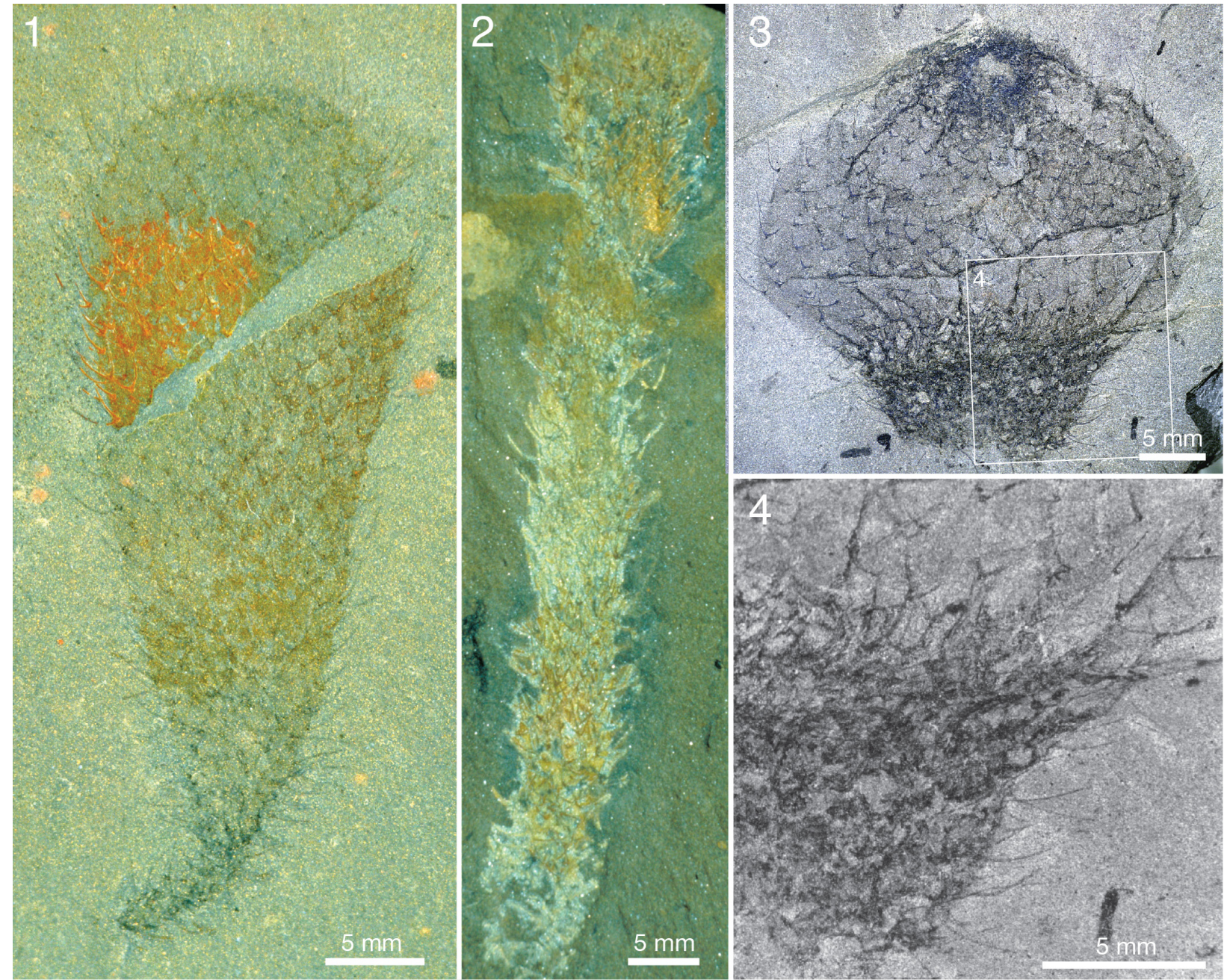

FIGURE 20. Allonnia tintinopsis n.sp. with stalk-like constrictions. 1. ROM 49616B, RQ 9.1, dry. 2. ROM 49596A, RQ 8.4, dry. 3, 4. ROM 49603, RQ 8.9. 3, Dry/pol. 4. Detail of 3 (position marked by frame), dry/pol.

sclerite density is higher than in the holotype, the interval between sclerite bases being roughly a millimetre in the wider parts of the body; toward the narrow abapical end of the body the density becomes even higher, resulting in a jumbled mass of sclerites.

The body shape in most of the larger specimens is similar to that of $C$. eros, i.e. club-shaped with an abapical taper or stalk. Smaller specimens tend to be more, spindle-shaped (e.g., Figure 17.2), with an acute apical contour, whereas larger ones may have a more flattened apical surface (e.g., Figure 16.1, right). There is some variation in body proportions, from broad (e.g., Figure 16.1) to more narrow (Figure 2.1).

An even greater variability exists in the expression of the stalk, from a narrow taper and apparent absence of a distinct stalk (e.g., Figures 16.1, left; 18), to a well-developed stalk, up to 40 $\mathrm{cm}$ long (e.g., Figure 19). The stalk differs from the more apical parts of the body only by its smaller diameter and greater crowding of sclerites. Figure 20 shows a diversity of stalk expression and body shape, from a thin flexible stalk attached to a large, club-shaped body (Figure 20.1) to a $67 \mathrm{~mm}$ long hose-like body (probably incomplete in its lower parts) that in itself has the dimensions and sclerite characteristics of a stalk (Figure 20.2). The specimen in Figure 20.3 and 20.4 has an apical bulb-like portion, with relatively scarcely distributed sclerites, and a constricted abapical portion, with a dense sclerite covering. These features strongly suggest that the stalk is not a permanent structure, but represents a temporary contraction of the body wall, starting from the abapical part. See further discussion of this feature in the section "Body shape and attachment." 

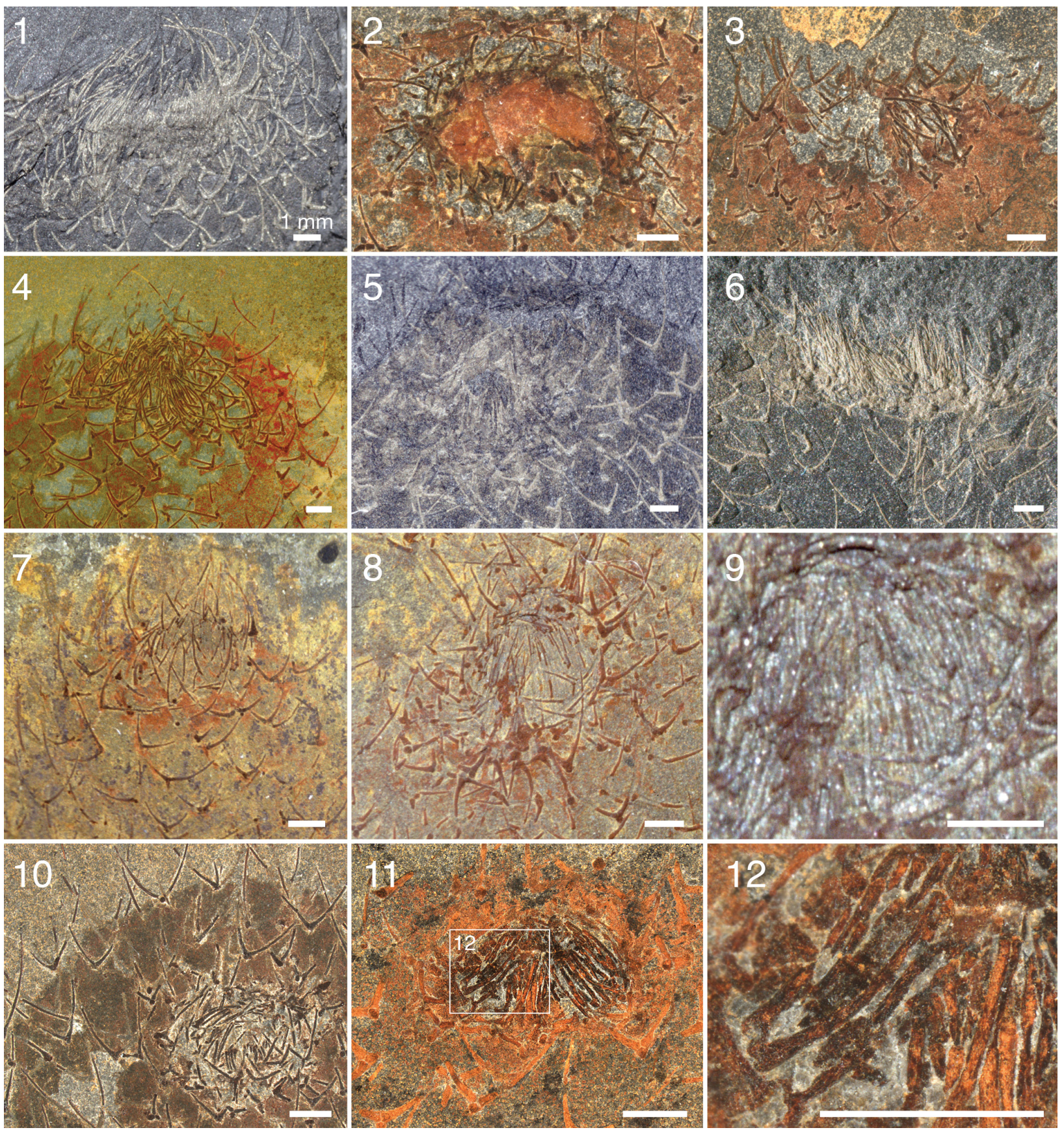

FIGURE 21. Allonnia tintinopsis n.sp. Apical tufts and orifices. 1. ROM 62524A (also in Figure 17.1), RQ 8.7, dry. 2. ROM 49608a, RT, dry/pol. 3. ROM 49608b, RT, dry/pol. 4. ROM 49607A, RQ 10.7, wet/pol. 5. ROM 62525B, RQ 8.4, dry. 6. ROM 62525B, RQ 8.4, dry/pol. 7. ROM 62520B (also in Figure 24.3), RQ 9.0, wet. 8, 9. ROM 62587, RQ 8.4, wet/pol (8), wet (9). 10. ROM 49614B, RQ 9.0, dry/pol. 11, 12. ROM 49620B (counterpart to the upper right specimen in Figure 27.3), RQ 9.0, 11. Dry/pol. 12. Detail of 11 (position marked by frame), dry/pol. Scale bars in all pictures equal $1 \mathrm{~mm}$.

Unlike the scleritome of Chancelloria eros, the sclerites in the Allonnia tintinopsis scleritome are of a constant size within most parts of the specimens. The exceptions are in the abapical part where the sclerites are somewhat smaller, and the apical part, where the apical tuft is formed by modified sclerites. Figure 18 shows the maximum ray length of sclerites at various distances from the abapical end in a small and a large specimen. The sclerite size increases gradually from the abapical end 


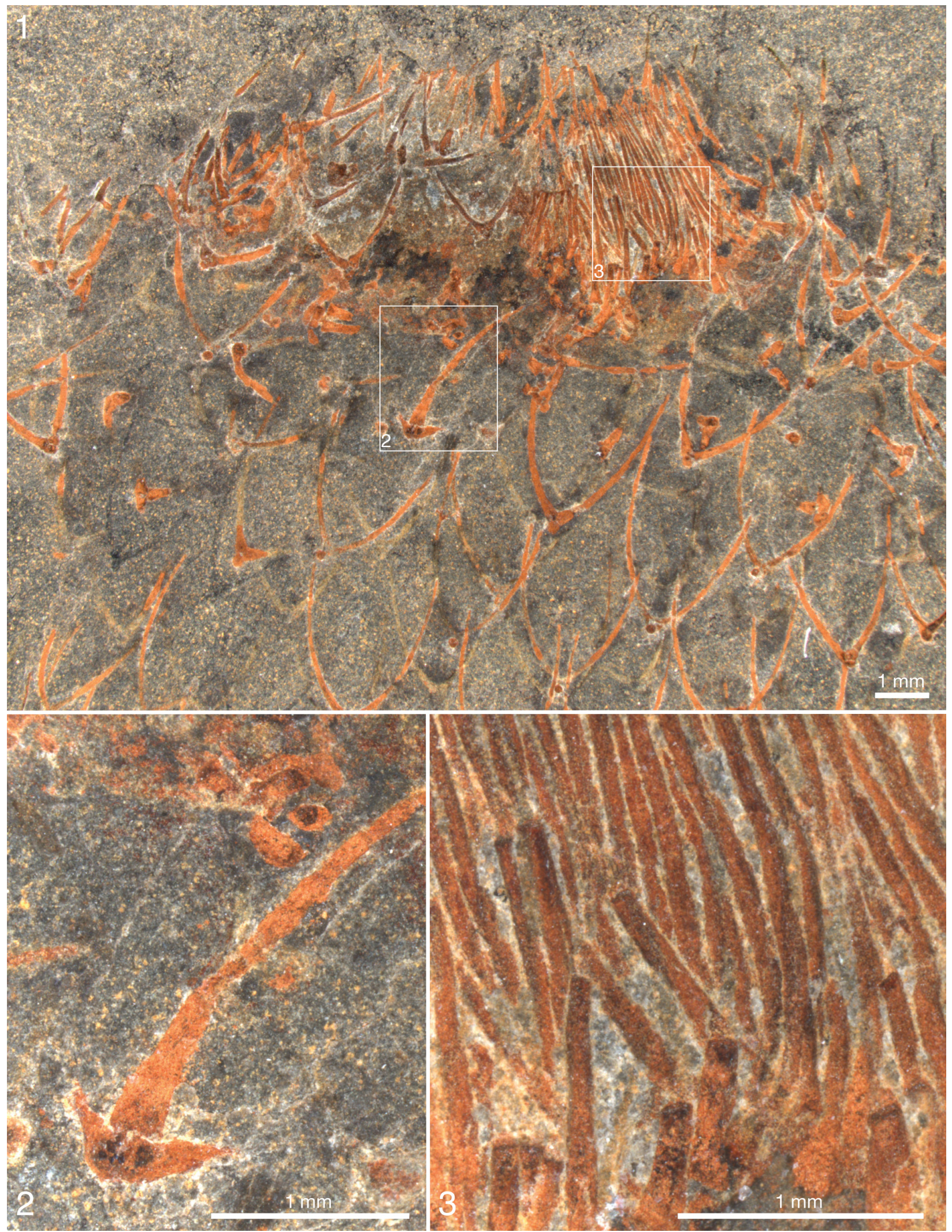

FIGURE 22. Allonnia tintinopsis n.sp. ROM 49612A, RQ 9.8, dry/pol. 1. Apical part of body, with tuft. 2, 3. Details of 1 (positions marked by frames). 

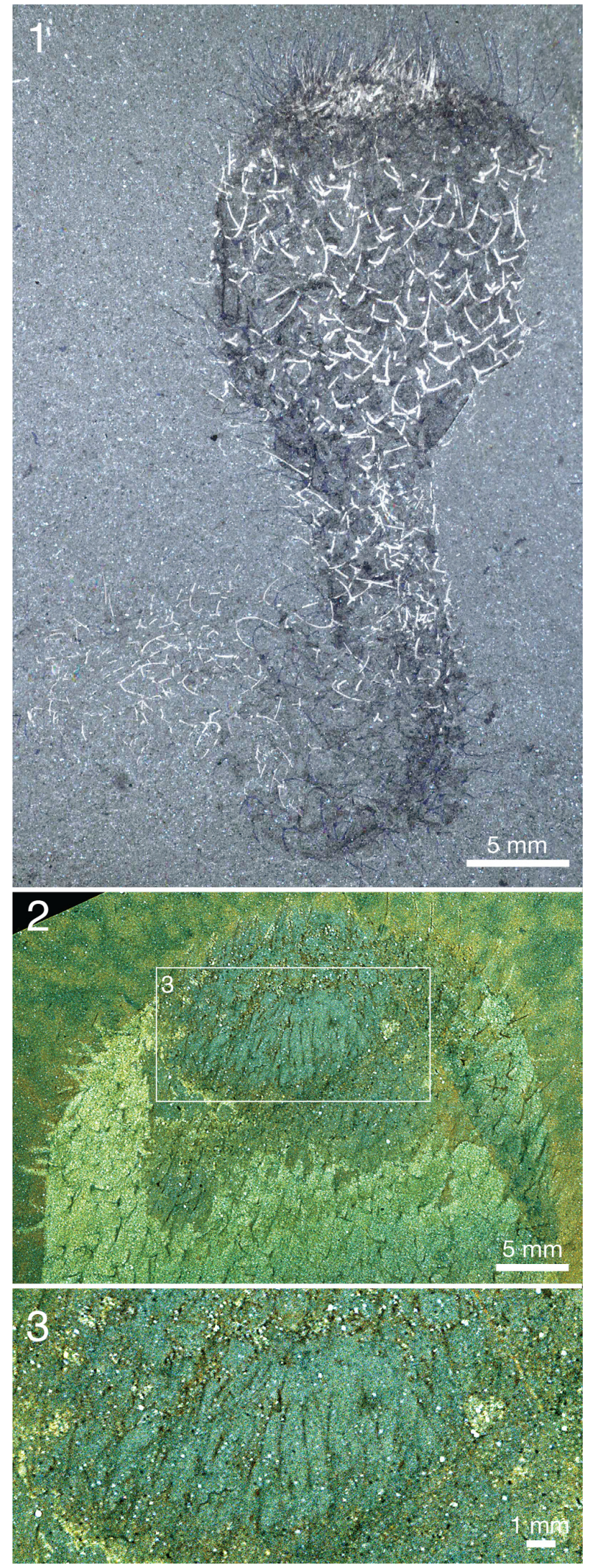

FIGURE 23. Allonnia tintinopsis n.sp. Apical tufts. 1. ROM 49605(1), RQ 9.2, wet/pol. 2, 3. ROM 62591, UE. 2. Wet. 3. Detail of 2 (position marked by frame), wet. toward the apex, but at a distance of about $20 \mathrm{~mm}$ from the lower end, the maximum size of ca $3 \mathrm{~mm}$ ray length has been reached. The sclerites of the small specimen cluster with those of the correspondingly sized abapical part of the larger specimen.

The apical tuft is a conspicuous feature in most specimens. It is usually expressed as a sclerite-dense ring, about 3-5 $\mathrm{mm}$ in diameter, around a circular field more-or-less devoid of sclerites (Figures 20.3 ; 21-23; 24.1, 24.3; 25.1). Fine rays typically form an upright palisade-like structure (e.g., Figures $17.4,17.5 ; 21.8,21.9 ; 22.1 ; 22.3 ; 23.1$ ), but commonly they converge upwards to form a teepee-like structure (e.g., Figure 21.11, 21.12). Where the apex of the specimen is obliquely compressed, the fine rays can be seen to cover the sclerite-free area in a more-or-less organized fashion (Figure 21.8-21.10). In one obliquely compressed specimen (Figure 26) the fine rays are radially directed toward the centre of the ring, seemingly covering the central area as a diaphragm shutter.

Although the basal portions of the tuft sclerites are seldom clearly visible, they sometimes seem to widen into a knob-like end (Figures 21.12; 22.3). An isolated three-rayed sclerite adjacent to the apical tuft in one specimen shows one long ascending ray and two very short lateral rays (Figure 22.2). This occurrence suggests a morphological transition from the normal body sclerites to the unirayed sclerites making up the tuft palisade. In the specimen showing spines closing the central area (Figure 26), the spines making up the tuft do not show a clearly defined base, but rather merge into a mass of fine-grained pyrite (Figure 26.3, left). Because of the oblique compression of this specimen, the three-rayed body sclerites adjacent to the apical tuft are preserved with all their rays visible at the base (Figure 26.2, 26.3). They have a more robust appearance than the tuft spines, but this is largely due to the fact that they represent proximal portions of the rays; the more distal ray parts of the body sclerites that are occasionally preserved are as thin as the tuft sclerites (Figure 26.2).

One specimen (ROM 62591; Figure 23.2, 23.3) has a peculiar fabric in the tuft in the form of ca. $0.5 \mathrm{~mm}$ broad, rounded sheets surrounding the fine spines. These structures have a distinct boundary and appear to imbricate. The material has a different reflectance than most of the skin (Figure 23.2, left and bottom), but this could be an effect of preservation, as there are areas surrounding the tuft that have a similar sheen. Although 

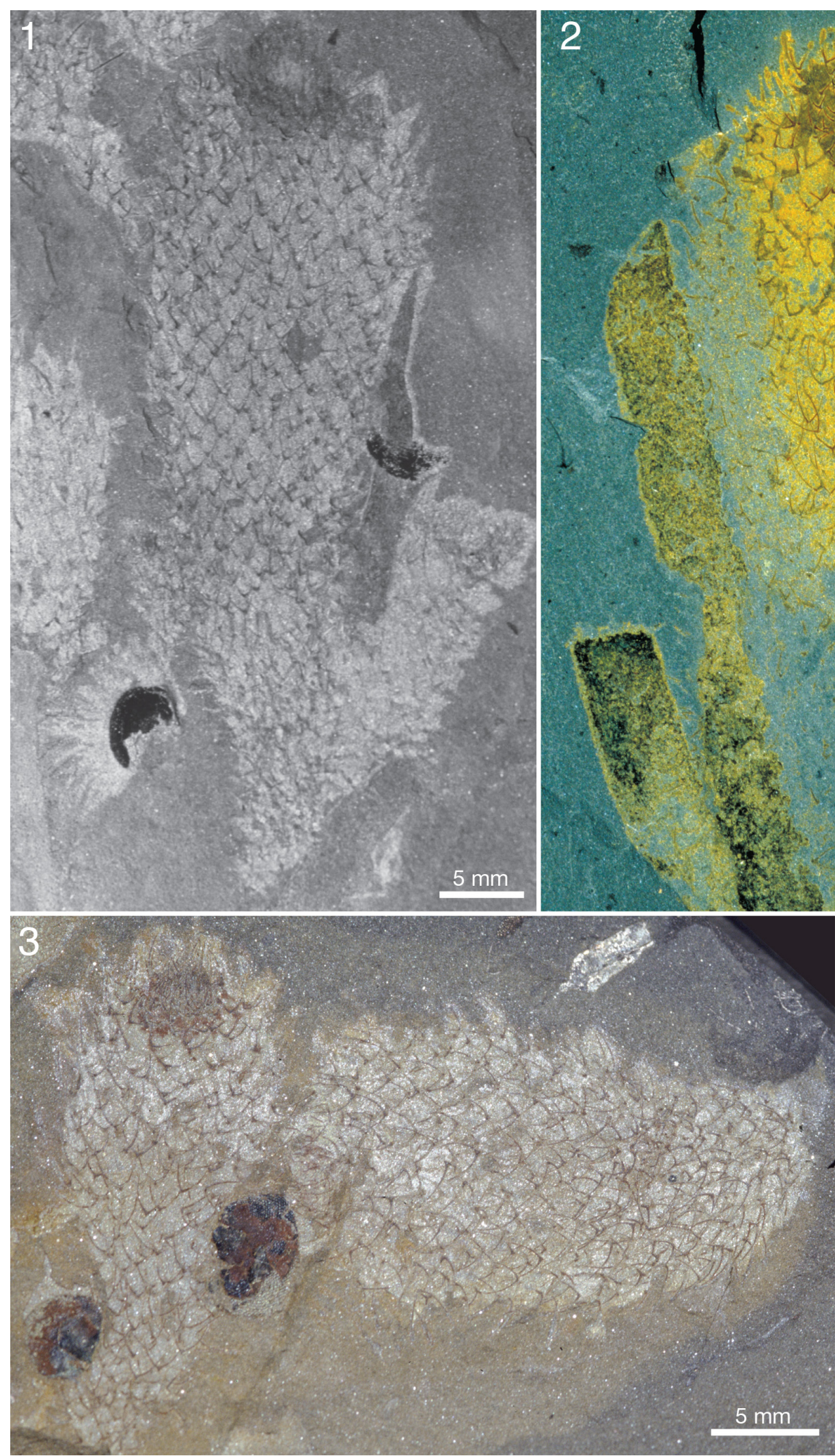

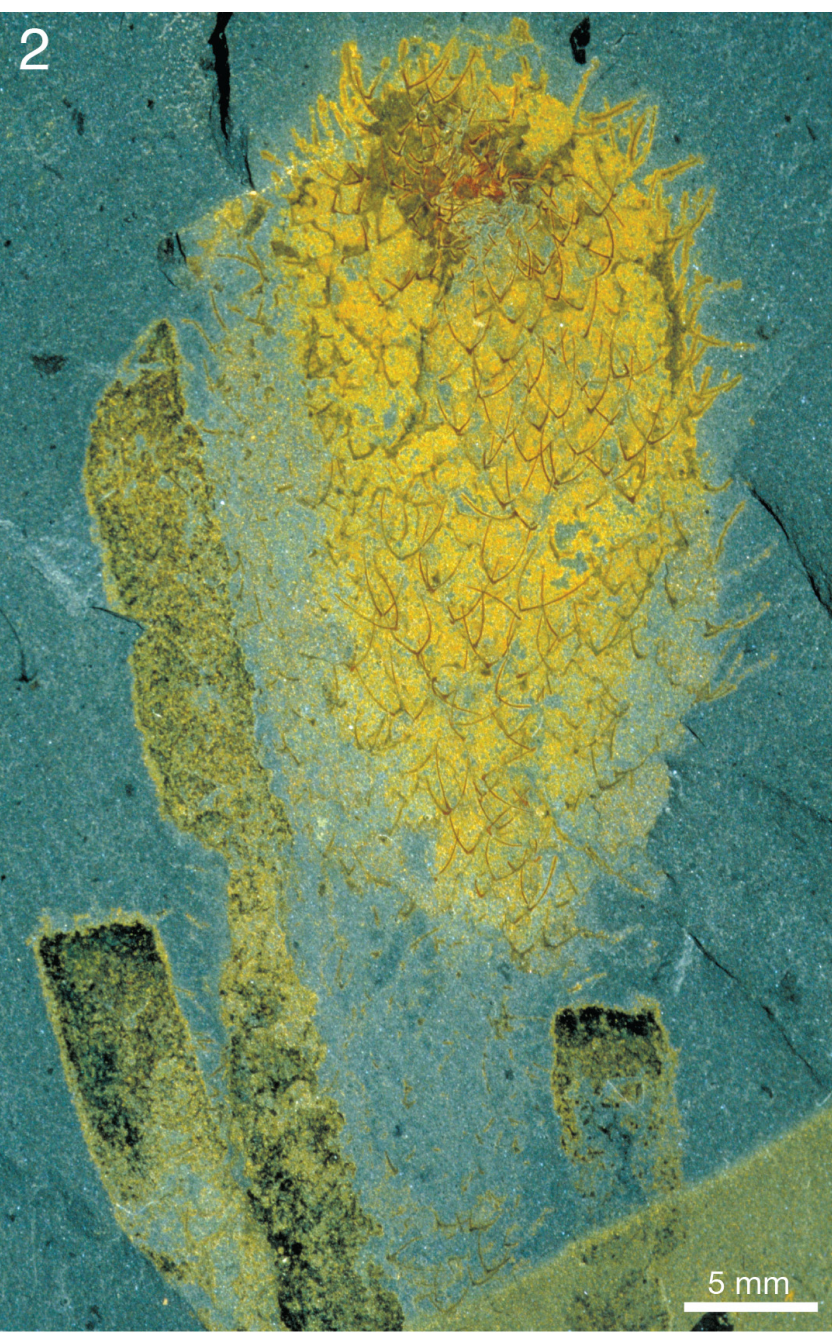

4

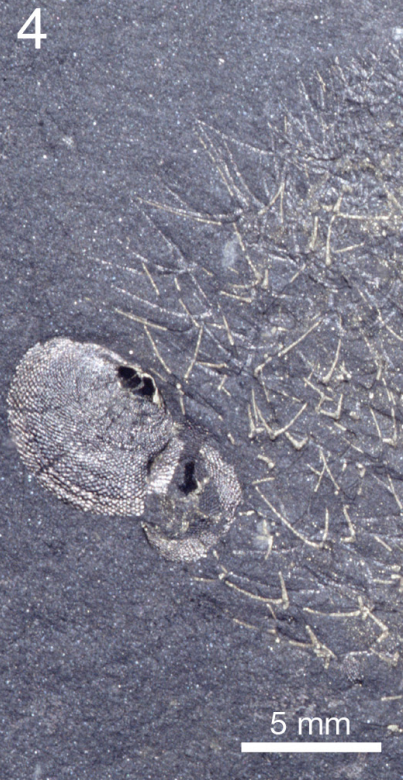

FIGURE 24. Allonnia tintinopsis n.sp. intergrown with Vauxia $(1,2)$ and having Micromitra attached to the spines (1, 3, 4). 1. ROM 49588B, RQ 9.0, wet/pol. 2. ROM 49606, RQ 8.9, wet. 3. ROM 62520B (also in Figure 21.7), RQ 9.0, wet. 4. ROM 62515B, RQ 8.8, wet. 

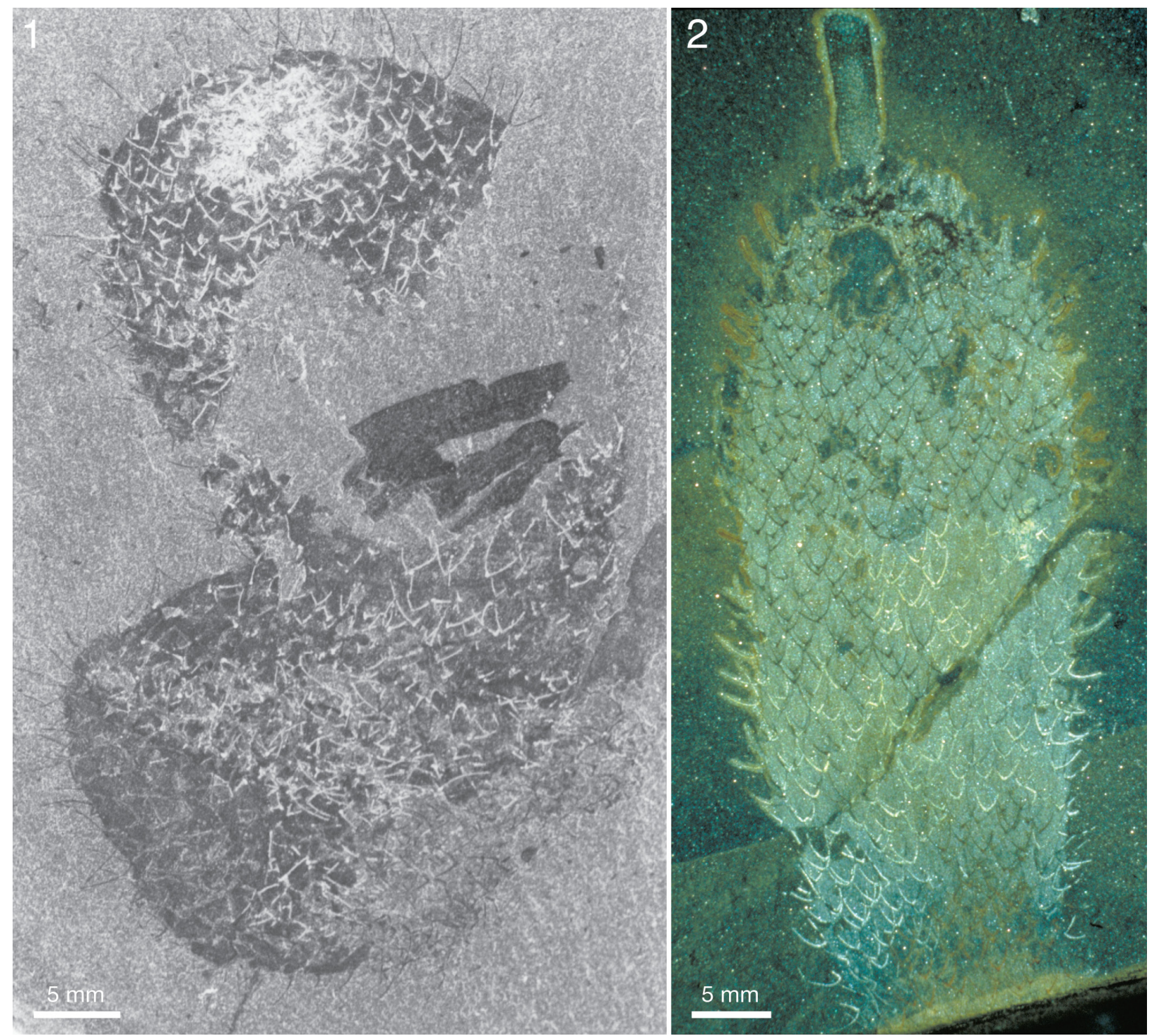

FIGURE 25. Allonnia tintinopsis n.sp. associated with Vauxia. 1. ROM 49587B, RQ 8.3, dry. 2. ROM 49584A, RQ 8.1, wet.

these structures might conceivably represent soft tentacle-like organs, they are more likely to represent diagenetic haloes around the spines, such that are commonly present around the rays of chancelloriid body sclerites (Figures $2.1 ; 3 ; 10$; 23.2, left; 25.2; 27.1, 27.2; 28.2; 29) and tuft sclerites (Figure 30.1). The tight packing of the tuft spines seen in other well-preserved specimens (e.g., Figures 22; 26) in any case does not leave room for surrounding soft tissues.

The apical structure represented by the ring forming the tuft is typically more heavily mineralized than the rest of the body, giving it a more solid appearance (Figures 3.1, 3.2; 17; 20.3; 21.1-21.3, $21.6,21.11 ; 22.1$; 24.1-3; 25.1; 26; 30). In speci- mens with pyritized sclerites and tufts, this feature is often expressed as an increasingly higher concentration of pyrite grains toward the apical end (Figures $17 ; 21.1 ; 26 ; 30.2 ; 30.4 ; 31.2$ ). In combination with the lack of distinct boundaries of the ring-like structure, this suggests that the latter structure does not represent a discrete organ but is rather a taphonomic phenomenon caused by a higher concentration of organic matter in the adapical region.

The skin is variably preserved but is commonly seen as a smooth surface with different colour or reflectance from that of the surrounding matrix. Occasionally it is longitudinally folded (Figure $32.1,32.2$ ). In most cases, no fine structure is 

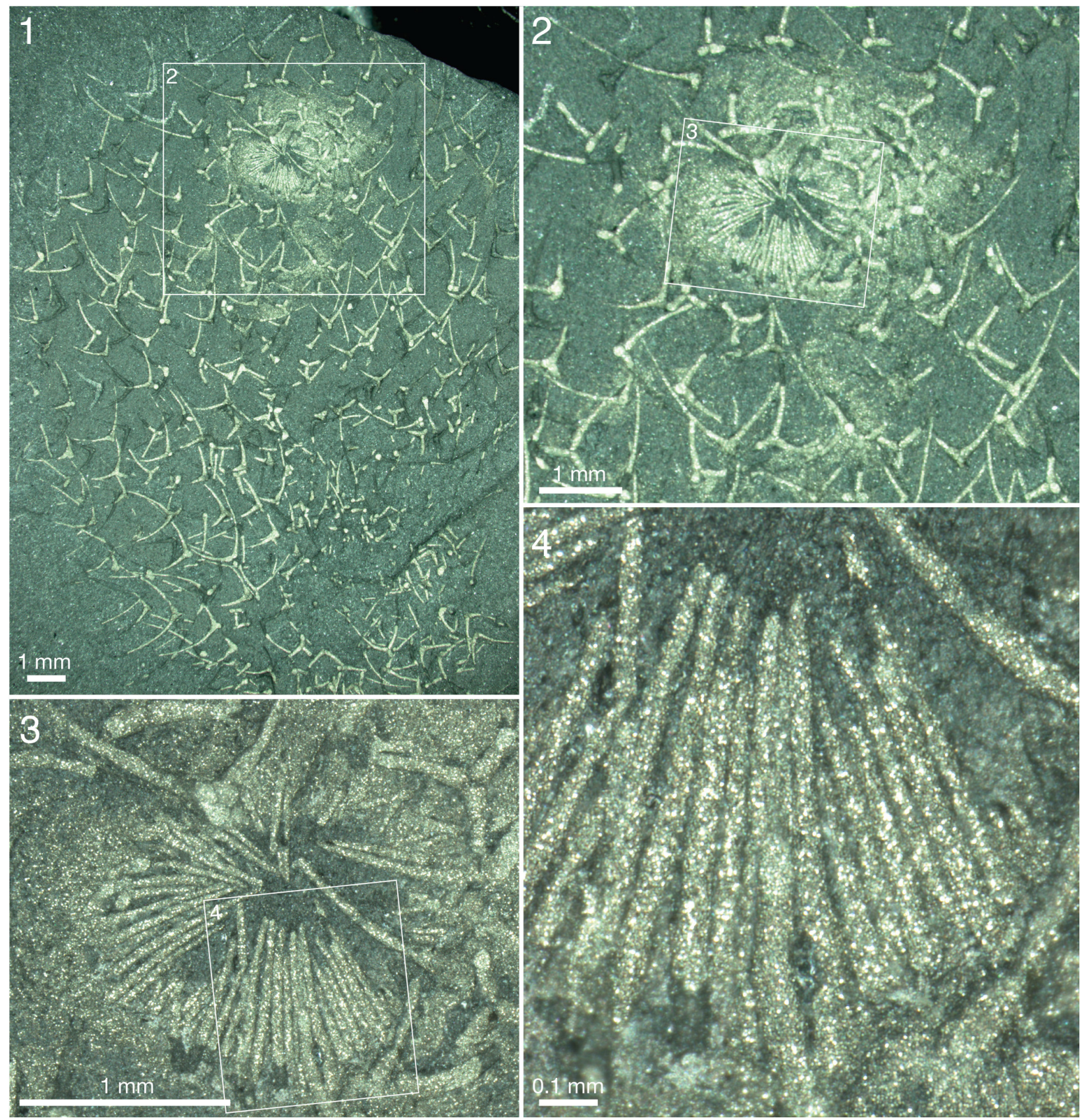

FIGURE 26. Allonnia tintinopsis n.sp. ROM 57574, RQ 8.5. Apical tuft and orifice. 1. Dry. 2-4. Details of preceding pictures (positions marked by frames), dry.

visible, but a few specimens show a granular surface (Figure 31.1-31.3) similar to that of Archiasterella coriacea (Figure 31.4). No evidence for regular openings is visible over the body surface, with the exception of the ring-shaped apical structure. The sclerite-free area inside the ring in several specimens has a different colour or reflectance from that of the surrounding skin (Figures 21.2$21.3,21.10 ; 24.1,24.3 ; 30.3)$. This suggests the presence of a body opening surrounded by the fine rays of the tuft.

The lower end of the specimen is in several specimens associated with shell debris or some other object. Lumps of shell debris are seen at the abapical ends of two specimens in Figure 33, and Figure 28.1 shows a specimen with two large hyolith conchs in the abapical end. The end of the stalk in the specimen in Figure 19 has a patch of dark material that differs in colour from the rest of the 

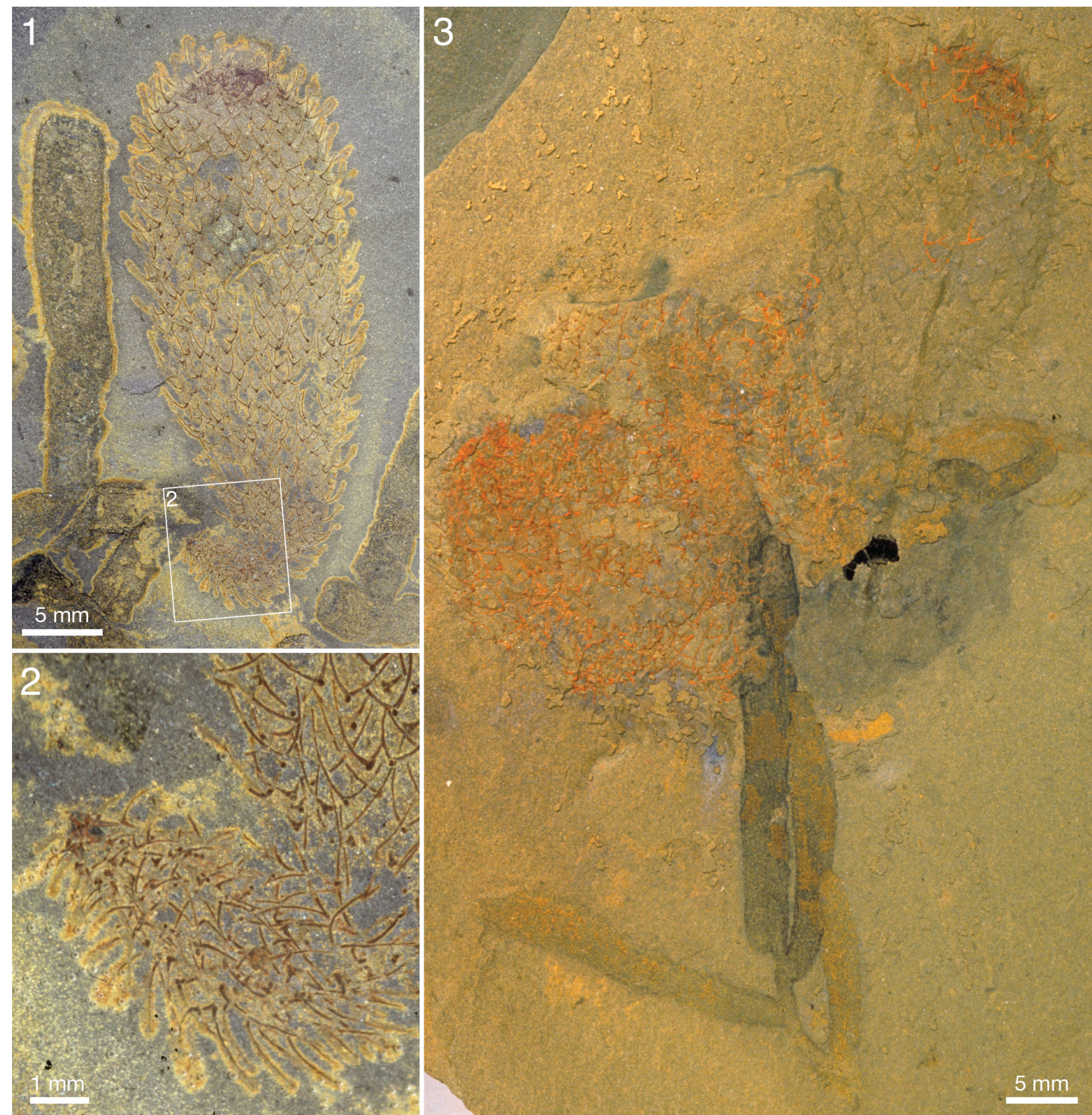

FIGURE 27. Allonnia tintinopsis n.sp., attachment to Vauxia. 1-2. ROM 62523A, RQ 8.4. 1. Wet. 2. Detail of 1 (position marked by frame), wet. 3. ROM 49620A (upper right-hand specimen is part to the one in Figure 21.11-12), RQ 9.0, wet.

specimen, but it is not clear whether this represents a solid object.

The large slab ROM 62585 (Figure 33) contains an association of 11 specimens of the general club shape characteristic of most large forms. Except for one specimen (lower left in figure), the bodies on this slab are strictly aligned; however, four of them lie with the apical end to the right (as oriented in Figure 33.2), and six with that end to the left. The specimens range from $45 \mathrm{~mm}$ to $226 \mathrm{~mm}$ in length, and they all taper abapically to nearly a point. A lump of shell debris at the lower end of the largest and one of the smaller specimens (grey patches in Figure 33.2) is interpreted to represent an anchoring root bulb; a third such lump on the same slab does not have any visible connection with an Allonnia individual. 

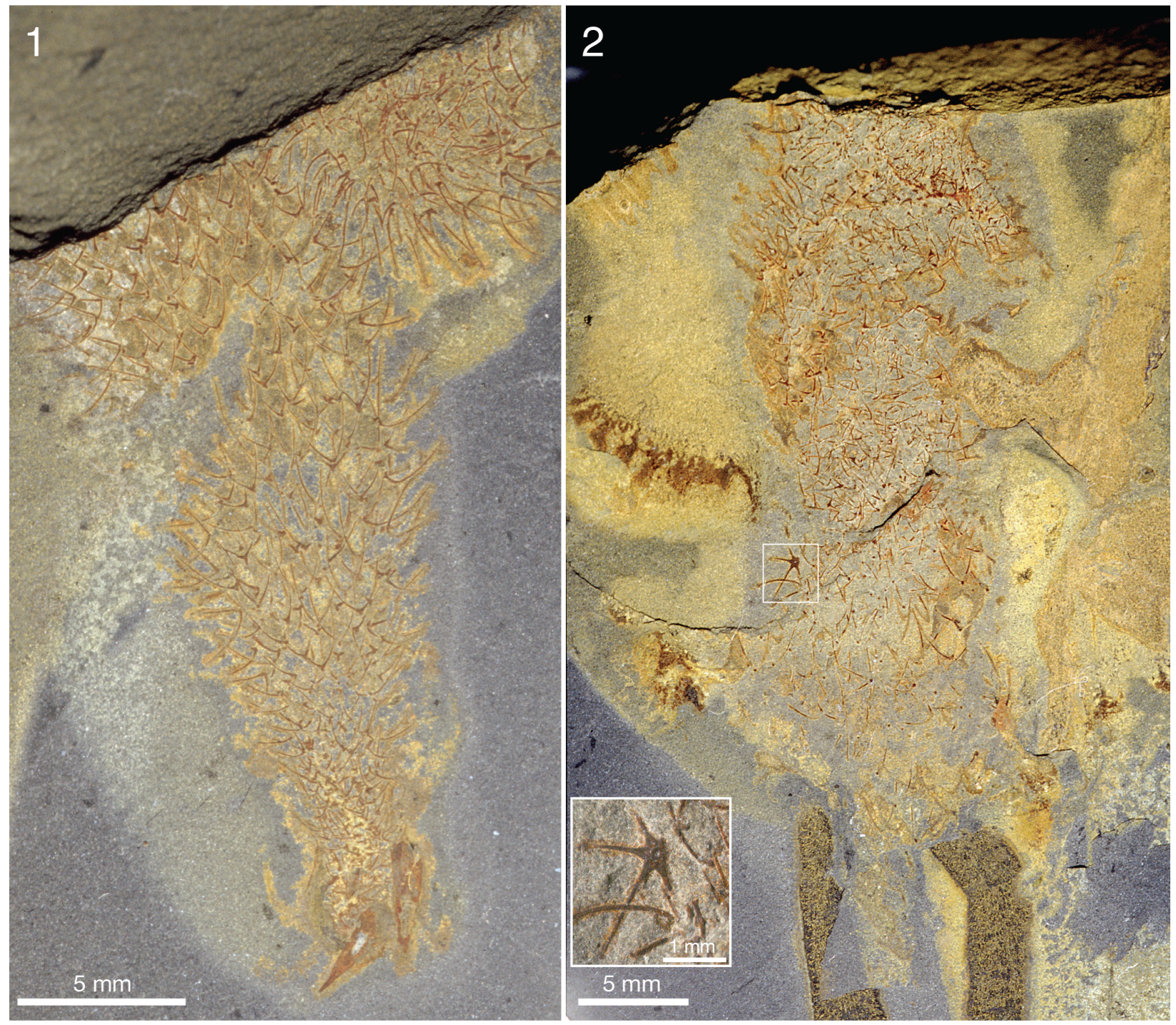

FIGURE 28. Allonnia tintinopsis n.sp., two specimens on the same slab showing probable attachment to hyoliths (1, wet) and Vauxia (2, wet). ROM 62518A, RQ 8.2. Inset in 2 (dry) shows blowup of isolated, probably extraneous, Chancelloria-like sclerite in Allonnia scleritome.

In addition to the evidence for anchoring by attachment to shell debris in the soft sediment, Allonnia tintinopsis is frequently preserved in a way that suggests that it attached to other sedentary organisms, in particular the sponge Vauxia and other chancelloriids. Figure 27.1-27.2 shows a specimen with a stalk-like abapical end that is strongly bent towards an assemblage of Vauxia. Although no direct attachment surface can be seen, the specimen appears complete and abuts directly to the sponge. It was therefore likely attached to the latter. Similarly, Figure 27.3 shows a branching Vauxia from which at least three Al. tintinopsis radiate. This is hardly a chance association, but rather evidence that Allonnia attached to the sponge. Probable direct attachments of Allonnia to Vauxia are also seen in Figures $17.4 ; 28.2$; and 34 .

Other associations with Vauxia are common, in which it is not possible to determine whether the individuals were attached to each other (Figures $12.1 ; 25.1 ; 29)$ or whether the roles of the two taxa may even be reversed (Figures 25.2; 35). The slab shown in Figure 29 suggests a complex thicket of intertwined Allonnia and Vauxia where both taxa appear to have been serving as substrate for the other.

Apart from the sponge Vauxia and other chancelloriids, there is evidence that brachiopod epizoans also used live chancelloriids for attachment. 




FIGURE 29. Intergrowths of Allonnia tintinopsis n.sp. and Vauxia. Part, ROM 62526A (2) and counterpart, ROM 62526B (1, 3), RQ 8.4. 1. Wet. 2. Detail of part (position marked by frame in 1), wet. 3. Detail of 1 (position marked by frame), wet. 

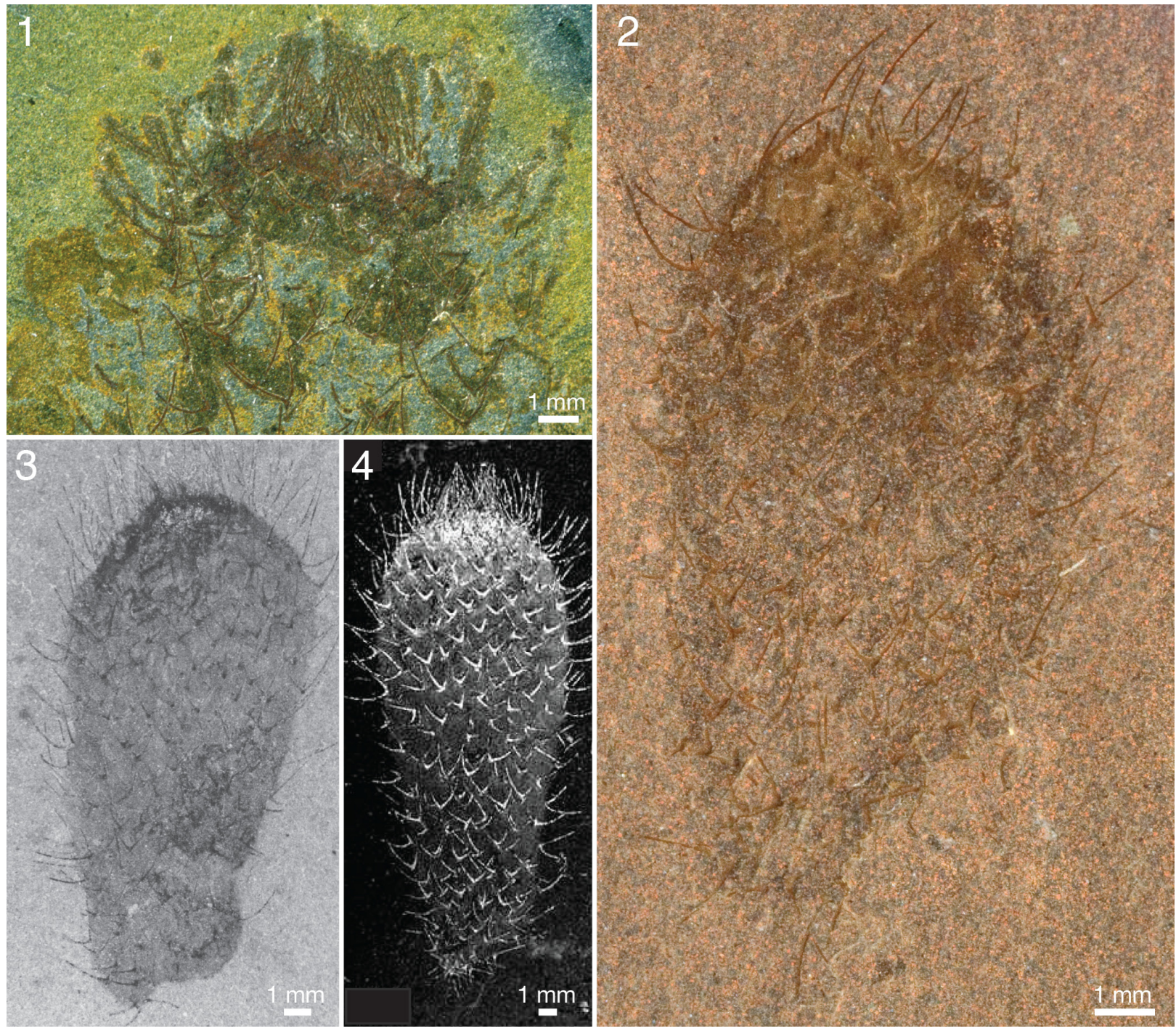

FIGURE 30. Allonnia tintinopsis n.sp, apical orifice with pyrite concentration. 1. ROM 49609A, RQ 9.0, dry. 2. ROM 62536, BW -400, wet/pol. 3. ROM 49582B, RQ 9.0, wet/pol. 4. ROM 49601A, RQ 9.7 (figure 1A2 in Bengtson, 2000; see that paper for details on settings).

Micromitra burgessensis is known to attach to sponge spines, in particular those of Pirania (Whittington, 1985; Caron, 2005). This brachiopod is also found in close association with Allonnia tintinopsis, in positions that make it likely that it attached directly to the spines of the chancelloriid (Figures $24.1,24.3,24.4 ; 36$ ). (See also the similar association of $C$. eros with the brachiopod Acrothyra gregaria described above, Figure 9.1-9.3.)

A life reconstruction of Allonnia tintinopsis growing on Vauxia is shown in Figure 37.

Comparison. Among Allonnia species known from whole-body preservation, Al. tintinopsis differs from
Al. phrixothrix in having sclerites only about half as large and a more pronounced apical tuft.

\section{Genus ARCHIASTERELLA Sdzuy, 1969}

Type Species. Archiasterella pentactina Sdzuy, 1969 (based on an association of several sclerites).

Species Known from Scleritome Preservation. Archiasterella pentactina Sdzuy, 1969, Archiasterella fletchergryllus Randell et al., 2005, Archiasterella coriacea n.sp.

Diagnosis. Chancelloriids with $4-5+0$ sclerites having one ascending, two lateral and one median ray, or one ascending and four lateral rays, all apically directed. 

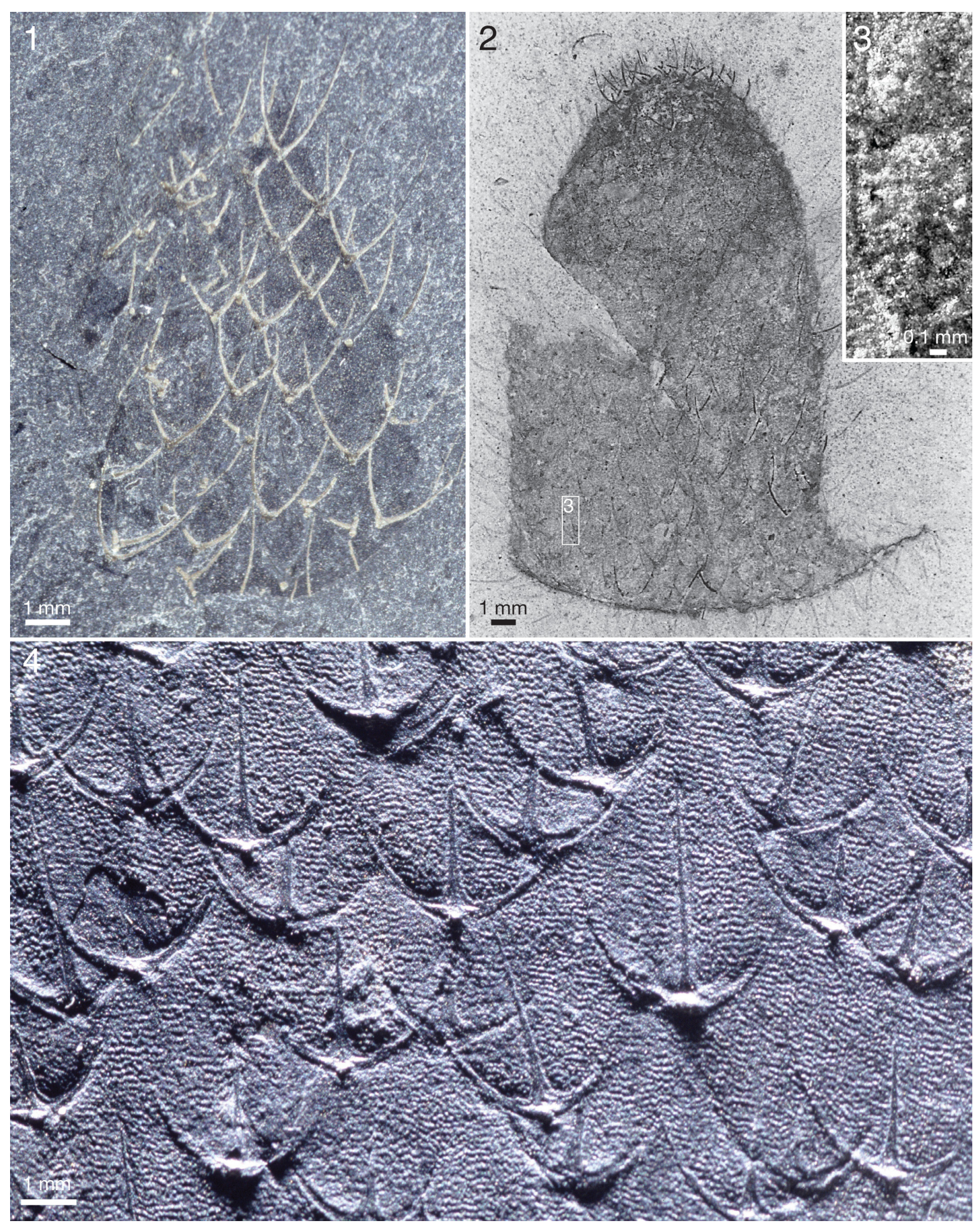

FIGURE 31. Integument structure of Allonnia and Archiasterella. 1. Allonnia tintinopsis n.sp. ROM 62514B, RQ 9.8, dry. 2, 3. Allonnia tintinopsis n.sp., ROM 49600A, UE. 2. Dry. 3. Detail of 2 (position marked by frame), dry. 4. Archiasterella coriacea n.sp., holotype, ROM 62531A, BW -130, dry. 


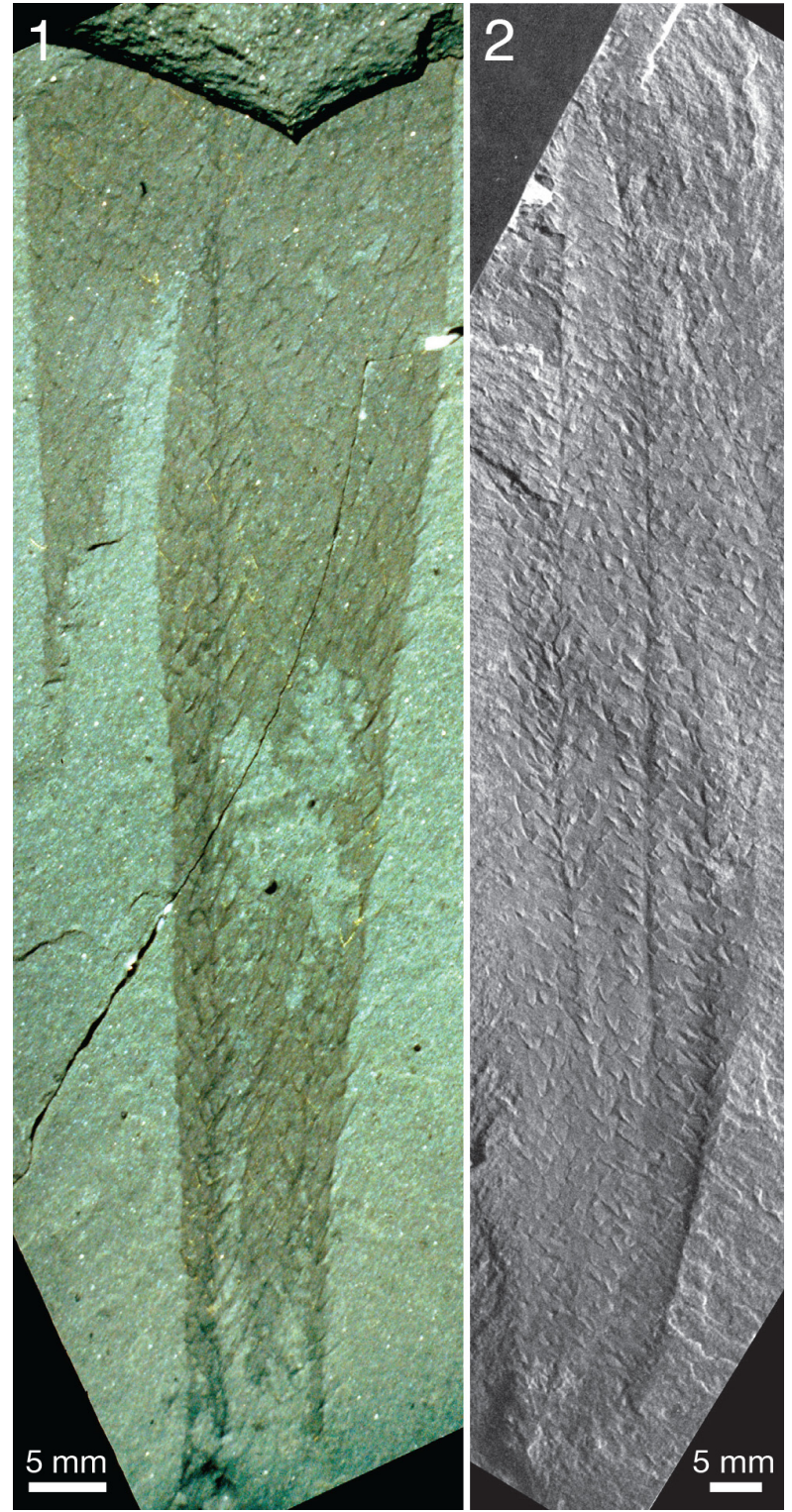

FIGURE 32. Allonnia tintinopsis n.sp. 1. ROM 49615A, WT, dry/pol. 2. ROM 49621, UE, dry.

Archiasterella coriacea n.sp.

Figures $4 ; 31.4 ; 38-45$

\section{http://zoobank.org/3BF76BF9-FA88-48E2-B80A- 9561B6C99543}

Chancelloria eros new species (Walcott, 1920, partim; pl. 88:1c). Chancelloria eros Walc. (de Laubenfels, 1955; figure 76).

Derivation of the Name. Latin coriaceus, leathery, alluding to the resilient integument of this species.

Holotype. ROM 62531 (Figures 31.4; 38; 39).

Figured Paratypes. USNM 66527, ROM 49567, 49583, 49617, 49619, 57573, 62528, 62529, 62530, 62532, 62533.
Diagnosis. Species of Archiasterella having a distinct integument with an imbricating scaly surface pattern. Ray formula $4+0$. Sclerite rays up to $5 \mathrm{~mm}$ long, of approximately the same length within each sclerite; size and spacing of sclerites within the scleritome may vary considerably. Apical tuft inconspicuous.

Description. The specimen USNM 66527 in Walcott's syntype series of Chancelloria eros (Walcott, 1920, pl. 88:1c) was used to illustrate the species C. eros in the first Porifera volume of the Treatise on Invertebrate Paleontology (de Laubenfels, 1955, figure 76). The specimen can be attributed to Archiasterella coriacea and is reillustrated here as Figure 4. It is imperfectly preserved, with the soft integument visible as a slightly darker stain of the rock surface. The outline of the soft parts is diffuse, and the specimen is probably incomplete, but it suggests a long and narrow body, at least $49 \mathrm{~mm}$ long and up to $8 \mathrm{~mm}$ wide. The sclerites are 3dimensional and show the typical Archiasterella morphology but are generally incompletely preserved. The longest preserved ray (near the top of the specimen) is $4 \mathrm{~mm}$.

Archiasterella coriacea has a conspicuous appearance in the Walcott and Raymond Quarries because of its sausage-shaped body and distinct integument, often folded more or less irregularly, sometimes with a finely scaly surface, and with its characteristic $4+0$ sclerites, usually sparsely distributed over the integument.

The holotype (Figures $31.4 ; 38 ; 39$ ) is $170 \mathrm{~mm}$ long and $40 \mathrm{~mm}$ broad at its widest. It is complete, except for the lower part, which is missing; where the specimen ends abapically the width is $13 \mathrm{~mm}$. The apical end is evenly rounded. It appears to be somewhat obliquely compressed, an apical orifice occupying a non-terminal position with its centre located $5 \mathrm{~mm}$ from the apical edge of the fossil.

The apical orifice of this specimen is indistinctly preserved, as is usual in Archiasterella coriacea. It is primarily noticeable through an elevated area of higher reflectance, like that of the sclerites, and a zone around it with a lumpy surface, contrasting with the more smooth preservation of the rest of the integument (Figure 38.2).

The sclerites are preserved as flattened, reflective structures, with the typical swallow-like outline of compressed Archiasterella sclerites (Figure 38.3). They vary considerably in size, the median ray in adjacent sclerites ranging from about 2.5 to $5 \mathrm{~mm}$ in length. The lateral rays are slightly shorter than the median ray, form about a $90^{\circ}$ angle with each other, and curve slightly in the api- 

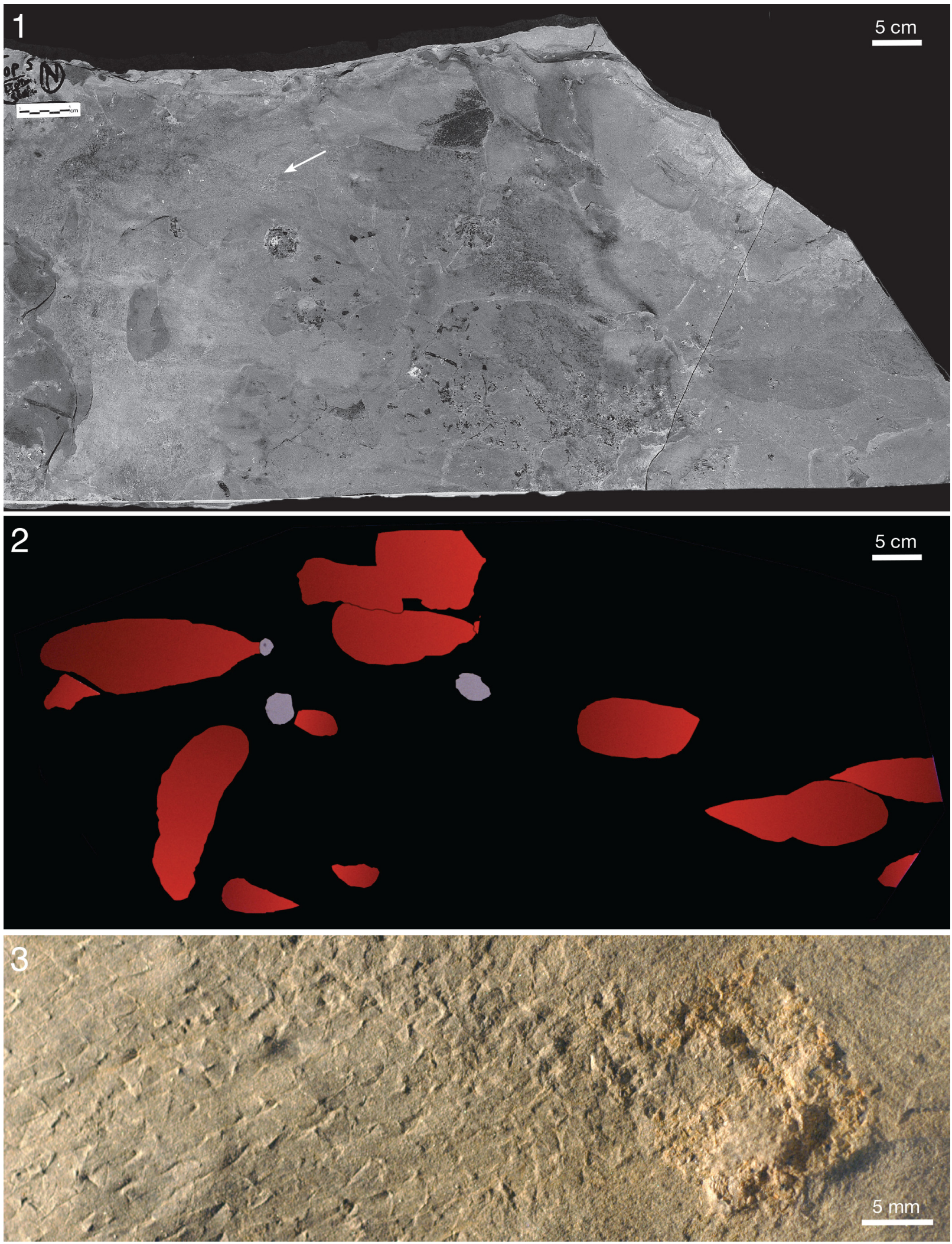

FIGURE 33. Association of Allonnia tintinopsis n.sp., bodies and attachments, on bedding slab. ROM 62585, RQ 8.4. 1. Part; arrow points to specimen represented by counterpart in 3, dry. 2. Tracing of bodies (red; darker tones toward the apex) and root bulbs (grey), based on both part and counterpart. 3. Counterpart of specimen with root bulb marked by arrow in 1 , dry. 


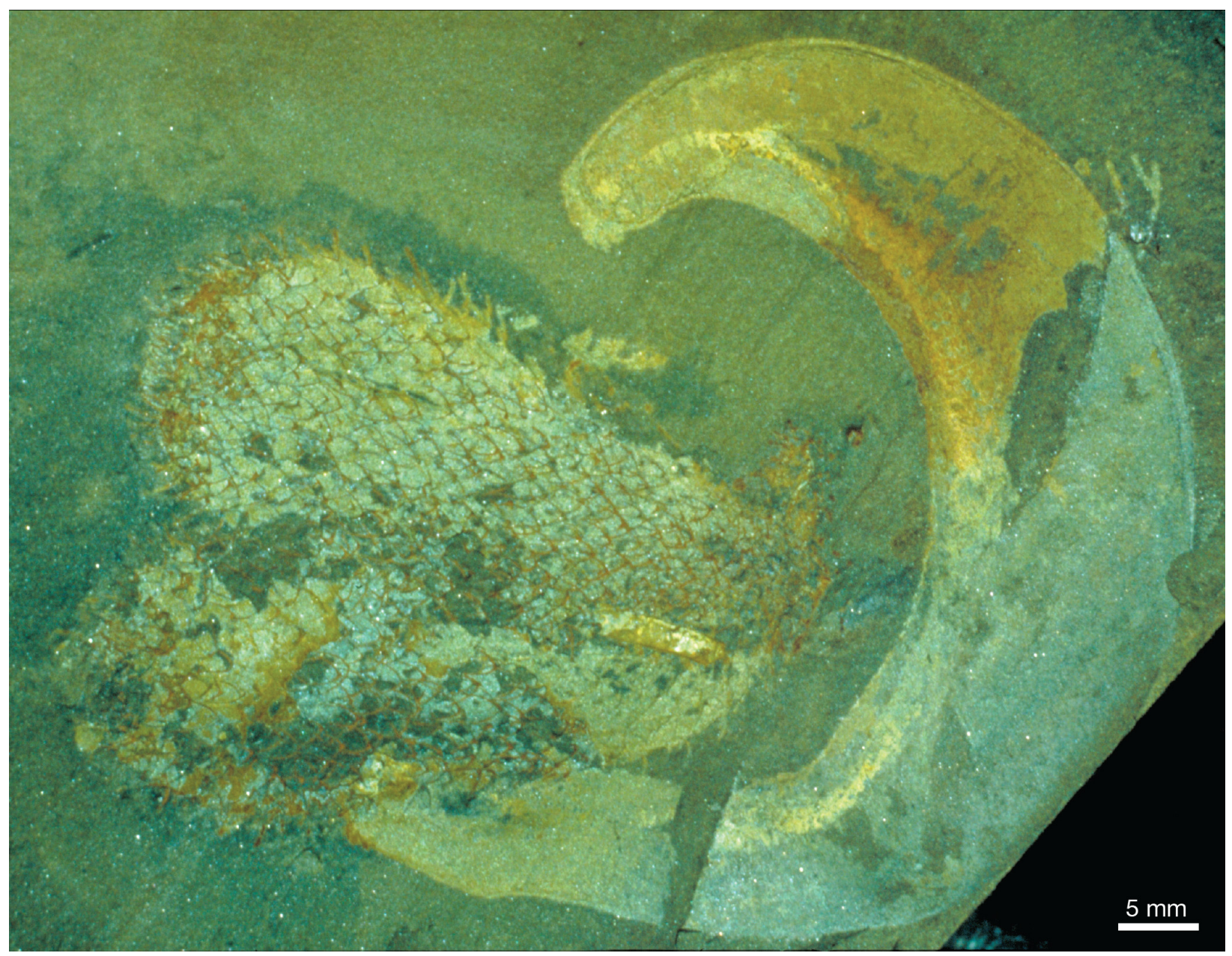

FIGURE 34. Two Allonnia tintinopsis n.sp. associated with a Vauxia. Ottoia to the right. ROM 49589A, RQ 9.0, wet.

cal direction. The ascending ray is usually visible only as a faint swelling, but at the edges of the fossil where the body wall is folded, ascending rays may be seen in side view (Figure 38.3, left), showing them to curve adapically and being of about the same length as the other rays. The median rays in these positions seem to form an angle of about 15$25^{\circ}$ with the body wall, but no sclerites are preserved with all their rays visible in their length, and so an identification of the individual rays is often not possible.

The sclerite rays commonly have a longitudinal fold, suggesting collapse of the originally hollow tube.

The sclerites are evenly and regularly distributed over the body surface, with a spacing of 4-6 $\mathrm{mm}$. The spacing appears denser, because sclerites from both sides of the flattened body are visible (cf. Figure 39). As a general rule, the sclerites are regularly oriented with their median ray pointing in the apical direction, and the distribution approximately follows a diagonal rhombic pattern.
The holotype has a clearly developed granulosity to the integument (Figure 31.4). The granulae are spaced about $100 \mu \mathrm{m}$ apart and packed more or less regularly in a rectangular or rhombic pattern, where the longitudinal direction is more pronounced than the transverse one. The alignment of the pattern largely follows the longitudinal orientation of the body.

The granular surface pattern has been investigated in more detail in the fragmentary specimen ROM 57573 (Figure 40). The SEM stereograms (Figure 40.2, 40.3) show the pronounced longitudinal alignment of the granules as well as their relationship to the sclerites of the upper and lower body surface (Figure 40.2, left and right sclerite, respectively) in the compressed specimen. Also visible is a pattern of imbrication, where the free tips of the imbricating objects, expressed as granules, appear to point adapically (Figure 40.3).

This specimen too has a sclerite spacing of 4$6 \mathrm{~mm}$ in the main body regions, with more crowded 

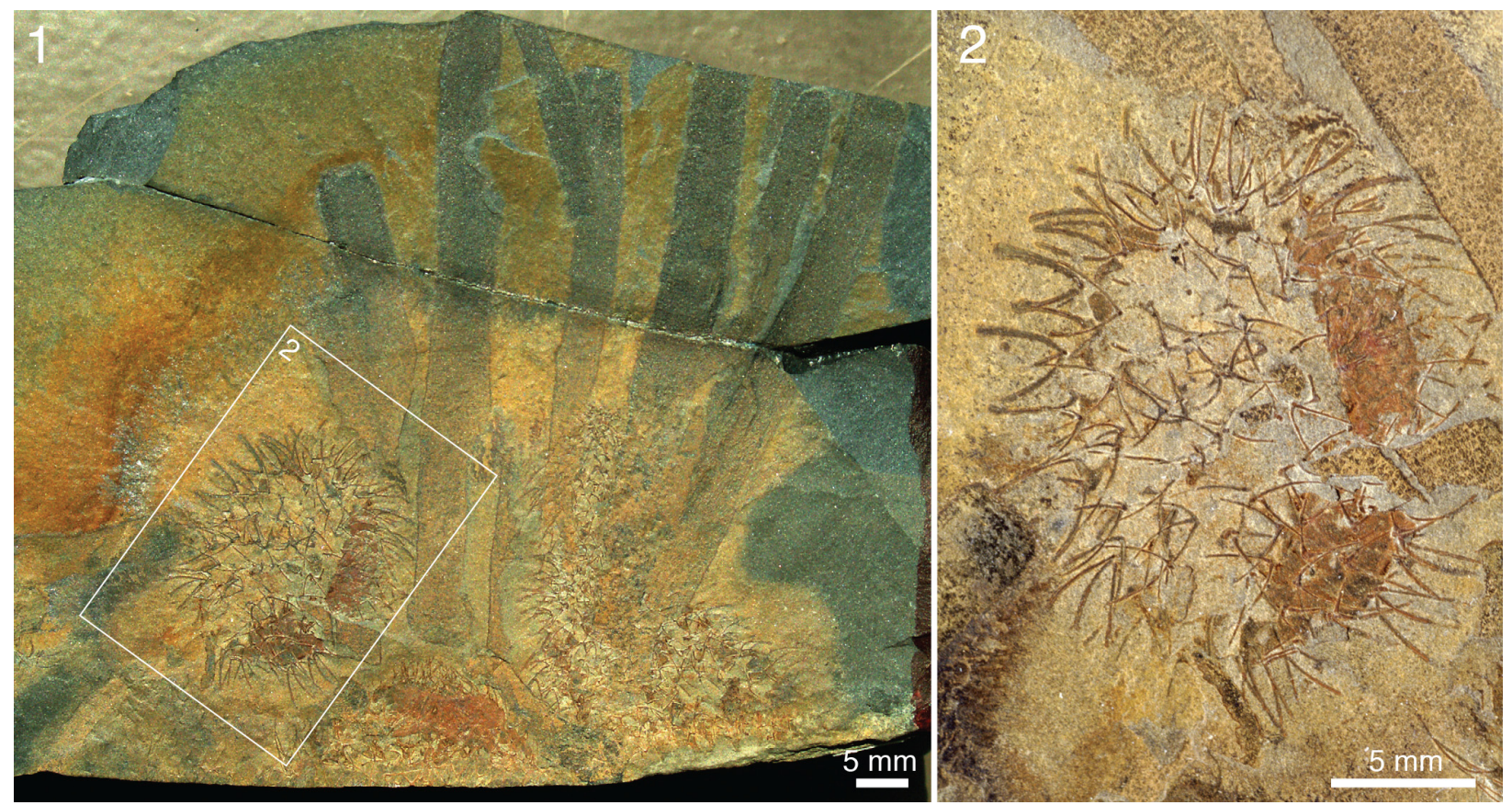

FIGURE 35. Intergrowth of Allonnia tintinopsis n.sp. with Vauxia. ROM 62521B, RQ 8.4. 1. Dry. 2. Detail of 1 (position marked by frame), dry.

sclerites in the preserved portions of the abapical part.

The specimen ROM 62529 (Figure 41.1, 41.2) is $111 \mathrm{~mm}$ long and $44 \mathrm{~mm}$ wide. Like the previous specimens, it lacks the lowermost part, but the rest of the body is well preserved and shows a sausage-shaped outline, almost cylindrical with a rounded apex. This specimen is less obliquely compressed than the holotype, and the apical tuft is expressed at the edge as an area with short, dense sclerite coverage, markedly differing from the clean edge with the occasional body sclerite visible elsewhere (Figure 41.2).

The sclerites are similar in shape and size to those of the holotype, and their disposition is similarly regular. Figure 41.2 shows three body sclerites in side view, demonstrating the orientation of the straight median ray (nearest to the body wall) and the ascending ray.

The integument is represented as a smooth film; no granulosity is visible. On one side of a joint in the rock (lower part of Figure 41.1), the integument and sclerites are covered with a thin, yellow veneer of limonite.

The specimen ROM 62530 (Figure 41.3) is of medium size, $47 \times 28 \mathrm{~mm}$, egg-shaped in outline. The sclerites are preserved in 3D relief; the shape, size, and arrangement of the body sclerites is similar to that of the holotype. The apical end shows a region with dense sclerite rays; the shape of those sclerites is not apparent, but the region clearly represents the apical orifice. There is no obvious base, but at the rounded abapical end (lower left in Figure 41.3) there is an area with more irregularly arranged sclerites than in the main part of the body; this may indicate proximity to a constricted stalk-like portion of the body such as is evident in other specimens of Archiasterella coriacea (Figures 42; 43.3), as well as Chancelloria eros and Allonnia tintinopsis. The integument is smooth and covered with a thin veneer of limonite.

A similar specimen, ROM 62532 (Figure 41.4), has only the apical part preserved. The sclerites are three-dimensionally preserved and agree in shape, size, and arrangement with those of the holotype. The compression appears to have been non-oblique, and an apical tuft is indicated by a region of dense sclerite rays capping the rounded apical end of the body. The integument has a faint granulosity, which in dimensions and orientation agrees with that of the holotype.

The remarkable specimen ROM 62528 (Figure $42.1,42.2$ ) is complete, except perhaps for the very attachment end. It is sausage-shaped, $57 \mathrm{~mm}$ long, and up to about $15 \mathrm{~mm}$ wide, but the shape is distorted by what appears to be irregular coarse folds of the integument, mostly in a transverse direction. A "head" is set off by one such fold about a centimetre from the apex, suggesting a slight sagging collapse of the body. 


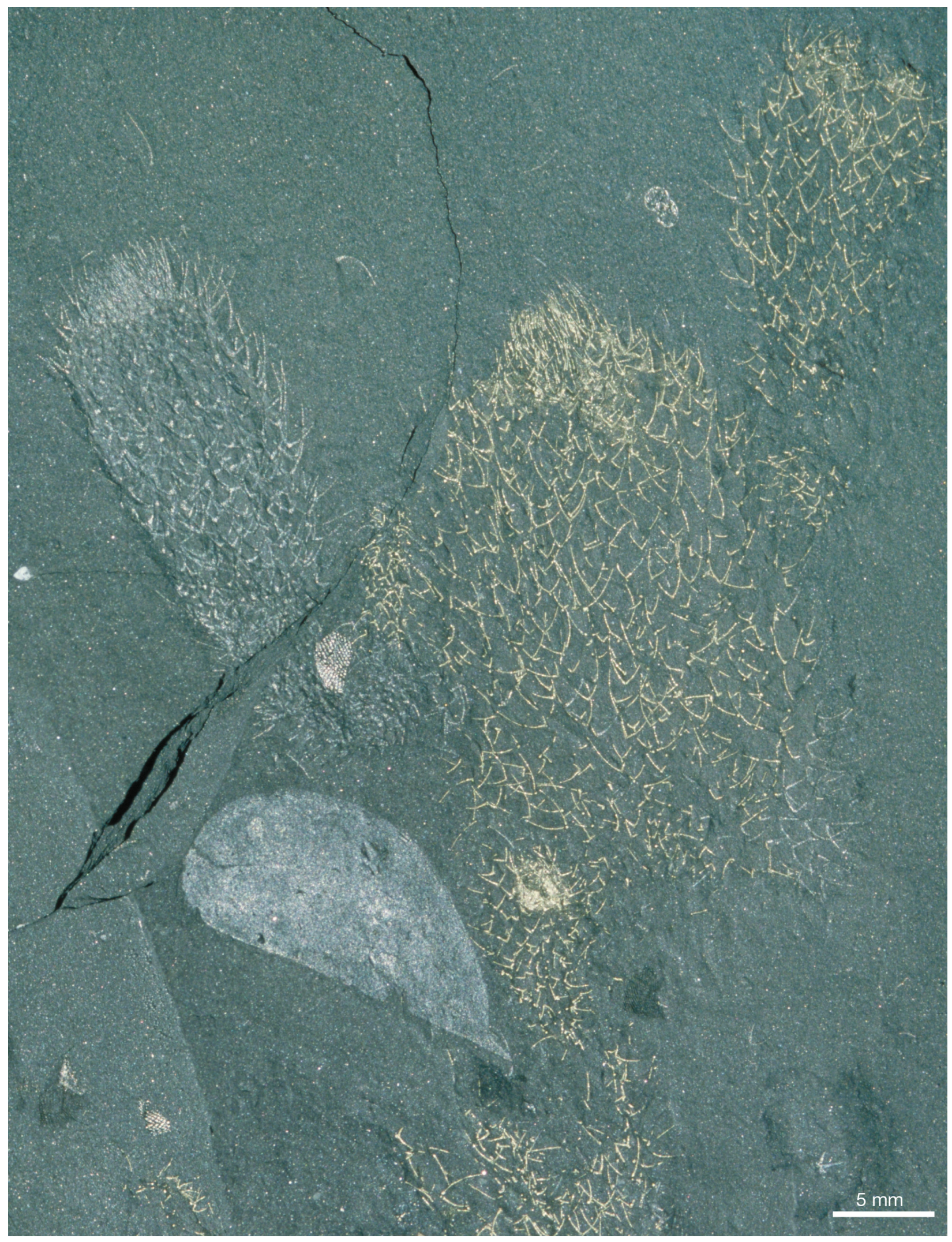

FIGURE 36. Allonnia tintinopsis n.sp. together with Micromitra shells and carapace of Isoxys. ROM 49602B, RQ 8.7, dry. 


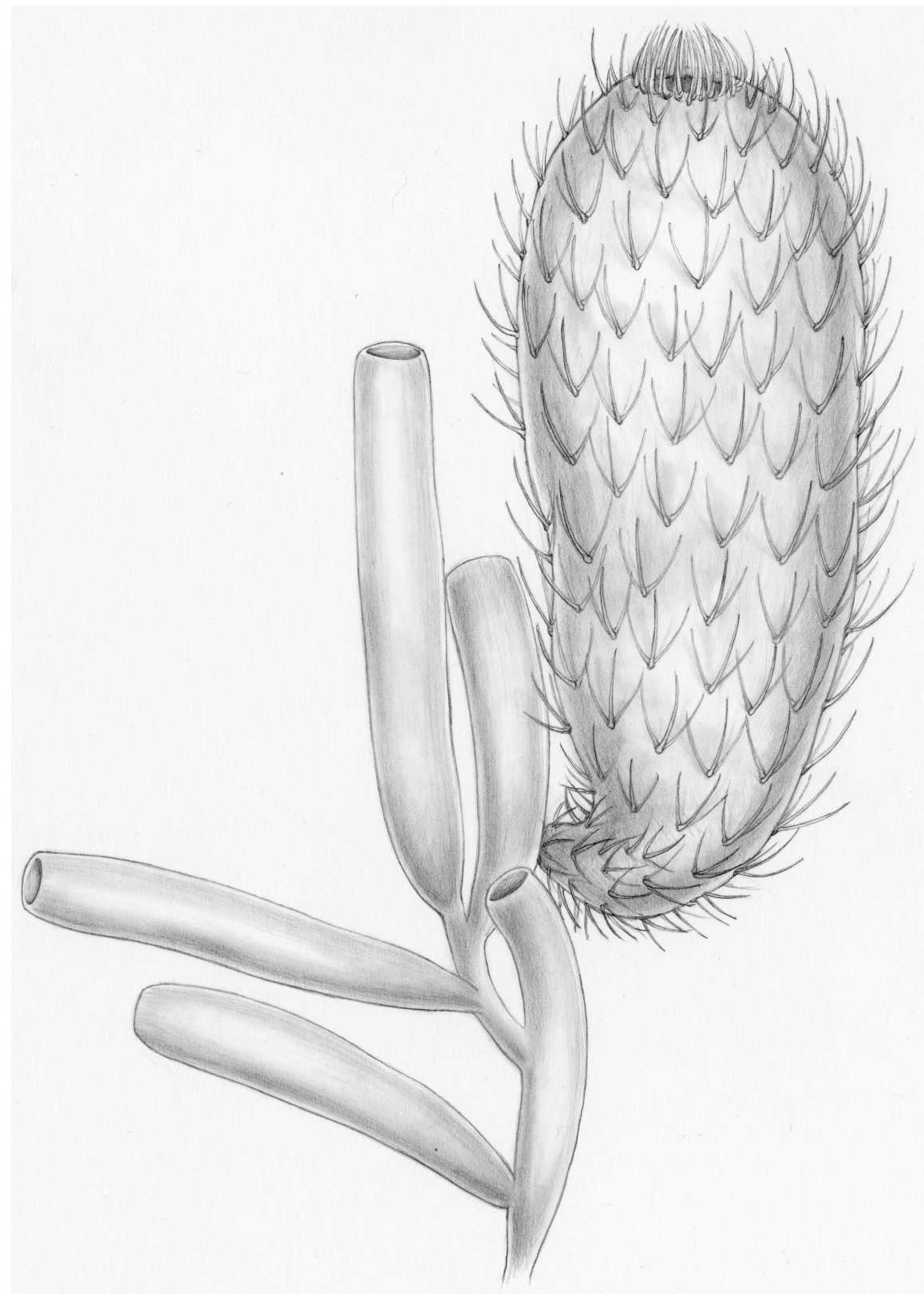

FIGURE 37. Life reconstruction of Allonnia tintinopsis, n.sp., growing on the sponge Vauxia. Artwork Pollyanna von Knorring.

This specimen also has a stalk-like abapical part preserved, similar to that found in Allonnia and Chancelloria, 3-5 $\mathrm{mm}$ thick. The stalk carries a dense sclerite cover and has an irregular texture; brachiopod shell fragments are juxtaposed to the stalk (creating the swelling in the lower part of the stalk; cf. Figure 42.1, 42.2).

The sclerite cover in this specimen is very uneven (Figure 42.1). Large portions in the middle part of the body lack sclerites altogether, and the "head" and lower part of the body have only scat- tered, irregularly placed sclerites. Their orientation, however, is roughly "correct", i.e., the median ray points apicalward. The sclerite density increases toward the lower part of the body, and the stalk appears fully sclerite-bearing, though its contorted nature makes it difficult to observe individual sclerites. The sclerites are preserved in a reflective material, with some $3 \mathrm{D}$ relief remaining.

The integument in this specimen is smooth in the lower part of the body; in the upper part a faint granulosity similar to that of the holotype is visible. 


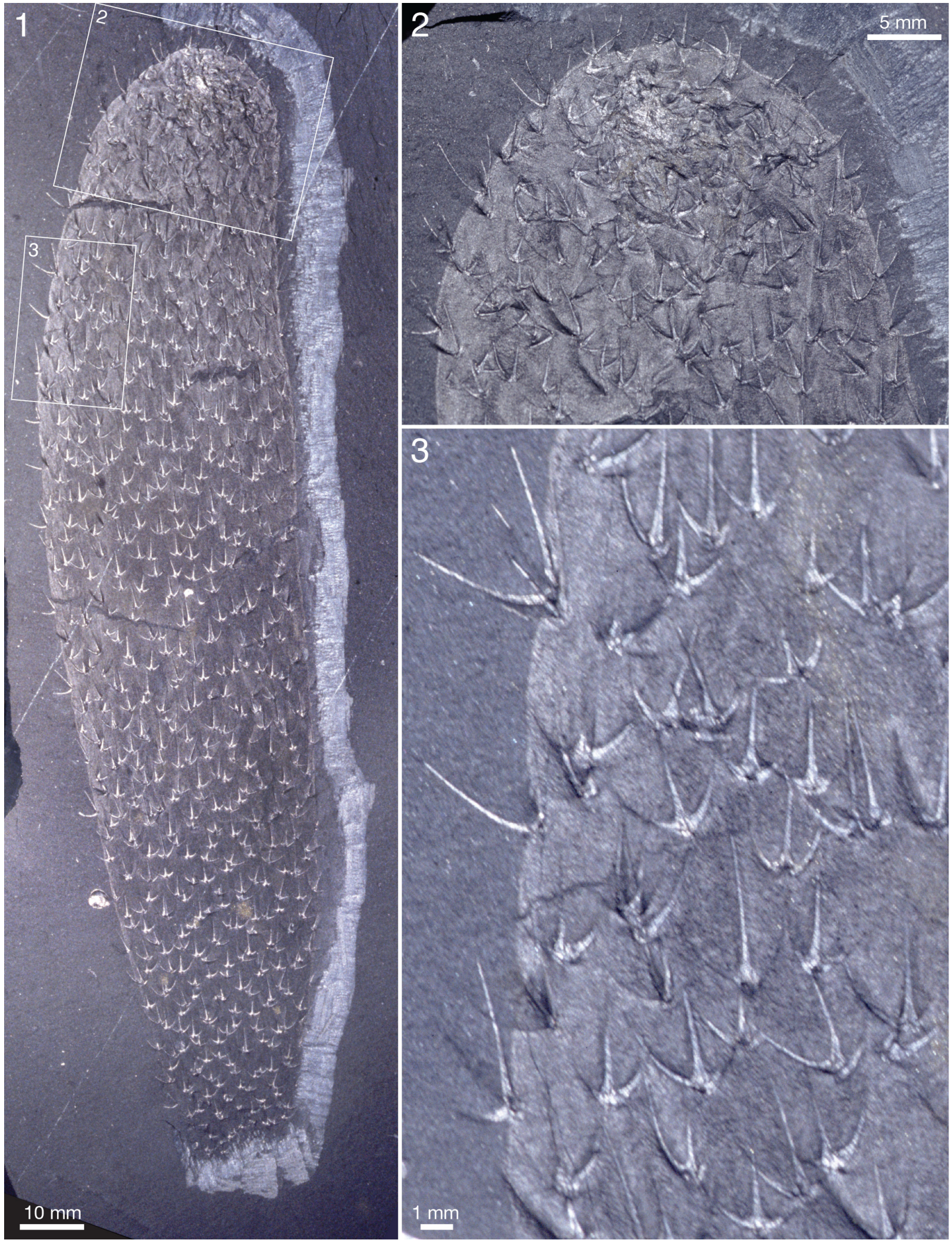

FIGURE 38. Archiasterella coriacea n.sp., holotype, ROM 62531A (same specimen as in Figures 31.4 and 39 ), BW 130. 1. Complete specimen showing alignment of sclerites, wet. 2. Detail of 1 (position marked by frame) showing the apical tuft, wet. 3. Detail of 1 (position marked by frame) showing the attitude of sclerites relative to the body wall, wet. 


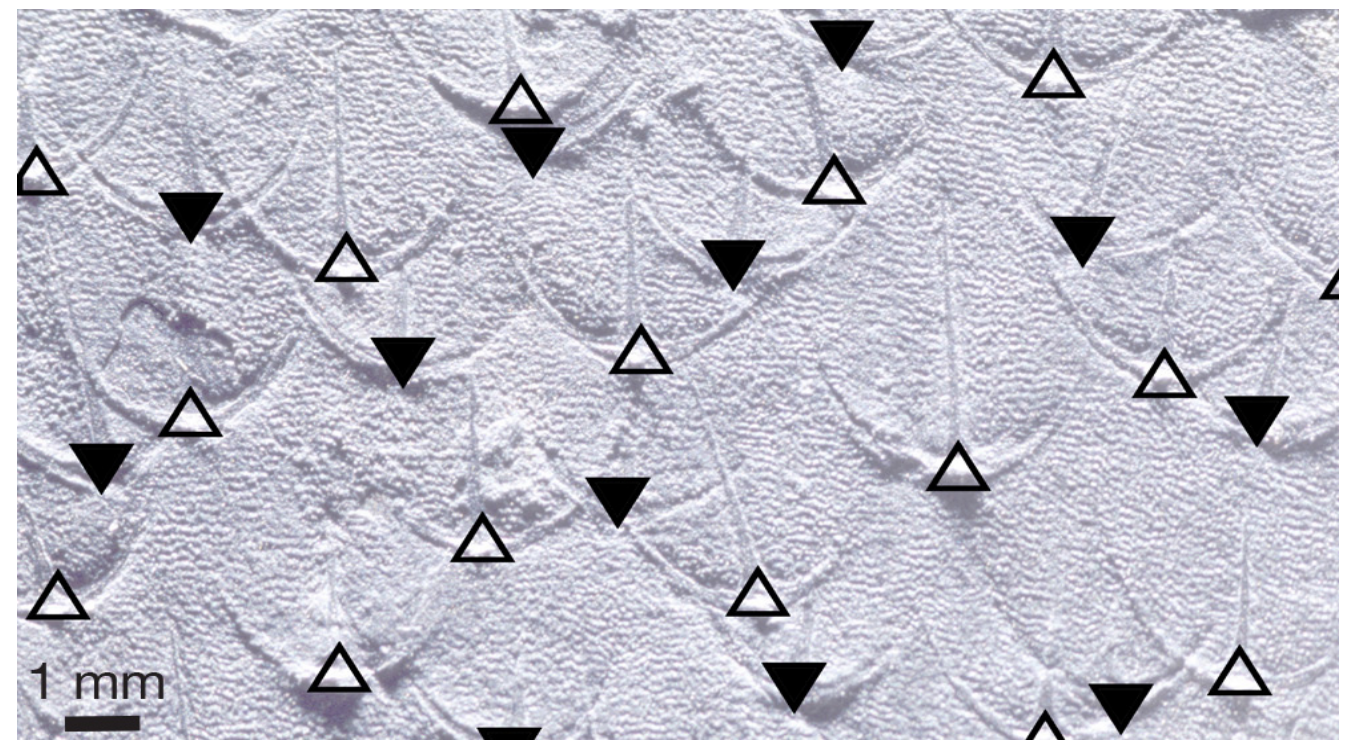

FIGURE 39. Archiasterella coriacea n.sp., holotype, ROM 62531A, BW -130, superposition of sclerites from two sides of body. $\triangle$-basal side down; $\boldsymbol{\nabla}$ - basal side up. Cf. Figures 31.4 and 38.

The apical end of this specimen is marked by a concentration of reflective matter (Figure 42.1, top). There is a broad, indistinctly preserved apical tuft, consisting of a faint striation parallel to the longitudinal axis of the body as well as some coarser arcuate structures of a similar orientation. No morphology of individual elements can be made out, but the structure, dimensions and orientation indicated similarities with the apical tuft seen in numerous specimens of Allonnia tintinopsis.

Another nearly complete specimen, $29 \mathrm{~mm}$ long and up to $12 \mathrm{~mm}$ wide, is shown in Figure 42.3 (ROM 62533). The sclerites are preserved in semi-3D, some of them with distinct longitudinal folds suggesting collapse of the hollow ray, and evenly distributed over the body. The integument is smooth, but a few patches preserve a granulosity similar to that of the holotype. The apical region is somewhat flattened in outline and marked by a more irregular structure; no discrete tuft can be made out. There is a concentration of limonite in the apical end suggesting the former presence of pyrite, but an even more prominent patch of limonite is seen in the midpart of the body. The abapical end tapers to about $3 \mathrm{~mm}$ width and has a smooth termination defined by the lowermost sclerites. No attachment structure is evident.

The incomplete specimen ROM 49583 appears to have the lower end preserved, in proximity to a Vauxia that it may have been attached to (Figure 42.4). The preserved length of the specimen is $50 \mathrm{~mm}$, and in the abapical part it tapers from 15 to $6.4 \mathrm{~mm}$ width. The lowermost sclerites are distinctly smaller (up to $1.1 \mathrm{~mm}$ ray length) than those of the more apicalward part (up to $2.9 \mathrm{~mm}$ ray length).

Specimen ROM 49617 shows two somewhat contorted, sausage-shaped individuals with integument preserved as a light, shiny surface, well set off from the surrounding matrix (Figure 43). The most complete specimen (Figure 43.1, top) is 180 $\mathrm{mm}$ long and up to $38 \mathrm{~mm}$ wide. Sclerites are unevenly distributed in the integument, sometimes with up to $10 \mathrm{~mm}$ distance between them (Figure 43.2). No apical tuft or orifice is visible. The second specimen (Figure 43.1, bottom) is of a similar appearance, but incompletely preserved in the apical portion. In the abapical part, it tapers abruptly to a thin, bristly, sclerite-studded stalk, about $3 \mathrm{~mm}$ in diameter. The stalk makes a U-turn and appears to join the side of the first specimen (Figure 43.3).

Similar specimens with distinctly preserved integuments are shown in Figure 44. ROM 49619 (Figure 44.1) is incomplete, and probably represents a single specimen that has been folded at the middle. This is indicated by the direction of the sclerites, the rays of which are pointing in different directions in the adjacent parts of the body. The length of the combined parts is $160 \mathrm{~mm}$ and the largest width is $34 \mathrm{~mm}$. The specimen ROM 49567 (Figure 44.2) has a contorted shape, with a folded and twisted integument. The specimen appears to have been twisted clock-wise, as indicated by the abapical part, where the regular curvature of the 


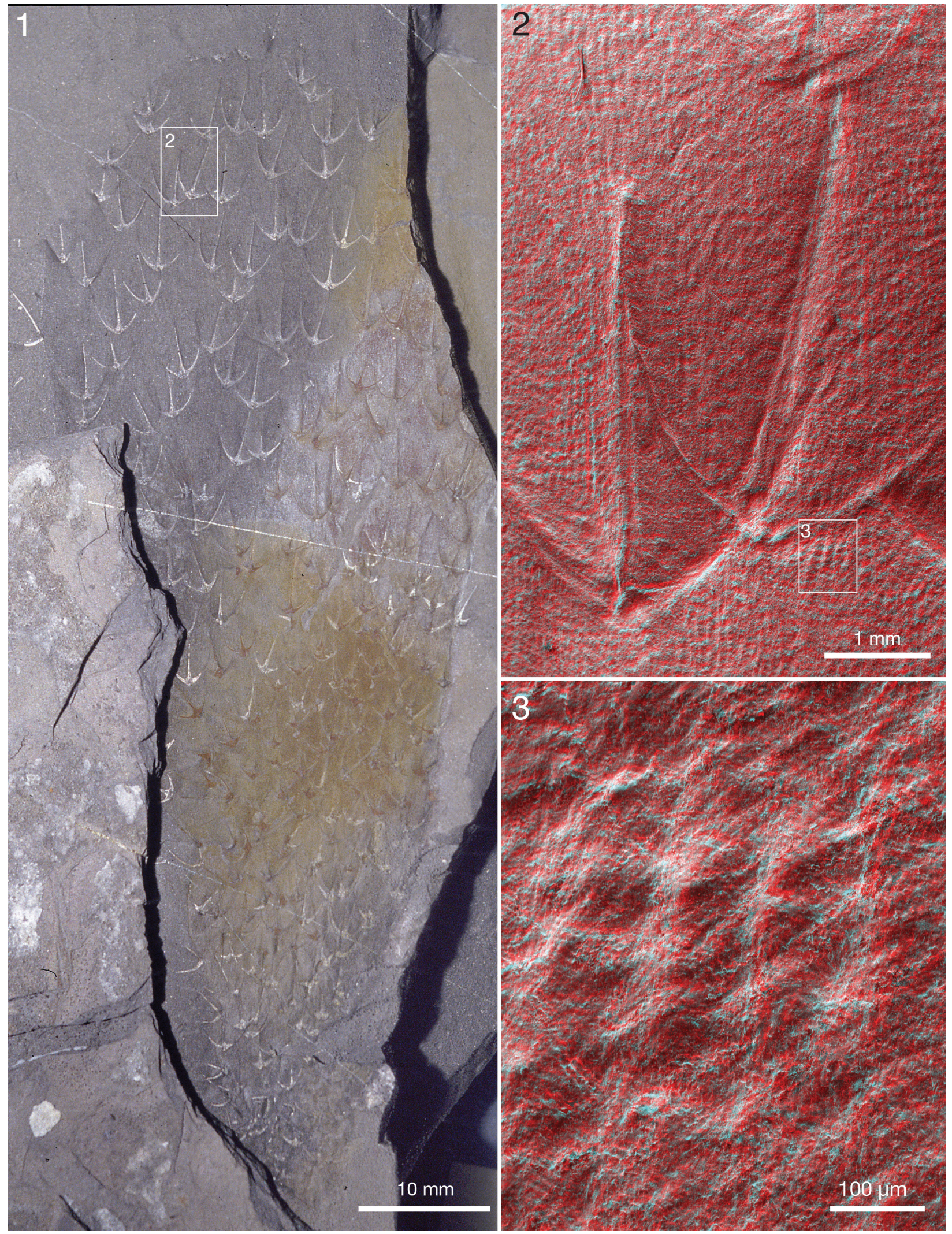

FIGURE 40. Archiasterella coriacea n.sp, ROM 57573, WQ -130. 1. Wet. 2, 3. SEM stereographs (red/blue anaglyphic images) of latex casts taken of counterpart to show structure of integument. Frames show positions of details 2 and 3. 

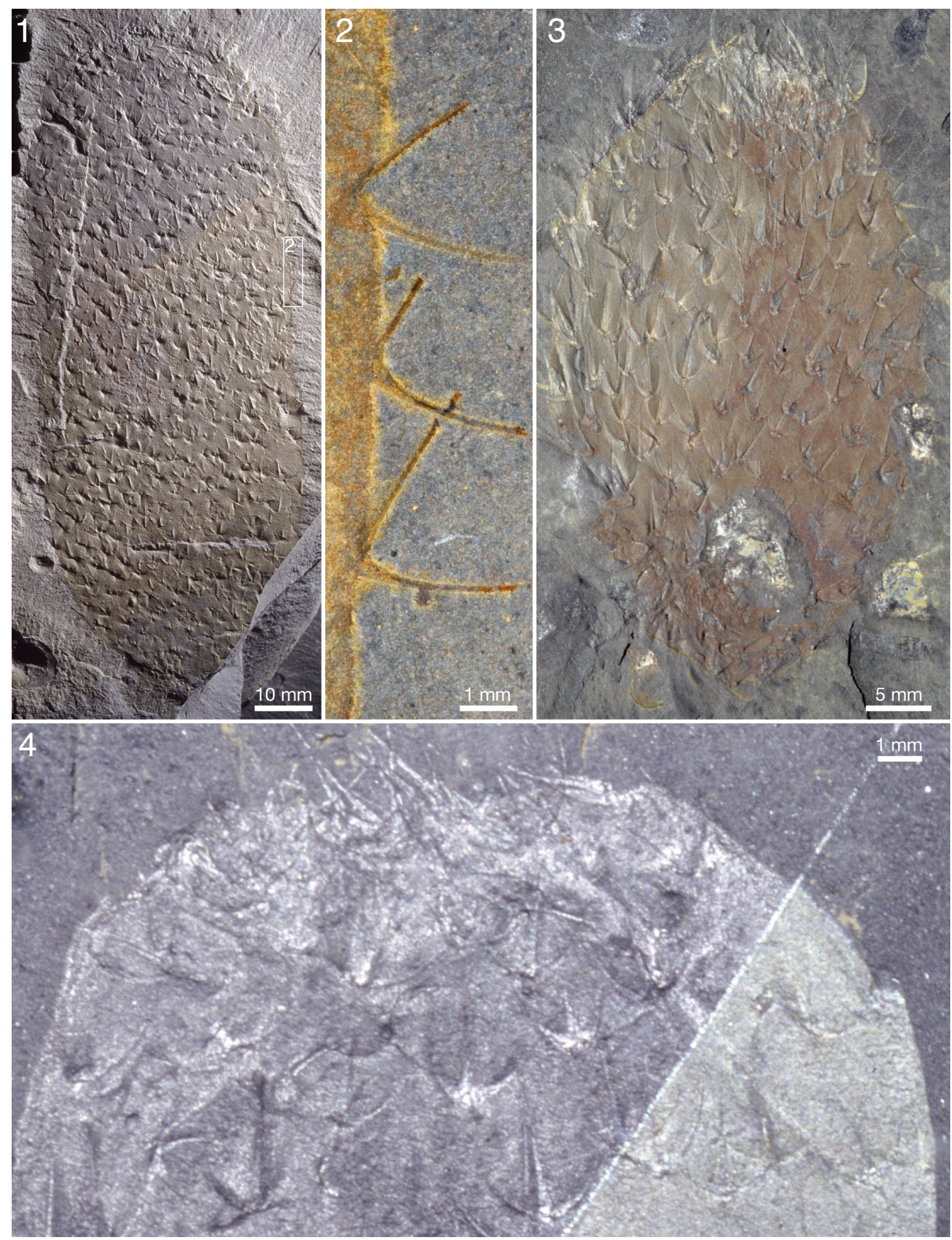

FIGURE 41. Archiasterella coriacea n.sp. 1, 2. ROM 62529B, BW -130. 1. Dry. 2. Detail of 1 (position marked by frame), wet/pol. 3. ROM 62530A, BW -130, wet. 4. ROM 62532, BW -130, apical part, wet. 

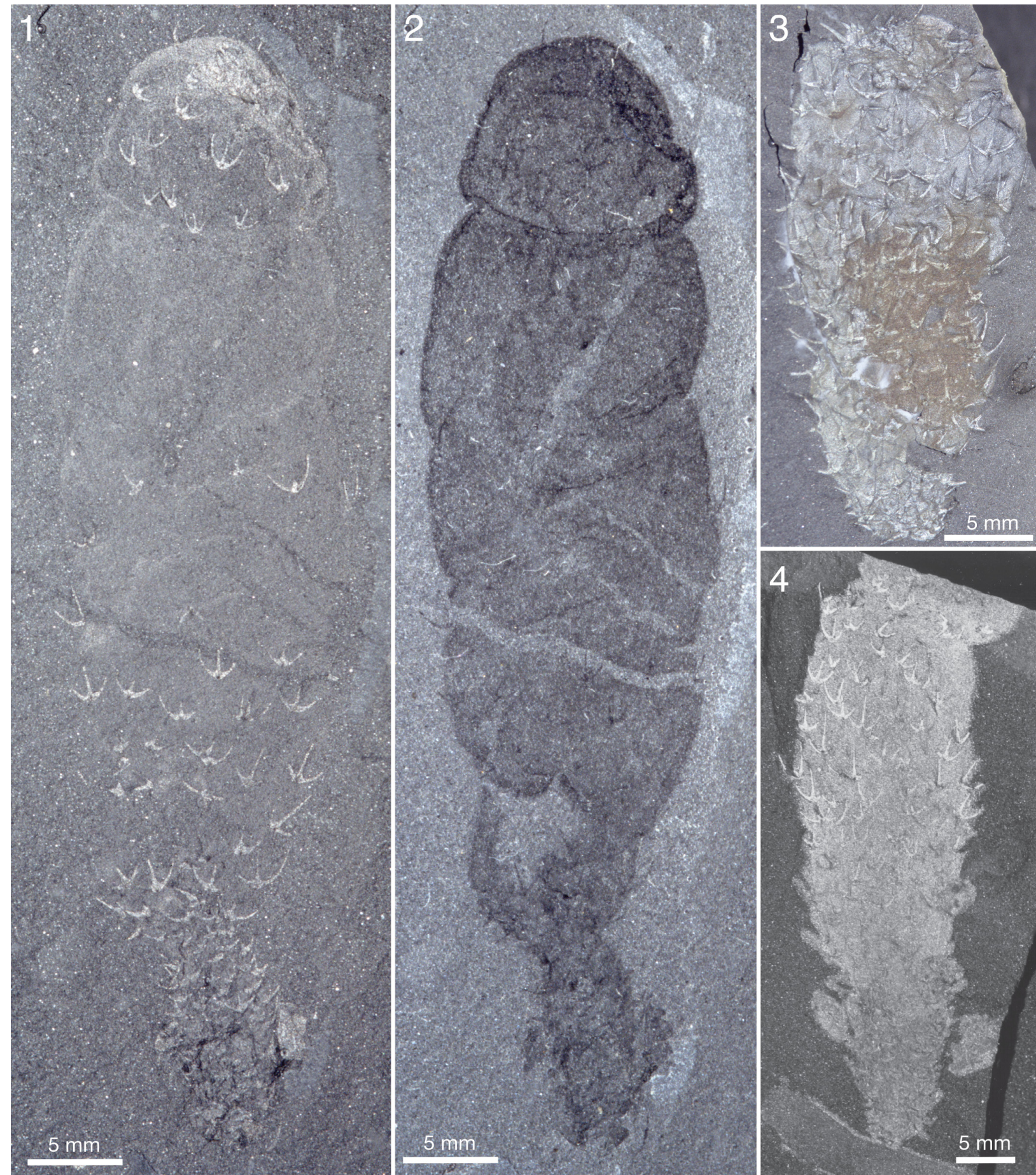

FIGURE 42. Archiasterella coriacea n.sp. 1, 2. ROM 62528A, RQ 8.4. 1. Showing distribution of sclerites, wet. 2. Showing integument, wet/pol. 3. ROM 62533A, BW -130, wet. 4. ROM 49583B, RQ 9.0, wet. Specimen attached to a Vauxia.

folds is clearly visible (Figure 44.2, bottom). This specimen has a broad oval patch at the apical end with a small, sclerite-dense region (arrow) that may represent an apical tuft.
In none of the specimens with preserved integument is there any evidence of pores.

A life reconstruction of Archiasterella coriacea is shown in Figure 45. 

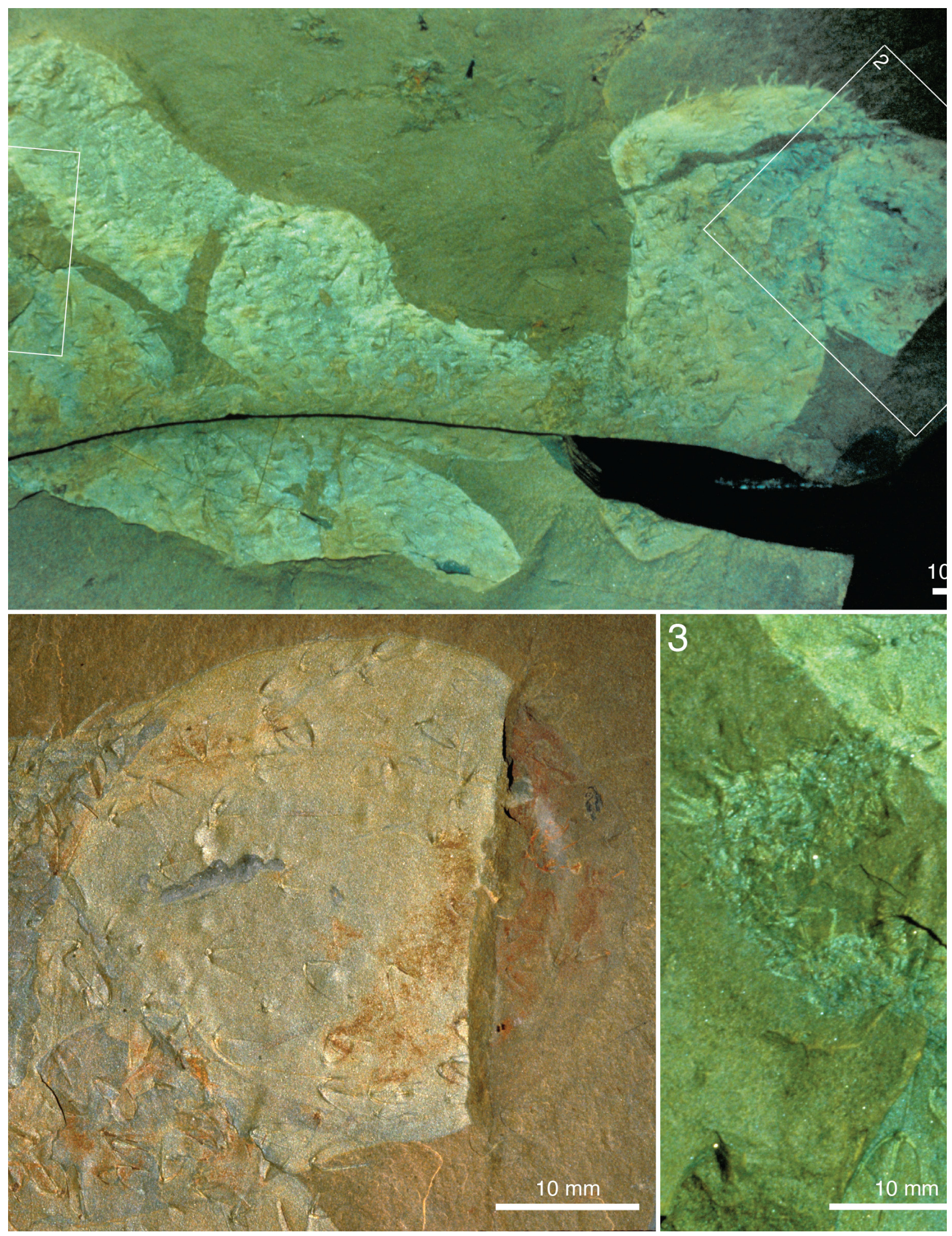

FIGURE 43. Archiasterella coriacea n.sp. ROM 49617B, RQ 13.8. 1. Complete specimen, wet. 2. Detail of upper specimen in 1 (position marked by frame), wet. 3. Detail of 1 (position marked by frame), wet, showing stalk uniting upper and lower specimen. 

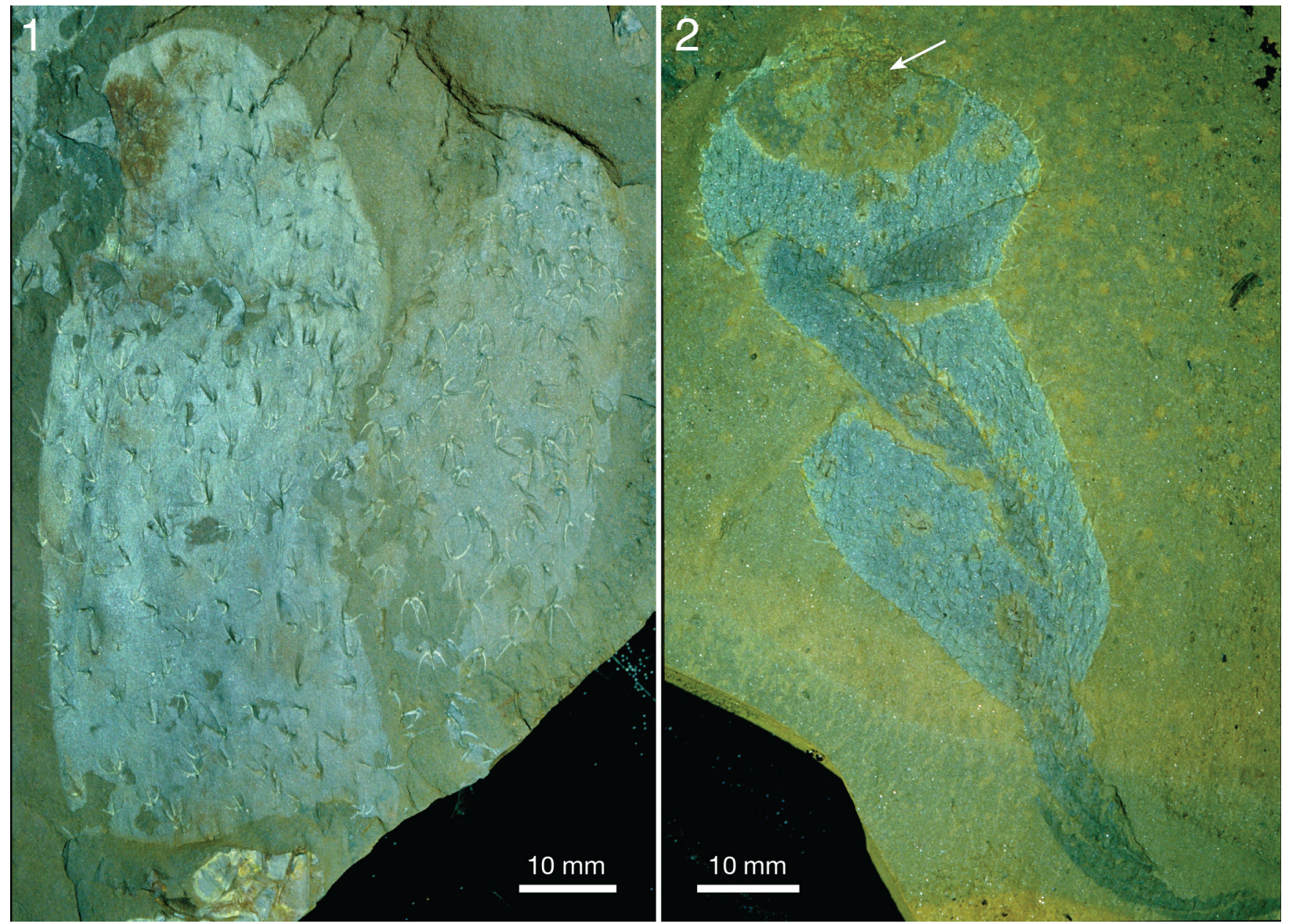

FIGURE 44. Archiasterella coriacea n.sp. 1. ROM 49619A, RQ, wet. 2. ROM 49567A, UE, wet. Arrow points to tuft.

Comparison. The species differs from Archiasterella pentactina Sdzuy, 1969, and Ar. fletchergryllus Randell et al., 2005, in having only $4+0$ sclerites.

\section{BIOLOGY OF CHANCELLORIIDS}

\section{Body Shape and Attachment}

The body shape is variable both within and between the species of chancelloriids described herein, but it generally resembles that of a semiinflated weather balloon: a narrow end that gradually, or sometimes more abruptly, transforms into a wider conical or cylindrical body that ends in a rounded apex with a centrally placed opening surrounded by an apical tuft of modified sclerites. The narrower parts of the body, in particular, appear to have been flexible and in many specimens form a stalk-like structure. There is no sign of deviation from a pure radial symmetry.

The transition between the narrow abapical end (or stalk) and the more inflated distal parts of the body varies considerably in appearance. Commonly, there is a gradual widening apicalwards, and seemingly no well-defined stalk. In many cases it cannot be excluded that a stalk was present but not preserved, but the specimens of Allonnia tintinopsis gradually tapering toward the anchoring root bulb in ROM 62585 (Figure 33) may confidently be interpreted as preserving the complete body. A distinct stalk is thus originally absent in some specimens.

The presence or absence of a stalk may be either a fixed character that varies between individuals or an expression of a changeable body shape of an individual. In view of the morphological continuum between stalked specimens and those with merely a tapering abapical end, as well as the increase in sclerite density in the narrower parts of the body (suggesting constriction of the soft integument), we interpret the stalk-like structures to reflect a temporary constriction of the lower part of the body. The relationship between constricted 


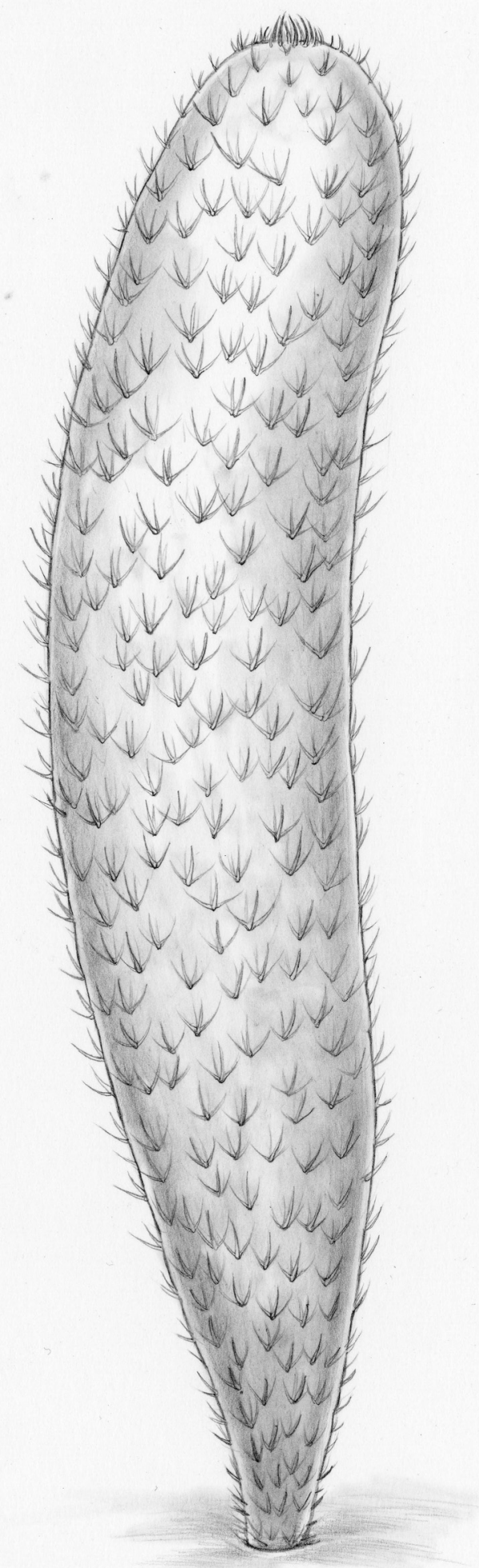

FIGURE 45. Life reconstruction of Archiasterella coriacea, n.sp. Artwork Pollyanna von Knorring. 
lower part and inflated upper part is particularly well illustrated by ROM 49603 (Figure 20.3, 20.4),

The presence of a single opening to the spacious interior of the chancelloriid body would necessitate a means of periodically expelling waste products and contaminations from the body cavity. A process of muscular constriction starting in the abapical region, as indicated by the occasional "stalks", would serve this function well. We interpret the specimens with a constricted base, such as the ones in Figures 19 and 20, to represent individuals that were preserved in the act of expelling bodycavity contents.

The Burgess Shale chancelloriids show three main modes of attachment: Formation of root bulbs binding coarse grains and debris in sediment (Figures 19 ; 33), attachment to larger shells or skeletons on the sea floor (Figure 28.1), or attachment to other living organisms, in particular the sponge Vauxia (Figure 27) and perhaps also other chancelloriids (Figure 43). In many cases it is impossible to distinguish between chance associations and attachment, and many of the potential cases of attachment to an object or organism (e.g., Figures $12.1 ; 17.4 ; 24.2$; 25 ; 36) may therefore go unrecorded as such. Where there are complex intergrowths between chancelloriids and sponges (Figures 29; 35) the two groups of organisms seem to use each other for purchase.

The Burgess Shale chancelloriids can thus be interpreted as hard-substrate dwellers that adapted to soft sediments by attaching to shell fragments or by binding coarser debris in root bulbs. A similar mode of life has also been inferred for roughly coeval Wheeler Shale Chancelloria, where Janussen et al. (2002) interpreted an irregular thickening at the abapical end as a root bulb anchoring the animal in the soft sediment. A proposal that the Burgess Shale chancelloriids were sediment-stickers, conical ends stuck in a firm, mat-bound, Proterozoic-style sediment (Dornbos et al., 2005) is not borne out by the sedimentological or morphological evidence. Kloss et al. (2009) expanded this concept to the Early Cambrian Chengjiang chancelloriids, suggesting that the sediment-sticking mode of life was in agreement with the disappearance of chancelloriids before the Late Cambrian (but see Mostler and Mosleh-Yazdi, 1976) when mat-bound sediments supposedly became rare. Also this hypothesis is incompatible with the evidence for hard-substrate attachment in Burgess Shale chancelloriids.

A report of dense clusters of chancelloriid sclerites in Lower Cambrian coelobiontic habitats
(Vennin et al., 2003) similarly suggests hard-surface attachment, and in any case adds a new possible mode of life for chancelloriids. Associations of chancelloriids with reefal environments have been noted (e.g., Rowland and Gangloff, 1988), but some studies of sponge-microbial bioherms have suggested that chancelloriid sclerites may be more frequent outside the reefal environments than within them (Kruse et al., 1995; Clausen and Álvaro, 2006).

\section{Associations with Other Organisms}

Burgess Shale chancelloriids commonly occur together with other organisms, most commonly sponges and brachiopods. In the Greater Phyllopod Bed, the most common sponges associating with chancelloriids are various species of Hazelia and, to a lesser extent, Takakkawia, Pirania, Leptomitus, and Eiffelia. In the Raymond Quarry, the chancelloriid association with the sponge Vauxia is particularly close. Devereux (2001) noted that where the chancelloriids congregated near to the Escarpment, Vauxia congregated in the community away from the Escarpment, whereas chancelloriids seem to have preferred the firmer, siltier seafloor near to the Escarpment. However, the congregations are not mutually exclusive - Allonnia and Vauxia commonly occur together.

Sponges are frequently used as substrate for attachment by the chancelloriids. In individual cases it may not be possible to determine whether the chancelloriid settled on a live or a dead sponge, but instances of complex intergrowth, such as in the Raymond Quarry associations of Allonnia and Vauxia shown in Figure 29, suggest a vivid interaction of live organisms. The chancelloriids and sponges seem to have used each other interchangeably as substrates, and often it is not clear who settled on whom.

With regard to brachiopods, the cases described in this paper where Micromitra burgessensis is found on Chancelloria sclerite rays, and Acrothyra gregaria occurs within the Allonnia tintinopsis scleritome, indicate that these brachiopods used the chancelloriids to obtain an elevated site for attachment.

\section{Integument Structure}

Based on a study of whole-body preserved Allonnia from the Lower Cambrian Chengjiang biota, Bengtson and Hou (2001) proposed a model of the chancelloriid body wall in which the sclerites formed an integral part of a continuous integument, representing its hard, mineralized parts. The soft, 
non-mineralized parts formed the flat skin between the sclerites. In this model, the sclerites are strictly dermal and exposed.

The Burgess Shale material supports this general reconstruction. There is no evidence that the sclerites are embedded beneath the epidermis. Their exposed nature is particularly clear at the compressed edges of specimens (e.g., Figure 38); where laterally preserved sclerites seem to be enveloped by tissue this is clearly due to a diagenetic halo around the sclerites, not to the presence of soft tissue (Figures 3; 10; 25.2; 27).

Mehl's (1996) observation of dermal tissues partly covering the sclerites in Chengjiang chancelloriids was challenged by Bengtson and $\mathrm{Hou}$ (2001) as being made on photographs rather than actual specimens. Mehl, however, after having studied the specimens, maintained that chancelloriids "possessed an internal skeleton formed beneath or within a probably cellular epidermal layer" (Janussen et al., 2002). She illustrated sclerites ostensibly lying both on top (Janussen et al., 2002, figure 5.5) and beneath (Janussen et al., 2002, figure 5.6) the integument, but these are fragments of sclerites, and it does not seem possible to distinguish upper from lower sclerites in the compressed specimen (see discussion and figure 4 in Bengtson and Hou, 2001). We conclude that there is no evidence for the sclerites representing an internal skeleton.

The discovery of three-dimensionally preserved chancelloriid body walls from the Lower Cambrian Sekwi Formation (Randell et al., 2005) further extends our knowledge of the chancelloriid integument. Sections through sclerites and soft integument confirm that the tissues are continuous and that the sclerites were fully external; in the Sekwi specimens the sclerites are positioned on protrusions from the body surface. The outermost layer of sclerites and soft integument in the Sekwi material contains regularly spaced, imbricating elements (Randell et al., 2005, figure 4) similar to those reported from the integument in Al. phrixothrix by Bengtson and $\mathrm{Hou}$ (2001) and in Al. tintinopsis and Ar. coriacea herein (Figures 31, 40). The imbricating arrangement shows that the elements are not fossilized cell walls. The pit-and-wall structure cited by Janussen et al. (2002) in support of the cell interpretation is most likely an artifact due to the preservation of the Chengjiang fossils as compressions with a complex relationship between parts and counterparts (cf. Bengtson and Hou, 2001, figures 4 and 6).

\section{Sclerite Function}

The presence of numerous sharp needles in the skin may be important to deter predators (Wainwright et al., 1976; Hartman, 1981), although this is not a straightforward conclusion. In sponges, the spicular skeleton has a structural role, and there is little evidence in support of a protective function for the spicules as such (Bergquist, 1978, p. 94). Experimental work (Chanas and Pawlik, 1995, 1996; Waddell and Pawlik, 2000a, 2000b) indicates that predators of various kinds (fish, arthropods, echinoderms) are not influenced in their selection by the presence of spicules in the sponge prey tissues. Whereas such results could partly be an effect of specialized spongivores having evolved mechanisms to diminish the potential harmfulness of sponge spicules (Oshel and Steele, 1985 , reported such a case concerning an amphipod predator), even generalist feeders are undeterred by spicules in the sponge prey (Chanas and Pawlik, 1995, 1996). In combination with chemical defenses, however, spicules indeed seem to play a role in the anti-predatorial defenses of some sponges (Hill et al., 2005).

A better morphological analogue than sponge spicules may be with cactus spines. Like the latter, chancelloriid sclerites are not embedded in the flesh, but are part of the outer integument, pointing the sharp tips of their rays outwards. The spines of cacti have been shown to have a significant deterring effect on predators/grazers (Theimer and Bateman, 1992; LeHouerou, 1996). This suggests that a major function of the similarly shaped and positioned chancelloriid sclerites was to provide protection against predators.

\section{Sclerite and Body Growth}

In the original analysis of sclerite mode of formation in coeloscleritophorans (Bengtson and Missarzhevsky, 1981; Bengtson and Conway Morris, 1984), a main conclusion was that the sclerites did not grow once they had been formed. This follows from the morphology of the sclerites, in particular the basal portion and the restricted basal pore. Structures similar to growth lines, i.e., indications of accretionary growth, are generally absent, though the basal region of halkieriid and siphogonuchitid sclerites sometimes shows striations parallel to the basal edge (e.g., Bengtson, 2005, figure 5G, H). Qian and Bengtson (1989) suggested this structure to reflect stepwise mineralization of the basal portion of the sclerite. It is different from the fine transverse striations seen on the inside of palmate sclerites of Sinosachites delicatus (Jell, 1981), the 
latter seemingly being structural features unrelated to growth (Bengtson et al., 1990; but see Vinther, 2009).

The sclerites in the abapical part of the Allonnia body are smaller than in the more apical parts, suggesting that the body grew by apical addition of integument and sclerites (Bengtson et al., 1996; Mehl, 1996). Figure 18 quantifies the relationship in a small and a large specimen of Al. tintinopsis: The trajectories of maximum ray length vs. distance from abapical end follow the same curve in the two specimens, and at a distance of about 20 $\mathrm{mm}$ from that end there is no further size increase of sclerites. Were the sclerites replaced during ontogenetic growth of the body, they would be expected to be generally larger in large specimens than in small ones. That this is not the case indicates that sclerites were generated in an apical growth zone and that they were not replaced once they had been formed. This conclusion is not necessarily valid for $C$. eros and Ar. coriacea, however, as these species have mixed sclerite sizes within their scleritomes.

\section{Feeding}

The only candidate for a body opening in the chancelloriids is seen at the apical end, where there is a circular area surrounded by modified sclerites forming a spiny palisade. There are two main alternatives for the function of this opening: (1) An exhalent outlet for water and waste products in a filter-feeding animal, analogous to the osculum of a sponge, and (2) an inhalent/exhalent opening for bringing in food and extruding waste products, analogous to the mouth of cnidarians.

The first alternative requires intakes for the unfiltered water, equivalent to the ostia of sponges. As discussed below in the comparison with sponges, however, not even the best-preserved chancelloriid integument shows any evidence of ostium-like openings. Unless such openings can be demonstrated, an inhalent/exhalent function of the apical orifice is best compatible with the available evidence.

The manner of feeding is still not evident from the anatomy, however. None of the hundreds of specimens found in the different Cambrian conservation lagerstätten have preserved any internal remains of prey organisms, which speaks against a predatory mode of life like that of cnidarians. Furthermore, there are no prey-capturing organs such as the circumoral tentacles found in most cnidarians. With regard to the possibility of suspension feeding, there is no evidence for a filtering organ.
Furthermore, the thin body wall and absence of evidence for surface-enlarging internal features suggest that most of the body volume consisted of a large internal cavity, an arrangement which is not optimal for suspension feeding or direct uptake of dissolved organic matter from the sea water. Against the latter possibility also speaks the presence of an outer leathery integument (Bengtson and Hou, 2001).

Bengtson and Hou (2001) proposed that chancelloriids may have been closely associated with bacterial or algal symbionts, which would then have provided a source of nutrition, as in the case of animals today living in hydrothermal-vent environments. A well-studied example is the vestimentiferan tube worms, which obtain most of their energy from facultative symbionts cultivated in specialized trophosomes (Bright and Lallier, 2010). There is, however, no evidence for a trophosome in the chancelloriids. If chancelloriids were dependent on symbionts for nutrition, the association is likely to have been less organized. The abapical-apical gradient in pyrite concentration seen in many specimens (e.g., Figure 17) may be compared with the vertical chemical gradient seen in cnidarian gastric cavities harboring symbionts (Agostini et al., 2012).

One additional significant clue to the feeding behaviour of the chancelloriids comes from the evidence discussed above for periodic constriction of the body from below, which might serve the function of expunging waste material from the internal cavity. (Other possible functions for the body change would be increased protection against predators or against being ripped off the attachments by temporary currents or storm waves.) For such a mechanism to be efficient there should also be a means of closing the apical orifice during the buildup of internal pressure, something that is indicated by the downfolding of the apical tuft seen in some specimens (Figure 26).

\section{AFFINITIES OF CHANCELLORIIDS}

"Of all the sponges occurring in the Burgess shale those of this genus have been the most difficult to classify" wrote Walcott (1920, p. 328) about Chancelloria. It is easy to agree - the classification of chancelloriids presents formidable problems even today. Superficially at least, chancelloriids are very like sponges, with a baglike body covered with more-or-less regularly arranged spicule-like objects, often forming a collar-like structure, seemingly surrounding an osculum, in the apical end. Walcott seems never to have doubted the poriferan affinity of the chancelloriids; his professed difficulty 
was with finding their proper position within the phylum. As we have seen, however, Walcott's reliance on a sponge model led to serious misjudgments regarding the mode of preservation, variability, and taxonomy of the Burgess Shale chancelloriids. In particular, had he recognized that the variability of "spicule" morphology did not reflect different degrees of embedding in soft tissues but a true variability of external, non-embedded, elements, he might have concluded that the sponge model was inappropriate.

Walcott's interpretation, however, was almost unanimously accepted for more than 60 years (de Laubenfels, 1955; Zhuravleva and Kordeh, 1955; Reid, 1959; Rezvoj et al., 1962; Robison, 1964; Rietschel, 1968; Romanenko, 1968; Sdzuy, 1969; Finks, 1970; Ziegler and Rietschel, 1970; Fuchs and Mostler, 1972; Rigby and Nitecki, 1975; Mostler and Mosleh-Yazdi, 1976; Rigby, 1976; Bergquist, 1978; Rigby, 1978; Hartman et al., 1980; Mostler, 1980, 1985). It was not until 1973 that Goryanskij pointed out that Walcott's Chancelloria eros was a heterogenous collection of taxa and that the morphology of chancelloriid "spicules" indicated them to be dermal skeletal elements. After Bengtson and Missarzhevsky (1981) argued that the mode of formation of chancelloriid sclerites precluded their homology with sponge spicules, most investigators have accepted (though sometimes with expressed hesitation) the flaws in the evidence for poriferan affinity (e.g., Grigor'eva and Zhuravleva, 1983; Rigby, 1983; Vasil'eva, 1985; Dzik, 1986; Rigby, 1986; Rozanov, 1986; Beresi and Rigby, 1994; Briggs et al., 1994; Dzik, 1994; Mehl, 1996; Chen and Zhou, 1997; Conway Morris, 1998; Mehl, 1998; Li, 1999; Demidenko, 2000; Fernández Remolar, 2001; Janussen et al., 2002; Beresi, 2003; Rigby and Collins, 2004; Wrona, 2004; Randell et al., 2005; Clausen and Álvaro, 2006; Porter, 2008; Kloss et al., 2009; Moore et al., 2010; Chen, 2012; Moore et al., 2014 - but see Butterfield, 1995; Butterfield and Nicholas, 1996; Botting and Butterfield, 2005; Sperling et al., 2007).

The relationships between the chancelloriid sclerites, integument, and other soft tissues are essential to the understanding of the nature of the animals. The Burgess collections give detailed information about the habit and mode of life of the different chancelloriid species, as well as the disposition of the sclerites over the body. They are less informative with regard to the structure and composition of the sclerites, but since these issues are central to the understanding of chancelloriid affinities, we discuss them here at some detail before dealing with the information provided by the soft tissues.

\section{The Sclerite Problem}

Chancelloriid sclerites are morphologically similar to certain calcareous sponge spicules, in particular those of the Cambrian-Permian Heteractinida (Rigby, 1983). (Compare, for example, the heteractinid Eiffelia araniformis figured by Bengtson et al., 1990, figures 12 and 13, with the cooccurring Chancelloria racemifundis, figures 2325.) Yet in their structure and composition they are different from sponge spicules, being composed of discrete elements, each element having thin aragonitic walls enclosing a spacious internal cavity, which opens through a basal foramen. This discrepancy is at the heart of most of the controversy surrounding the nature of chancelloriids.

The Construction of Sponge Skeletons. Spicules of modern sponges are made up of high-magnesian calcite or opal with organic admixtures. They are supported by an organic skeleton consisting of dispersed fibrillar, banded collagen and, in demosponges, a non-banded type of collagen termed spongin, unique to sponges (Bergquist, 1978; Garrone and Exposito, 1992; Maldonado, 2009). The composition, structure and formation of sponge spicules have been described in a number of publications (e.g., Ebner, 1887; Minchin, 1898; Woodland, 1905; Minchin, 1908; Jones, 1970, 1979; Bavestrello et al., 1994; Aizenberg, Hanson, Ilan, et al., 1995; Ilan et al., 1996; Uriz, 2006; Sethmann and Wörheide, 2008); (for siliceous spicules, see Reiswig, 1971a; Jones, 1979; Wilkinson and Garrone, 1980; Garrone et al., 1981; Hartman, 1981; Imsiecke et al., 1995; Aizenberg et al., 2005; Müller et al., 2006). In all reported cases, sponge spicules are formed by specialized cells, sclerocytes, or by syncytia. They are then transported to their final position (Weissenfels, 1978), sometimes protruding through the pinacoderm (Garrone et al., 1981, figures 17-2, 17-3; De Vos et al., 1991, pls. 6-8).

For siliceous spicules, the primordia are laid down intracellularly or intrasyncytially in a membrane-bound organelle, the silicalemma. First to be laid down is an organic axial filament, around which the inorganic phase (opal) is deposited concentrically (Garrone et al., 1981; Imsiecke et al., 1995; Aizenberg et al., 2005). The axial filament is proteinaceous in composition, but does not appear to contain any collagen (Shore, 1972). In fossil spicules, the organic filament is typically lost by degradation and leaves a central canal (Reiswig, 
1971a). The spicules range in shape from simple monaxons to very complex multirayed forms, and there is commonly a more-or-less distinct bimodal size distribution into megascleres and microscleres.

In contrast to the siliceous spicules of the Hexactinellida and Demospongea, the spicules of calcareous sponges are simple in shape, usually monaxons or triaxons without embellishments, without any pronounced size bimodality, and without an axial filament (Sethmann and Wörheide, 2008). As with siliceous spicules, the mineralized substance is deposited in concentric layers from the outside. Each spicule consists of a single crystal of calcite. The crystal faces are not expressed in the morphology of the spicules, and growth is primarily modified by the insertion of acidic proteins in the calcite lattice, producing dislocations (Aizenberg, Hanson, Ilan, et al., 1995; Aizenberg, Hanson, Koetzle, et al., 1995; Aizenberg, Ilan, et al., 1996; Ilan et al., 1996). Calcium carbonate also occurs in an amorphous phase together with the calcite (Aizenberg, Lambert, et al., 1996).

Fibrillar collagen, similar to the collagens of other metazoan phyla (Runnegar, 1985; Garrone and Exposito, 1992) is present in all sponges. Spongin, on the other hand, is a character only of the Demospongea, where spongin skeletons may have evolved more than once (Maldonado, 2009). In addition to forming the classical "spongy" skeleton of networked fibres, the spongin may also embed and connect the mineralized spicules (perispicular spongin). Some other, less common, spongin structures are briefly described by Bergquist (1978, pp. 88-90). Granular inclusions of lepidocrocite $(\mathrm{\gamma}-\mathrm{FeO}(\mathrm{OH}))$ are common in the spongin of some forms (Vacelet et al., 1988).

Spongin is laid down by spongocytes, in a way very similar to the formation of spicules by sclerocytes. The fibres are invariably built up of concentric layers; in a few cases a central pith consisting of non-lamellar spongin is laid down first, to be later covered by denser concentric layers (Carter, 1881; Vacelet, 1971b). An illustration of the similarity in formation between spicules and spongin is that one demosponge, Darwinella, produces diactinal, triactinal, and tetractinal "pseudospicules" of spongin, together with the ordinary spongin skeleton (Müller, 1865; Carter, 1872, 1881; Bergquist, 1978).

In addition to spicules, a number of sponges may also form aragonitic or calcitic basal skeletons of various construction (Vacelet, 1985; Wood, 1991). These are laid down in close to isotopic equilibrium with the ambient sea water (Böhm et al., 2000), forming crystal structures that resemble those inorganically grown but are to a considerable extent mediated by a mucilaginous extracellular matrix containing acidic macromolecules (Reitner et al., 1997; Gilis et al., 2012; Gilis et al., 2013). In the context of the discussion of the nature of chancelloriid sclerites and the possible sponge affinity of chancelloriids, these skeletal structures serve as a reminder that sponges may have the ability to construct other kinds of mineralized skeletons. It is also significant that the basal calcareous skeletons in sponges, in spite of having distinctly polyphyletic origins, show a number of biochemically similar pathways towards biomineralization (Gilis et al., 2013).

Comparisons with Sponge Spicules. Walcott's (1920) interpretation of Chancelloria as a sponge presumed quite reasonably that the sclerites were spicules, and because he misinterpreted the variation in ray numbers as a taphonomic feature he regarded the spicules to be partly embedded in the integument. This would agree with the organization of a sponge, in which spicules are transported to their final position in the sponge body and may partly protrude through the pinacoderm.

Having expressed his difficulties in classifying Chancelloria, Walcott referred his fossils to the Suborder Heteractinellida Hinde under the Order Hexactinellida Schmidt. The concept of Chancelloria as a siliceous sponge survived for almost 50 years (de Laubenfels, 1955; Zhuravleva and Kordeh, 1955; Romanenko, 1968), although no investigation of the composition of the "spicules" had been made. (A recent revival of the idea of chancelloriids as silica biomineralizers by Babcock and Ciampaglio, 2007, was unaccompanied by analyses or data.) Reid (1959), assuming a siliceous composition of the "spicules", suggested that the depressions on the lower side may be analogous with the hilum in some demosponge microscleres, a structure presumed to mark the position of the nucleus of the secreting scleroblast.

A few years later, however, Reid (1967) concluded that Chancelloria was a calcareous sponge. Even this conclusion was not based on a chemical or mineralogical analysis, but Reid instead compared the sutured rays with similar structures in triactine spicules of the living calcareous sponge Leucettusa, suggesting a similar mode of formation.

Rietschel (1968) likewise compared Chancelloria with the Palaeozoic Octactinellida (largely corresponding to the Heteractinida as used by Rigby, 
1983). He identified these as calcareous sponges, concluding that also Chancelloria had calcareous spicules. Like Reid (1967), Rietschel (1968) stressed the sutured nature of chancelloriid sclerites, with the understanding that triaxon or tetraxon calcareous sponge spicules were composites, having been formed by the union of three or four monaxons during the early stages of growth. This concept stemmed from earlier observations by Minchin (1898) and Woodland (1905). Soon after the publication of Reid's and Rietschel's papers, however, Jones (1970) suggested that Minchin and Woodland had been in error, their observations having been done on corroded specimens. A later study on spicule formation in Sycon sp. by llan et al. (1996) demonstrated conclusively that even the first primordia of triradiate spicules in this form are coherent structures. This is likely to be true of all calcarous sponge spicules, in congruence with the well-known fact that they behave like single crystals of calcite (Sollas, 1885a, 1885b; Ebner, 1887; Schmidt, 1924; Jones, 1955; Aizenberg, Ilan, et al., 1996; Sethmann and Wörheide, 2008).

Rietschel (1968) also compared the sutured chancelloriid sclerites with the hexaradial spicules of the presumed heteractinid Eiffelia, which Walcott (1920, figure 10) had figured with distinct sutures between the rays. Neither Walcott's photographs nor his written description give any evidence for such sutures, and in his revision of Burgess Shale sponges Rigby (1986) concluded that Eiffelia spicules were solid and unsutured. Studies of threedimensionally preserved phosphatized spicules in carbonate rocks in Australia confirmed the lack of sutures in Eiffelia (Bengtson et al., 1990). (See further about Eiffelia below.)

It appears that Sdzuy (1969) was the first to identify the chancelloriid "spicules" as consisting of thin calcareous walls enclosing a spacious internal cavity, which opened through a basal pore. Sdzuy further observed and figured the double nature of the walls separating the cavities of adjacent elements in a composite sclerite. Nonetheless, his interpretation of these structures was "main-stream poriferan," insofar as he regarded the internal cavity to be an axial canal reflecting a correspondingly thick axial filament. He argued that the fact that chancelloriids lived in shallow water suggested that the "spicule" interiors were filled with spongin, which he regarded to be continuous with an extraspicular spongin skeleton by means of the basal pores (Sdzuy, 1969, p. 120).

Like those of his predecessors, Sdzuy's interpretation is inconsistent with several aspects of extant calcareous sponges. These do not have an axial canal in their spicules (Jones, 1970; Sethmann and Wörheide, 2008), nor a spongin skeleton (Bergquist, 1978). Even in demosponges, which usually have a well-developed spongin skeleton and axial canals in their siliceous spicules, the organic axial filaments are not connected to the spongin skeleton and do not appear to contain collagenous material at all (Shore, 1972). Thus, although Sdzuy correctly established the basic structure and composition of the chancelloriid sclerites, he did not confront the problems thereby created for the sponge model.

Butterfield and Nicholas (1996) argued that the spongin "pseudospicules", or "horn cells", in the demosponge Darwinella are topologically equivalent with multirayed chancelloriid sclerites, and that the two structures are homologous, both being derived from spongin fibres. This idea was criticized at length by Bengtson and Hou (2001), who argued that organic (spongin) and mineralized sponge spicules are both built by external deposition from enveloping amoeboid cells, thus fundamentally different from the mode of formation of chancelloriid sclerites.

Botting and Butterfield (2005) returned to the proposal of spicule-sclerite homology in a restudy of Burgess Shale Eiffelia. In his original description, Walcott (1920, p. 324) had observed that the spicules of this taxon seemed to have a central canal, like spicules of siliceous sponges. His observation remained inconclusive, however, and when Eiffelia was identified as a calcareous sponge, Rigby's (1986) conclusion that the spicules were solid was generally accepted (Bengtson et al., 1990). Botting and Butterfield (2005), however, discovered numerous but previously overlooked hexactinellid-type spicules in the skeleton, and in connection with this they also found evidence of a bi-layered structure in the regular hexaradiate spicules. The presence of an axial canal could later be confirmed in studies of three-dimensionally preserved spicules (Bengtson and Vinther, 2006). Botting and Butterfield (2005) proposed that Eiffelia represents stem-group hexactinellids retaining a hexaradiate spicule shape and a partly calcareous spicule mineralogy from the last common ancestor of sponges with siliceous and calcareous skeletons. With regard to chancelloriids, they suggested that "the bipartite constitution of chancelloriid rays (the hollow core and lightly mineralized wall) conceivably corresponds to the bipartite constitution of Eiffelia spicules." This proposal, however, does not address the problem of the fun- 
damental difference between sponge spicules, built from the outside by sclerocytes, and chancelloriid sclerites, built by mineralization of the outer layers of organic precursors.

It is important to note that the arguments against homology between chancelloriid sclerites and sponge spicules are not per se arguments against sponge affinity. Qian and Bengtson (1989, p. 16) pointed out that sponges can secrete other kinds of mineralized substances, and that the lack of homology with spicules thus only "removes the main argument for such an interpretation." Sperling et al. (2007) wrote "... because there are clear differences between the spicules of chancelloriids and sponges, most authors agree that the two are not homologous. We agree. Most workers argue further that if the spicules are not homologous, then chancelloriids are not sponges. We disagree." The arguments against a sponge affinity, however, have generally been based on the implications of the nature of the epithelium (e.g., Bengtson and Hou, 2001; Janussen et al., 2002) and on the hypothesized affinities with the slug-like halkieriids (Bengtson and Conway Morris, 1984; Bengtson et al., 1990; Bengtson, 2005; Porter, 2008; Moore et al., 2010).

Comparisons with Echinoderm Ossicles. Goryanskij (1973), observing isolated sclerites from microfossil samples, concluded that the varying number of rays and the presence of a basal flat surface on each composite sclerite rendered Walcott's interpretation unlikely, and that the sclerites were entirely exposed, resting on the dermal layer. Goryanskij restricted his conclusion to the forms we refer to herein as Chancelloria eros and Archiasterella coriacea. Having correctly recognized that Walcott's type material was taxonomically heterogeneous, Goryanskij concluded that the form herein recognized as Allonnia tintinopsis was a true sponge, not closely related to the chancelloriids. In this he was mistaken, as shown by the chancelloriid structure of Allonnia sclerites (Bengtson et al., 1990) and their position as dermal sclerites.

In Goryanskij's interpretation, the thin walls observed by Sdzuy (1969) were the diagenetically mineralized remnants of a thin epidermis, surrounding the solid rays of the sclerites, which consisted of a carbonate-phosphate compound. He had observed (Goryanskij, 1973, p. 41) that the material inside the walls often differed from the surrounding matrix and argued that the sclerite interiors had had an original mineralogy different from that of the sedimentary matrix. Selective phosphatization or glauconitization of cavities with restricted pore-water access is a common phenomenon, however, and constitutes no evidence for an original mineralogical difference. Goryanskij also remarked that the composite sclerites were commonly dissociated into individual rays without evidence of abrasion. Again, this would be a natural result of the thin calcareous walls being dissolved, leaving a narrow space between ray fillings. Finally, Goryanskij argued that if the sclerites were thin-walled and hollow, one would expect to find compressed and broken rays. In fact, such compression is common in shales, where longitudinal cracks in flattened chancelloriid sclerite rays show them to have had an internal cavity (e.g., Rigby, 1976).

Goryanskij concluded that no known organism was directly comparable to chancelloriids. Nonetheless, he suggested that they were most closely related to echinoderms because of the epidermal [sic] skeleton and the morphology of its elements, and speculated that the chancelloriids might be an extinct branch of holothurians. This idea is clearly based on his misinterpretation of the original structure of chancelloriid sclerites; a comparison with the mesodermal skeleton of echinoderms is hardly possible. The presence of internal cavities in the mineralized sclerite rays is supported by numerous observations (e.g., Sdzuy, 1969; Qian and Bengtson, 1989; Bengtson et al., 1990; Beresi and Rigby, 1994; Randell et al., 2005; Moore et al., 2010, 2014). Herein lies a crucial difference with sponge spicules and with echinoderm ossicles.

Comparisons with Ascidian Spicules. Mehl (1996) has suggested that chancelloriid sclerite formation may be comparable to spiculogenesis in ascidians, and that chancelloriids thus may be deuterostomes. These proposals were critically discussed by Bengtson and Hou (2001). In a later paper on chancelloriid affinities, Mehl (Janussen et al., 2002) did not mention the ascidian hypothesis, concluding only that chancelloriids were eumetazoans (epitheliozoans).

Comparisons with Cnidarian Spicules. An admittedly speculative hypothesis was presented by Randell et al. (2005), who noted a similarity between the imbricating platelets of chancelloriids with the minute imbricating sclerites in the integument of some octocorals. They proposed that chancelloriids might represent armoured cnidarian polyps but concluded that this was merely an interesting possibility without further supporting evidence.

Comparisons with Other Coeloscleritophoran Sclerites. The significance of the hollow interior 
and restricted aperture of chancelloriid sclerite rays was pointed out by Bengtson and Missarzhevsky (1981). They concluded that the thin-walled composite sclerites, in which adjacent ray cavities are separated by a double wall, must have been formed by mineralization of an external layer of organic precursors occupying the space of the cavities. Thus the sclerites were not likely to have been formed by sponge sclerocytes, and, consequently, they would not be homologous to sponge spicules.

Whereas this interpretation did not exclude the possibility that chancelloriids were sponges, it removed the main argument for such an affinity. Bengtson and Missarzhevsky (1981) instead proposed affinity with other Cambrian animals having a similar structure and composition of the sclerites; these forms were united in the taxon Coeloscleritophora, characterized by the common possession of coelosclerites. As originally defined, the taxon contained the Wiwaxiidae, Chancelloriidae, and Siphogonuchitidae. The Wiwaxiidae was taken to include the Burgess Shale fossil Wiwaxia as well as the Lower Cambrian mineralized forms (now referred to the Halkieriidae and Sachitidae) on which Bengtson and Missarzhevsky (1981) based their structural observations of the sclerites. Morphological comparisons suggested these groups to be closely related (cf. also Bengtson and Conway Morris, 1984; Bengtson et al., 1990), although the lack of mineralization of Wiwaxia sclerites, indeed the lack of coelosclerites, precludes direct structural comparisons (Butterfield, 1990; Porter, 2008). The subsequent discovery of articulated halkieriid scleritomes (Conway Morris and Peel, 1990, 1995) demonstrated one further significant difference, in that the halkieriids possessed large anterior and posterior shell plates, lacking in the wiwaxiid scleritome. The Halkieriidae and Wiwaxiidae are therefore by most authors treated as separate families, but Conway Morris and Caron (2007) reported the Burgess Shale Orthrozanclus, a form combining wiwaxiid-type sclerites with a halkieriid-like anterior plate, and concluded that halkieriids, wiwaxiids, Orthrozanclus, and siphogonuchitids constitute a monophyletic clade, informally termed halwaxiids.

If defined as animals carrying coelosclerites (cf. Bengtson et al., 1990; Conway Morris and Chapman, 1996; Bengtson, 2005; Porter, 2008), coeloscleritophorans include the Chancelloriidae, Sachitidae, "ninellids", Siphogonuchitidae, and Halkieriidae. Sachitids have spine-shaped sclerites but are poorly understood taxonomically (cf. Bengtson et al., 1990). Ninellids have one type of strongly curved, highly variable, sclerite (Conway Morris and Chapman, 1996). Siphogonuchitids have spine-shaped sclerites that may be merged into mollusc-like, bilaterally symmetrical shell plates (Missarzhevsky, 1989; Qian and Bengtson, 1989; Bengtson, 1992; Conway Morris and Chapman, 1996). Halkieriids are slug-like, scale-clad bilaterians that, in addition to numerous scale- and spine-shaped sclerites, include two terminal shell plates (Conway Morris and Peel, 1990, 1995).

The affinities of the non-chancelloriid coeloscleritophorans are even more controversial than those of the chancelloriids (Bengtson and Conway Morris, 1984; Conway Morris, 1985; Dzik, 1986; Butterfield, 1990; Bengtson, 1992; Bengtson, 1993; Yochelson, 1993; Conway Morris and Peel, 1995; Williams and Holmer, 2002; Bengtson, 2005; Vinther and Nielsen, 2005; Porter, 2008; Vinther, 2009; Smith, 2014), but a sponge affinity has never been seriously entertained for these organisms.

Bengtson and Missarzhevsky (1981) based the proposed homology of sclerites within the Coeloscleritophora on the general structure, composition, and mode of formation. Later studies (Bengtson et al., 1990; Porter, 2004; Bengtson, 2005; Porter, 2008) have revealed additional similarities in the detailed structure that further support the homology.

Bengtson et al. (1990) demonstrated the presence of longitudinal, parallel striations on the internal moulds of all investigated coeloscleritophorans from South Australia: Chancelloriids (Chancelloria racemifundis: 0.7-1 $\mu \mathrm{m}$ interval, Bengtson et al., 1990, figure 24D), sachitids (Sachites proboscideus: 1-2 $\mu \mathrm{m}$ interval, Bengtson et al., 1990, figure 22C), and halkieriids (Halkieria sp.: $1.5 \mu \mathrm{m}$ interval, Bengtson et al., 1990, figure 49B). Their presence in siphogonuchitids is less well established - the striations figured in Lopochites quadrogonus (1-2 $\mu \mathrm{m}$ interval) by Qian and Bengtson (1989, figure $16 A_{6}$ ) may represent fanning aragonite crystals. No information exists about such structures in ninellids (cf. Conway Morris and Chapman, 1996).

[Butterfield (1990, figure 3B) illustrated similar internal structures in Burgess Shale Wiwaxia corrugata $(0.5-1 \mu \mathrm{m}$ interval, possibly $\geq 2 \mu \mathrm{m})$, which he interpreted as corresponding to the longitudinal tubules in polychaete setae (e.g., Orrhage, 1971). $\mathrm{He}$ also identified the same structure in the cooccurring presumed polychaete Canadia spinosa. On this basis he referred Wiwaxia and Canadia to the modern order Phyllodocida, and explicitly ruled out any phylogenetic relationship between Wiwaxia and the mineralized Coeloscleritophora. Eibye- 
Jacobsen (2004) agreed with the proposed homology of Wiwaxia scales with lophotrochozoan chetae but concluded from a phylogenetic analysis that the evidence was insufficient to conclude whether Wiwaxia was more closely related to annelids or to molluscs. In contrast, Smith (2014) concluded that Wiwaxia is closely related to halkieriids, and that a molluscan affinity for both is robustly established.]

A conspicuous feature of many coeloscleritophoran sclerites is the fine, imbricating spine- or scale-shaped platelets that tend to occur on the upper surfaces (Bengtson et al., 1990; Bengtson and Hou, 2001; Randell et al., 2005; Porter, 2008; Moore et al., 2010, 2014). These have been interpreted as cuticular elements incorporated in the sclerite fabric by mineralization of the surrounding matrix (Bengtson and Hou, 2001); a process analogous to the incorporation of sclerites in siphogonuchitid shell plates (Missarzhevsky, 1989; Bengtson, 1992). A phosphatized chancelloriid sclerite illustrated by Kouchinsky (2000, figure 2) shows the main wall to be built up of imbricating fibres, sometimes fused into laths. He suggested these laths to be formed during diagenesis, but Porter (2008) proposed that such structures are identical to the platelets, and that the fibrous structure is a surface expression of the longitudinal fibres seen in the underlying layers. This proposal seems difficult to reconcile with the discrete platelets in sclerites observed by Randell et al. (2005, "oblong structures" in their figure 4), but the latter might possibly represent sclerotized tips of longer fibres or fibre bundles and so fit Porter's model. Further microstructural work on suitably preserved sclerites is necessary to answer this question.

The morphological gap between chancelloriid and halkieriid/siphogonuchitid/sachitid sclerites has been bridged by discoveries of intermediate forms in South Australia (Bengtson et al., 1990) and China (Moore et al., 2010, 2014), but the relationship of the chancelloriids to the other groups remains controversial because of the anatomical differences of the end members. Conway Morris and Chapman (1996) wrote "The difference [in habit] is of such magnitude that it seems likely that the similarity between the sclerites of chancelloriids and other coeloscleritophorans is convergent." Similar sentiments have been expressed by Vasil'eva (1985), Butterfield and Nicholas (1996), Li (1999), and Sperling et al. (2007). However, Porter (2008), on the basis of detailed structural comparisons of various coeloscleritophorans, concluded that the structures are unique and that coeloscleritophoran sclerites are homologous.

\section{Inferences from Soft-body Anatomy}

Symmetry. No trace of bilateral symmetry has been found in chancelloriids, neither in the disposition of the sclerites nor in the apical features observed in the few obliquely compressed specimens. This is consistent with a primary radial symmetry, and the lack of preserved anatomical features that would be expected in large bilaterians, such as a gut, further weakens the alternative hypothesis, that chancelloriids are bilaterians that secondarily regained radial symmetry.

Integument. The type of leathery integument with integrated sclerites inferred for chancelloriids does not fit a sponge model. Non-hexactinellid sponges have an outer pinacoderm consisting of pinacocytes (Bergquist, 1978). Some demosponges in addition form a collagenous cuticle, that may be as thin as $25-30 \mathrm{~nm}$ but occasionally up to about a micrometre thick (Lévi and Porte, 1962; Bagby, 1970; Vacelet, 1971a; De Vos et al., 1991). This cuticle may be temporarily developed over parts of the body surface, sealing off the inhalant ostia, locally shutting off the water circulation.

Although ostia in certain sponges may thus under occasional conditions be hidden by a thin cuticle, this is not a normal condition, as the function of the ostia as inhalant openings is vital to the animal. If chancelloriids are sponges, they should thus be expected to possess ostia.

Sponge ostia are typically up to about $50 \mu \mathrm{m}$ in diameter (Bergquist, 1978), which roughly corresponds to the maximum particle retention size (Reiswig, 1971b; Ribes et al., 1999; Thurber, 2007). Reiswig (1971b) studied retention of various particulate matter by three species of marine demosponges (Mycale sp., Verongia gigantea and Tethya crypta) and found that the mean retention by volume was around $90 \%$ (83.2-97.7\%) for naked eukaryotic cells $5-50 \mu \mathrm{m}$ in diameter and slightly higher (90.2-98.95) for bacteria. Armoured eukaryotic cells (fungi, diatoms, dinoflagellates, coccolithophores, etc.) had a lower retention rate (44.9-92.0\%). In two of the three species, however, the retention rate of armoured cells was strongly correlated to cell size, smaller $(2 \mu \mathrm{m})$ cells being retained at low levels (20-45\%) and larger cells at nearly $100 \%$. Material larger than 5 $\mu \mathrm{m}$ is generally phagocytosed by archaeocytes and collencytes in the inhalant canals (van Trigt, 1919; van Weel, 1949; cited in Reiswig, 1971b). 
Although $5 \mu \mathrm{m}$ openings might be difficult to discern, given the level of preservation of the Burgess and Chengjiang material, openings around 50 $\mu \mathrm{m}$ in diameter should be readily visible both under the light microscope and under the SEM. We have searched all available well-preserved portions of chancelloriid integuments from both sites but have not found any evidence of such openings. Thus, also in this regard, the chancelloriids fail the predictions of a sponge model.

Circular Contractile Tissue. We propose herein that chancelloriids periodically constricted the body from the abapical end, as a means of flushing water and waste from the body cavity through the apical orifice. Such a behaviour requires circular contractile tissues. Whereas muscles or contractile ligaments are unknown in sponges, the freshwater sponge Ephydatia has been found to contain actin bundles in the pinacocytes that act in coordination to produce peristaltic contractions of the body (Elliott and Leys, 2007). The contractions are coordinated with dilation of the exhalent oscula and closure of affected inhalent ostia and act to expel lumps of waste material from the spongocoel. Contraction waves in sponges are typically very slow, around $20 \mu \mathrm{m}$ per second (Leys, 2007), although speeds up to $375 \mu \mathrm{m} \mathrm{s}^{-1}$ have been reported from waves in Ephydatia induced by electrical stimulation (McNair, 1923).

A propagating contractile wave produced by circular muscles is common in eumetazoans, which use it for locomotion, burrowing, circulation of body fluids, propagation of food in guts, etc. Cnidarians use this method to "blow out" the contents of the coelenteron (Hyman, 1940). These movements are very fast, being performed by innervated musculature.

A large Al. tintinopsis may be $20 \mathrm{~cm}$ from abapical to apical end (Figure 16.1). A contractional wave at normal sponge speed of $20 \mu \mathrm{m} \mathrm{s}^{-1}$ would take almost three hours to travel this distance. Even calculating with the speeds artificially induced by electrical shocks in Ephydatia the contraction would take almost 10 minutes. Such sluggish contraction would hardly be functional, neither to react to environmental changes (increasing water energy or appearance of a predator) nor to flush out water and waste products. The type of contraction inferred for chancelloriids thus would seem to require innervated circular musculature, a feature unknown in sponges.

\section{Phylogenetic Alternatives}

The implication of the existence of a coeloscleritophoran clade, as expressed by Bengtson and Conway Morris (1984) is that chancelloriids represent a branch of bilaterians that have lost their bilateral symmetry through becoming sessile, thereby taking on a superficially sponge-like appearance. In a later analysis of the coeloscleritophorans, mainly based on the sclerite types, Bengtson et al. (1990) concluded that the chancelloriids were the sister group of the clade consisting of the other coeloscleritophorans, although the lack of an outgroup prevented an indication of whether or not the radial symmetry was primitive or derived.

The similarities in morphology, structure, and composition between chancelloriid sclerites and those of the coeval sachitids, halkieriids, and siphogonuchitids can be interpreted in one of three ways.

1. The sclerites are a synapomorphy of a monophyletic clade Coeloscleritophora.

2. The sclerites are plesiomorphic for the Eumetazoa, and the Coeloscleritophora are paraphyletic.

3. The sclerites are a convergent character, and the Coeloscleritophora are polyphyletic.

None of these hypotheses can at present be definitely falsified. However, the evidence for crown-group molluscan affinity of the halkieriids (Bengtson, 1992; Vinther and Nielsen, 2005; Vinther, 2009) and the lack of bilaterian characters in the chancelloriids make No. 1 unlikely, and the mounting evidence for homology of coeloscleritophoran sclerites (Porter, 2004; Bengtson, 2005; Porter, 2008) speaks against No. 3, polyphyly of the Coeloscleritophora. The most likely hypothesis is therefore that coelosclerites are a eumetazoan plesiomorphy and the Coeloscleritophora paraphyletic. The implications of this conclusion were discussed by Bengtson (2005).

\section{ACKNOWLEDGEMENTS}

We thank B. Runnegar, K. Peterson, S. Conway Morris, N. Butterfield, and A. Kouchinsky for valuable discussions on the nature of chancelloriids; J.-B. Caron and F. Collier for access to the ROM and Smithsonian collections, respectively; and J. Waddington and P. Fenton for helpful assistance in the ROM collections. P. von Knorring provided the artwork. Two anonymous reviewers contributed to the improvement of the paper. The 18 seasons of Burgess Shale fieldwork that yielded 
the chancelloriids in this study could not have been completed without the support of Parks Canada Western Region in Calgary, and the officers of Yoho National Park, especially the contact wardens, Chief Warden and Superintendent. Fieldwork financial support came from the federal Department of Energy, Mines and Resources, NSERC, Park Service contracts, and especially from eight National Geographic Grants. SB acknowledges support from the Swedish Research Council (NFR/ VR) and the Danish National Research Foundation (DNRF53).

\section{REFERENCES}

Agostini, S., Suzuki, Y., Higuchi, T., Casareto, B.E., Yoshinaga, K., Nakano, Y., and Fujimura, H. 2012. Biological and chemical characteristics of the coral gastric cavity. Coral Reefs, 31:147-156.

Aizenberg, J., llan, N., Weiner, S., and Addadi, L. 1996. Intracrystalline macromolecules are involved in the morphogenesis of calcitic sponge spicules. Connective Tissue Research, 35:17-23.

Aizenberg, J., Lambert, G., Addadi, L., and Weiner, S. 1996. Stabilization of amorphous calcium carbonate by specialized macromolecules in biological and synthetic precipitates. Advanced Materials, 8:222-226.

Aizenberg, J., Hanson, J., Koetzle, T.F., Leiserowitz, L., Weiner, S., and Addadi, L. 1995. Biologically induced reduction in symmetry - a study of crystal texture of calcitic sponge spicules. Chemistry - A European Journal, 1:414-422.

Aizenberg, J., Weaver, J.C., Thanawala, M.S., Sundar, V.C., Morse, D.E., and Fratzl, P. 2005. Skeleton of Euplectella sp.: Structural hierarchy from the nanoscale to the macroscale. Science, 309:275-278.

Aizenberg, J., Hanson, J., Ilan, M., Leiserowtiz, L., Koetzle, T.F., Addadi, L., and Weiner, S. 1995. Morphogenesis of calcitic sponge spicules: a role for specialized proteins interacting with growing crystals. FASEB Journal, 9:262-268.

Ax, P. 1995. Das System der Metazoa I, Ein Lehrbuch der phylogenetischen Systematik. Gustav Fischer, Stuttgart.

Babcock, L.E. and Ciampaglio, C.N. 2007. Frondose fossil from the Conasauga Formation (Cambrian: Drumian Stage) of Georgia, USA. Memoirs of the Association of Australasian Palaeontologists, 34:555-562.

Bagby, R.M. 1970. The fine structure of pinacocytes in the marine sponge Microciona prolifera (Ellis and Solander). Zeitschrift für Zellforschung, 105:579594.

Bavestrello, G., Cattaneovietti, R., Cerrano, C., Giovine, M., and Sara, M. 1994. Rate of spiculogenesis in some common Mediterranean calcispongiae - a tetracycline and $\mathrm{Ca}-45++$ labeling study. Bollettino di Zoologia, 61:197-201.
Bengtson, S. 1985. Taxonomy of disarticulated fossils. Journal of Paleontology, 59:1350-1358.

Bengtson, S. 1992. The cap-shaped Cambrian fossil Maikhanella and the relationship between coeloscleritophorans and molluscs. Lethaia, 25:401-420.

Bengtson, S. 1993. Molluscan affinity of coeloscleritophorans - reply. Lethaia, 26:48.

Bengtson, S. 2000. Teasing fossils out of shales with cameras and computers. Palaeontologia Electronica, 3.1.4:14 pp, 7.7 MB; http://palaeo-electronica.org/ 2000_1/fossils/issue1_00.htm

Bengtson, S. 2005. Mineralized skeletons and early animal evolution., p. 101-124. In Briggs, D.E.G. (ed.), Evolving Form and Function: Fossils and Development. Yale Peabody Museum, New Haven, Connecticut.

Bengtson, S. and Conway Morris, S. 1984. A comparative study of Lower Cambrian Halkieria and Middle Cambrian Wiwaxia. Lethaia, 17:307-329.

Bengtson, S. and Hou, X. 2001. The integument of Cambrian chancelloriids. Acta Palaeontologica Polonica, 46:1-22.

Bengtson, S. and Missarzhevsky, V.V. 1981. Coeloscleritophora - a major group of enigmatic Cambrian metazoans., p. 19-21. In Taylor, M.E. (ed.), Short papers for the Second International Symposium on the Cambrian System 1981. U.S. Geological Survey Open-File Report 81-743.

Bengtson, S. and Vinther, J. 2006. The role of Eiffelia in early sponge evolution. Geological Society of America Abstracts with Programs, 38:304.

Bengtson, S., Collins, D.H., and Runnegar, B. 1996. Chancelloriid sclerite formation - turning the problem inside out. The Paleontological Society Special Publication, 8:29.

Bengtson, S., Conway Morris, S., Cooper, B.J., Jell, P.A. and Runnegar, B.N. 1990. Early Cambrian fossils from South Australia. Memoirs of the Association of Australasian Palaeontologists, 9:1-364.

Beresi, M.S. 2003. Cambrian sponge spicules and Chancelloriid sclerites from the Argentine Precordillera: A review. Geologica Acta, 1:73-84.

Beresi, M.S. and Rigby, J.K. 1994. Sponges and chancelloriids from the Cambrian of western Argentina. Journal of Paleontology, 68:208-217.

Beresi, M.S. and Rigby, J.K. 2013. Middle Cambrian protospongiid sponges and chancelloriids from the Precordillera of Mendoza Province, western Argentina. Neues Jahrbuch für Geologie und Paläontologie. Abhandlungen, 268:259-274.

Bergquist, P.R. 1978. Sponges. University of California Press, Berkeley.

Böhm, F., Jochimski, M.M., Dullo, W.C., Eisenhauer, A., Lehnert, H., Reitner, J., and Wörheide, G. 2000. Oxygen isotope fractionation in marine aragonite of coralline sponges. Geochimica et Cosmochimica Acta, 64:1695-1703. 
Botting, J.P. and Butterfield, N.J. 2005. Reconstructing early sponge relationships by using the Burgess Shale fossil Eiffelia globosa, Walcott. Proceedings of the National Academy of Sciences, 102:1554-1559.

Boyle, B. 1992. Fossil detail leaps with double polarization. The Professional Photographers of Canada, 22:10-12.

Briggs, D.E.G., Erwin, D.H., and Collier, F.J. 1994. The Fossils of the Burgess Shale. Smithsonian Institution Press, Washington, DC.

Bright, M. and Lallier, F.H. 2010. The biology of vestimentiferan tube worms. Oceanography and Marine Biology: An Annual Review, 48:213-266.

Butterfield, N.J. 1990. A reassessment of the enigmatic Burgess Shale fossil Wiwaxia corrugata (Matthew) and its relationship to the polychaete Canadia spinosa Walcott. Paleobiology, 16:287-303.

Butterfield, N.J. 1995. Chancelloriids from the Middle Cambrian of the Mackenzie Mountains: implications for early poriferan evolution. Geological Society of America Abstracts with Programs, 27:A-269.

Butterfield, N.J. and Nicholas, C.J. 1996. Burgess Shaletype preservation of both non-mineralizing and 'shelly' Cambrian organisms from the Mackenzie Mountains, northwestern Canada. Journal of Paleontology, 70:893-899.

Caron, J.-B. 2005. Taphonomy and community analysis of the Middle Cambrian Greater Phyllopod Bed, Burgess Shale. Ph.D. Thesis, University of Toronto, Toronto, Ontario.

Caron, J.-B. and Jackson, D.A. 2008. Paleoecology of the Greater Phyllopod Bed community, Burgess Shale. Palaeogeography, Palaeoclimatology, Palaeoecology, 258:222-256.

Carter, H.J. 1872. Description, with illustrations, of a new species of Aplysina from the N.W. coast of Spain. Annals and Magazine of Natural History, Ser. 4, 10:101-110.

Carter, H.J. 1881. On the development of the fibre in the Spongida. Annals and Magazine of Natural History, Ser. 5, 8:112-122.

Chanas, B. and Pawlik, J.R. 1995. Defenses of Caribbean sponges against predatory reef fish .2. Spicules, tissue toughness, and nutritional quality. Marine Ecology Progress Series, 127:195-211.

Chanas, B. and Pawlik, J.R. 1996. Does the skeleton of a sponge provide a defense against predatory reef fish? Oecologia, 107:225-231.

Chen, J.-Y. 2012. Evolutionary scenario of the early history of the animal kingdom: Evidence from Precambrian (Ediacaran) Weng'an and Early Cambrian Maotianshan Biotas, China. In Talent, J.A. (ed.), Earth and Life. Global Biodiversity, Extinction Intervals and Biogeographic Perturbations Through Time. International Year of Planet Earth. Springer, Dordrecht.
Chen, J. and Zhou, G. 1997. Biology of the Chengjiang fauna, p. 11-105. In Chen, J., Cheng, Y.-n., and Van Iten, H.V. (eds.), The Cambrian Explosion and the Fossil Record. Bulletin of the National Museum of Natural Science. National Museum of Natural Science, Taichung, Taiwan.

Chen J.Y., Zhou G.Q., Zhu M.Y., and Yeh K.Y. 1996. The Chengjiang Biota. A Unique Window of the Cambrian Explosion. The National Museum of Natural Science, Taichung, Taiwan. (In Chinese)

Clausen, S. and Álvaro, J.J. 2006. Skeletonized microfossils from the Lower-Middle Cambrian transition of the Cantabrian Mountains, northern Spain. Acta Palaeontologica Polonica, 51:223-238.

Conway Morris, S. 1985. The Middle Cambrian metazoan Wiwaxia corrugata (Matthew) from the Burgess Shale and Ogygopsis Shale, British Columbia, Canada. Philosophical Transactions of the Royal Society of London, B, 307:507-586.

Conway Morris, S. 1998. The Crucible of Creation. Oxford University Press, Oxford.

Conway Morris, S. and Caron, J.-B. 2007. Halwaxiids and the early evolution of the lophotrochozoans. Science, 315:1255-1258.

Conway Morris, S. and Chapman, A.J. 1996. Lower Cambrian coeloscleritophorans (Ninella, Siphogonuchites) from Xinjiang, and Shaanxi, China. Geological Magazine, 133:33-51.

Conway Morris, S. and Peel, J.S. 1990. Articulated halkieriids from the Lower Cambrian of north Greenland. Nature, 345:802-805.

Conway Morris, S. and Peel, J.S. 1995. Articulated halkieriids from the Lower Cambrian of North Greenland and their role in early protostome evolution. Philosophical Transactions of the Royal Society of London B, 347:305-358.

de Laubenfels, M.W. 1955. Porifera, p. 21-112. In Moore, R.C. (ed.), Treatise on Invertebrate Paleontology. Geological Society of America and University of Kansas Press, Lawrence, Kansas.

De Vos, L., Rützler, K., Boury-Esnault, N., Donadey, C., and Vacelet, J. 1991. Atlas of Sponge Morphology. [Atlas de morphologie des éponges.]. Smithsonian Institution Press, Washington, DC.

Demidenko, Y.E. 2000. Novye sklerity khantselloriid iz nizhnego kembriya yuzhnoj Avstralii. [New chancelloriid sclerites from the Lower Cambrian of South Australia.]. Paleontologicheskij zhurnal, 2000:20-24. (In Russian)

Devereux, M.G. 2001. Palaeoecology of the Middle Cambrian Raymond Quarry fauna, Burgess Shale, British Columbia. M.Sc. Thesis, University of Western Ontario, London, ON.

Doré, F. and Reid, R.E. 1965. Allonnia tripodophora nov. gen., nov. sp., nouvelle Eponge du Cambrien inférieur de Carteret (Manche). C.R. Sommaire des Séances de la Société Géologique de France, 1965:20-21. 
Dornbos, S.Q., Bottjer, D.J., and Chen, J.-Y. 2005. Paleoecology of benthic metazoans in the Early Cambrian Maotianshan Shale biota and the Middle Cambrian Burgess Shale biota: evidence for the Cambrian substrate revolution. Palaeogeography, Palaeoclimatology, Palaeoecology, 220:47-67.

Dzik, J. 1986. Turrilepadida and other Machaeridia., p. 116-134. In Hoffman, A. and Nitecki, M.H. (eds.), Problematic Fossil Taxa. Oxford Monographs on Geology and Geophysics. Oxford U. P., N.Y., and Clarendon, Oxford.

Dzik, J. 1994. Evolution of 'small shelly fossils' assemblages of the Early Paleozoic. Acta Palaeontologica Polonica, 39:247-313.

Ebner, V.v. 1887. Über den feineren Bau der Skelettheile der Kalkschwämme nebst Bemerkungen über Kalkskelette überhaupt. Sonder-Berichte der Akademie der Wissenschaften, Wien, Abt. 1, 95:55-149.

Eibye-Jacobsen, D. 2004. A reevaluation of Wiwaxia and the polychaetes of the Burgess Shale. Lethaia, 37:317-335.

Elicki, O. 2011. First skeletal microfauna from the Cambrian Series 3 of the Jordan Rift Valley (Middle East). Memoirs of the Association of Australasian Palaeontologists, 42:153-173.

Elliott, G.R.D. and Leys, S.P. 2007. Coordinated contractions effectively expel water from the aquiferous system of a freshwater sponge. Journal of Experimental Biology, 210:3736-3748.

Fernández Remolar, D.C. 2001. Chancelloriidae del Ovetiense Inferior de la Sierra de Córdoba, España. [Chancelloridae from the lower Ovetian of Sierra de Cordoba, Spain.]. Revista Española de Paleontología, 16:39-61.

Finks, R.M. 1970. The evolution and ecologic history of sponges during Palaeozoic times., p. 3-22. In Fry, W.G. (ed.), The Biology of the Porifera. Symposia of the Zoological Society of London. Academic Press, London.

Fletcher, T.P. and Collins, D.H. 1998. The Middle Cambrian Burgess Shale and its relationship to the Stephen Formation in the southern Canadian Rocky Mountains. Canadian Journal of Earth Sciences, 35:413-436.

Fuchs, G. and Mostler, H. 1972. Der erste Nachweis von Fossilien (kambrischen Alters) in der Hazira-Formation, Hazara, Pakistan. Geologisch-Paläontologische Mitteilungen Innsbruck, 3:1-12.

Garrone, R. and Exposito, J.Y. 1992. The collagen family of proteins: two distinct lines of evolution. Belgian Journal of Zoology, 122:17-22.

Garrone, R., Simpson, T.L., and Pottu-Boumendil, J. 1981. Ultrastructure and deposition of silica in sponges., p. 495-525. In Simpson, T.L. and Volcani, B.E. (eds.), Silicon and siliceous structures in biological systems. Springer, New York, New York.
Gilis, M., Baronnet, A., Dubois, P., Legras, L., Grauby, O., and Willenz, P. 2012. Biologically controlled mineralization in the hypercalcified sponge Petrobiona massiliana (Calcarea, Calcaronea). Journal of Structural Biology, 178:279-289.

Gilis, M., Grauby, O., Willenz, P., Dubois, P., Heresanu, V., and Baronnet, A. 2013. Biomineralization in living hypercalcified demosponges: Toward a shared mechanism? Journal of Structural Biology, 183:441454.

Goryanskij, V.Y. 1973. O neobkhodimosti isklyucheniya roda Chancelloria Walcott iz tipa gubok. [On the necessity of excluding the genus Chancelloria Walcott from the sponge phylum.], p. 39-44. In Zhuravleva, I.T. (ed.), Problemy paleontologii $i$ biostratigrafiki nizhnego kembriya Sibiri i Dal'nego vostoka. Trudy Instituta Geologii i Geofiziki SO AN SSSR. (In Russian)

Grigor'eva, N.V. and Zhuravleva, I.T. 1983. Skeletnye problematichnye organizmy. [Skeletal problematic organisms.], p. 155-169. In Sokolov, B.S. and Zhuravleva, I.T. (eds.), Yarusnoe raschlenenie nizhnego kembriya Sibiri. Nauka, Moscow. (In Russian)

Gunther, L.F. and Gunther, V.G. 1981. Some Middle Cambrian Fossils of Utah. Geology Studies, 28. Brigham Young University, Department of Geology, Provo, Utah.

Hartman, W.D. 1981. Form and distribution of silica in sponges, p. 453-493. In Simpson, T.L. and Volcani, B.E. (eds.), Silicon and Siliceous Structures in Biological Systems. Springer, New York, New York.

Hartman, W.D., Wendt, J.W., and Wiedenmayer, F. 1980. Living and Fossil Sponges. Sedimenta, 7. The University of Miami, Miami, Florida.

Harvey, T.H.P. and Butterfield, N.J. 2011. Great Canadian Lagerstätten 2. Macro- and Microfossils of the Mount Cap Formation (Early and Middle Cambrian, Northwest Territories). Geoscience Canada, 38:165173.

Hill, M.S., Lopez, N.A., and Young, K.A. 2005. Anti-predator defenses in western North Atlantic sponges with evidence of enhanced defense through interactions between spicules and chemicals. Marine Ecology Progress Series, 291:93-102.

Hou, X., Bergström, J., Wang, H., Feng, X. and Chen, A. 1999. The Chengjiang Fauna. Exceptionally WellPreserved Animals from 530 Million Years Ago. Yunnan Science and Technology Press, Kunming. (In Chinese, with an English summary)

Hu, S., Zhu, M., Steiner, M., Luo, H., Zhao, F., and Liu, Q. 2010. Biodiversity and taphonomy of the Early Cambrian Guanshan biota, eastern Yunnan. Science China Earth Sciences, 53:1765-1773.

Hyman, L.H. 1940. The Invertebrates: Protozoa through Ctenophora. McGraw-Hill, New York, New York.

Ilan, M., Aizenberg, J., and Gilor, O. 1996. Dynamics and growth patterns of calcareous sponge spicules. Proceedings of the Royal Society of London. B. Biological Sciences, 263:133-139. 
Imsiecke, G., Steffen, R., Custodio, M., Borojevic, R., and Müller, W.E.G. 1995. Formation of spicules by sclerocytes from the freshwater sponge Ephydatia muelleri in short-term cultures in vitro. In Vitro Cellular and Developmental Biology Animal, 31:528-535.

Janussen, D., Steiner, M., and Zhu M. 2002. New wellpreserved scleritomes of Chancelloridae from the Early Cambrian Yuanshan Formation (Chengjiang, China) and the Middle Cambrian Wheeler Shale (Utah, USA) and paleobiological implications. Journal of Paleontology, 76:596-606.

Jell, P.A. 1981. Thambetolepis delicata gen. et sp. nov., an enigmatic fossil from the Early Cambrian of South Australia. Alcheringa, 5:85-93.

Jones, W.C. 1955. Crystalline properties of spicules of Leucosolenia complicata. Quarterly Journal of Microscopical Sciences, 96:129-149.

Jones, W.C. 1970. The composition, development, form and orientation of calcareous sponge spicules, p. 91123. In Fry, W.G. (ed.), The Biology of the Porifera. Symposia of the Zoological Society of London. Academic Press, London.

Jones, W.C. 1979. The microstructure and genesis of sponge biominerals, p. 425-447, Biologie des spongiaires. Colloques internationaux du C.N.R.S.

Kloss, T.J., Dornbos, S.Q., and Chen, J.-Y. 2009. Paleoecology and taphonomy of the Early Cambrian Maotianshan Shale biota chancelloriid Allonnia junyuani: Adaptation to nonactualistic Cambrian substrates. Palaeogeography, Palaeoclimatology, Palaeoecology, 277:149-157.

Kouchinsky, A.V. 2000. Shell microstructures in Early Cambrian molluscs. Acta Palaeontologica Polonica, 45:119-150.

Kruse, P.D., Zhuravlev, A.Y., and James, N.P. 1995. Primordial metazoan-calcimicrobial reefs: Lower Cambrian, Aldan river, Siberian Platform. Palaios, 10:291-321.

LeHouerou, H.N. 1996. The role of cacti (Opuntia spp) in erosion control, land reclamation, rehabilitation and agricultural development in the Mediterranean basin. Journal of Arid Environments, 33:135-159.

Lévi, C. and Porte, A. 1962. Étude au microscope électronique de l'éponge Oscarella lobularis Schmidt et de sa larve amphiblastula. Cahiers de Biologie Marine, 3:307-315.

Leys, S.P. 2007. Sponge coordination, tissues, and the evolution of gastrulation., p. 53-59. In Custódio, M., Lôbo-Hajdu, G., Hajdu, E., and Muricy, G. (eds.), Porifera Reserach: Biodiversity, Innovation and Sustainability. Museu Nacional, Rio de Janeiro.

Li, G.-X. 1999. Early Cambrian chancelloriids from Emei, Sichuan Province, SW China. Acta Palaeontologica Sinica, 38:238-247. (In Chinese, with an English summary)

Liu, Q. and Lei, Q. 2013. Discovery of an exceptionally preserved fossil assemblage in the Balang Formation (Cambrian Series 2, Stage 4) in Hunan, China. Alcheringa, 37:269-271.
Maldonado, M. 2009. Embryonic development of verongid demosponges supports the independent acquisition of spongin skeletons as an alternative to the siliceous skeleton of sponges. Biological Journal of the Linnean Society, 97:427-447.

McNair, G.T. 1923. Motor reactions of the fresh-water sponge, Ephydatia fluviatilis. Biological Bulletin, 44:153-166.

Mehl, D. 1996. Organization and microstructure of the chancelloriid skeleton: implications for the biomineralization of the Chancelloriidae. Bulletin de I'Institut océanographique, Monaco, no. spécial, 14:377-385.

Mehl, D. 1998. Porifera and Chancelloriidae from the Middle Cambrian of the Georgina Basin, Australia. Palaeontology, 41:1153-1182.

Minchin, E.A. 1898. Materials for a monograph of the ascons. I. On the origin and growth of the triradiate and quadriradiate spicules in the family Clathrinidae. Quarterly Journal of Microscopical Sciences, 40:569-588.

Minchin, E.A. 1908. Materials for a monograph of the ascons. II. The formation of spicules in the genus Leucosolenia, with some notes on the histology of the sponges. Quarterly Journal of Microscopical Sciences, 52:301-335.

Missarzhevsky, V.V. 1989. Drevnejshie skeletnye okamenelosti i stratigrafiya pogranichnykh tolshch dokembriya i kembriya. [The oldest skeletal fossils and stratigraphy of the Precambrian-Cambrian boundary beds.]. Trudy Geologicheskogo Instituta AN SSSR, 443:1-237. (In Russian)

Moore, J.L., Li, G., and Porter, S.M. 2014. Chancelloriid sclerites from the Lower Cambrian (Meishucunian) of eastern Yunnan, China, and the early history of the group. Palaeontology, 57:833-878.

Moore, J.L., Porter, S.M., Steiner, M., and Li, G. 2010. Cambrothyra ampulliformis, an unusual coeloscleritophoran from the Lower Cambrian of Shaanxi Province, China. Journal of Paleontology, 84:1040-1060.

Mostler, H. 1980. Zur Mikrofauna des Unterkambriums in der Haziraformation - Hazara, Pakistan. Annalen des Naturhistorischen Museums in Wien, 83:245257.

Mostler, H. 1985. Neue heteractinide Spongien (Calcispongea) aus dem Unter- und Mittelkambrium Südwestsardiniens. Berichte des Naturwissenschaftlichen-Medizinischen Vereins in Innsbruck, 72:7-32.

Mostler, H. and Mosleh-Yazdi, A. 1976. Neue Poriferen aus oberkambrischen Gesteinen der Milaformation im Elburzgebirge (Iran). Geologisch-Paläontologische Mitteilungen Innsbruck, 5:1-36.

Müller, F. 1865. Ueber Darwinella aurea, einen Schwamm mit sternförmigen Hornnadeln. Archiv für mikroskopische Anatomie, 1:344-353.

Müller, W.E.G., Belikov, S.I., Tremel, W., Perry, C.C., Gieskes, W.W.C., Boreiko, A. and Schröder, H.C. 2006. Siliceous spicules in marine demosponges (example Suberites domuncula). Micron, 37:107120. 
Orrhage, L. 1971. Light and electron microscope studies of some annelid setae. Acta Zoologica, 52:157-169.

Oshel, E. and Steele, D.H. 1985. Amphipod Paramphithoe hystrix: a micropredator on the sponge Haliclona ventilabrum. Marine Ecology Progress Series, 23:307-309.

Porter, S.M. 2004. Halkieriids in Middle Cambrian phosphatic limestones from Australia. Journal of Paleontology, 78:574-590.

Porter, S.M. 2008. Skeletal microstructure indicates chancelloriids and halkieriids are closely related. Palaeontology, 51:865-879.

Qian, Y. and Bengtson, S. 1989. Palaeontology and biostratigraphy of the Early Cambrian Meishucunian Stage in Yunnan Province, South China. Fossils and Strata, 24:1-156.

Randell, R.D., Lieberman, B.S., Hasiotis, S.T., and Pope, M.C. 2005. New chancelloriids from the Early Cambrian Sekwi Formation with a comment on chancelloriid affinities. Journal of Paleontology, 79:987-996.

Reid, R.E.H. 1959. Occurrence of Chancelloria Walcott in the Comley Limestone. Geological Magazine, 96:261-262.

Reid, R.E.H. 1967. Hyalostelia Zittel and the Heteractinellida. Geological Magazine, 104:398-399.

Reiswig, H.M. 1971a. The axial symmetry of sponge spicules and its phylogenetic significance. Cahiers de Biologie Marine, 12:505-514.

Reiswig, H.M. 1971b. Particle feeding in natural populations of three marine demosponges. Biological Bulletin, 141:568-591.

Reitner, J., Wörheide, G., Lange, R., and Thiel, V. 1997. Biomineralization of calcified skeletons in three Pacific coralline demosponges - an approach to the evolution of basal skeletons. Courier Forschungsinstitut Senckenberg, 201:373-383.

Rezvoj, P.D., Zhuravleva, I.T., and Koltun, V.M. 1962. Klass Porifera (Spongia). [Class Porifera (Spongia).], p. 17-74. In Sokolov, B.S. (ed.), Gubki, Arkheotsiaty, Kishechnopolostnye, Chervi. Osnovy Paleontologii. Izdatel'stvo Akademii Nauk SSSR, Moskva. (In Russian)

Ribes, M., Coma, R., and Gili, J.-M. 1999. Natural diet and grazing rate of the temperate sponge Dysidea avara (Demospongiae, Dendroceratida) throughout an annual cycle. Marine Ecology Progress Series, 176:179-190.

Rietschel, S. 1968. Die Octactinellida und innen verwandte paläozoische Kalkschwämme (Porifera, Calcarea). Paläontologische Zeitschrift, 42:13-22.

Rigby, J.K. 1976. Some observations on occurrences of Cambrian Porifera in western North America and their evolution. Brigham Young University Geology Studies, 23:51-60.

Rigby, J.K. 1978. Porifera of the Middle Cambrian Wheeler Shale, from the Wheeler Amphitheater, House Range, in western Utah. Journal of Paleontology, 52:1325-1345.
Rigby, J.K. 1983. Heteractinida., p. 70-89. In Broadhead, T. (ed.), Sponges and Spongiomorphs - Notes for a Short Course. University of Tennessee, Department of Geological Sciences, Studies in Geology.

Rigby, J.K. 1986. Sponges of the Burgess Shale (Middle Cambrian), British Columbia. Palaeontographica Canadiana, 2:1-105.

Rigby, J.K. and Collins, D. 2004. Sponges of the Middle Cambrian Burgess Shale and Stephen Formations, British Columbia. ROM Contributions in Science, 1:1-155

Rigby, J.K. and Nitecki, M.H. 1975. An unusually well preserved heteractinid sponge from the Pennsylvanian of Illinois and a possible classification and evolutionary scheme for the Heteractinida. Journal of Paleontology, 49:329-339.

Robison, R.A. 1964. Late Middle Cambrian faunas from western Utah. Journal of Paleontology, 38:510-566.

Romanenko, E.V. 1968. Kembrijskie gubki otryada Heteractinellida Altaya. [Cambrian sponges of the order Heteractinellida from Altaj.]. Paleontologicheskij zhurnal, 1968:134-137. (In Russian)

Rowland, S.M. and Gangloff, R.A. 1988. Structure and paleoecology of Lower Cambrian reefs. Palaios, 3:111-135.

Rozanov, A.Y. 1986. Problematica of the Early Cambrian, p. 87-96. In Hoffman, A. and Nitecki, M.H. (eds.), Problematic Fossil Taxa. Oxford Monographs on Geology and Geophysics. Oxford U. P., N.Y., and Clarendon, Oxford.

Runnegar, B. 1985. Collagen gene construction and evoIution. Journal of Molecular Evolution, 22:141-149.

Rusconi, C. 1954. Nuevas especies cámbricas del cerro Aspero. Boletin Paleontologico de Buenos Aires, 29:2 pp.

Schmidt, W.J. 1924. Bausteine des Tierkörpers in polarisiertem Lichte. Friedrich Cohen, Bonn.

Sdzuy, K. 1969. Unter- und mittelkambrische Porifera (Chancelloriida und Hexactinellida). Paläontologische Zeitschrift, 43:115-147.

Sethmann, I. and Wörheide, G. 2008. Structure and composition of calcareous sponge spicules: A review and comparison to structurally related biominerals. Micron, 39:209-228.

Shore, R.E. 1972. Axial filament of siliceous sponge spicules, its organic components and synthesis. Biological Bulletin, 143:689-698.

Smith, M.R. 2014. Ontogeny, morphology and taxonomy of the soft-bodied Cambrian 'mollusc' Wiwaxia. Palaeontology, 57:215-229.

Sollas, W.J. 1885a. Note on the artificial deposition of crystals of calcite on spicules of a calci-sponge. The Scientific Proceedings of the Royal Dublin Society, $5: 73$.

Sollas, W.J. 1885b. On the physical characters of calcareous and siliceous sponges. The Scientific Proceedings of the Royal Dublin Society, 4:374-392. 
Sperling, E.A., Pisani, D., and Peterson, K.J. 2007. Poriferan paraphyly and its implications for Precambrian paleobiology. Geological Society, London, Special Publications, 286:355-368.

Theimer, T.C. and Bateman, G.C. 1992. Patterns of prickly-pear herbivory by collared peccaries. Journal of Wildlife Management, 56:234-240.

Thurber, A.R. 2007. Diets of Antarctic sponges: links between the pelagic microbial loop and benthic metazoan food web. Marine Ecology Progress Series, 351:77-89.

Uriz, M.-J. 2006. Mineral skeletogenesis in sponges. Canadian Journal of Zoology, 84:322-356.

Vacelet, J. 1971a. L'ultrastructure de la cuticule d'éponges cornées du genre Verongia. Journal de Microscopie, 10:113-116.

Vacelet, J. 1971b. Ultrastructure et formation des fibres de spongine d'éponges cornées Verongia. Journal de Microscopie, 10:13-32.

Vacelet, J. 1985. Coralline sponges and the evolution of the Porifera, p. 1-13. In Conway Morris, S., George, J.D., Gibson, R., and Platt, H.M. (eds.), The Origins and Relationships of Lower Invertebrates. The Systematics Association, Special Volume. Clarendon Press, Oxford.

Vacelet, J., Verdenal, B., and Perinet, G. 1988. The iron mineralization of Spongia officinalis L. (Porifera, Dicytoceratida) and its relationships with the collagen skeleton. Biology of the Cell, 62:189-198.

van Trigt, H. 1919. A contribution to the physiology of the freshwater sponges (Spongillidae). Tijdschrift voor Diergeneeskunde Ser. 2, 17:1-220.

van Weel, P.B. 1949. On the physiology of the tropical freshwater sponge Spongilla proliferens Annand. I. Ingestion, digestion, and excretion. Physiologia Comparata et Oecologia, 1:110-126.

Vasil'eva, N.I. 1985. K sistematike otryada Chancelloriida Walcott, 1920 (incertae sedis) iz nizhnekembrijskikh otlozhenij vostoka Sibirskoj platformy. [On the systematics of the order Chancelloriida Walcott, 1920 (incertae sedis) from Lower Cambrian deposits of the western part of the Siberian Platform.], p. 115-126. In Sokolov, B.S. and Zhuravleva, I.T. (eds.), Problematiki pozdnego dokembriya i paleozoya. Trudy Instituta Geologii i Geofiziki SO AN SSSR. (In Russian.)

Vennin, E., Álvaro, J.J., Moreno-Eiris, E., and Perejón, A. 2003. Early Cambiran coelobiontic communities in tectonically unstable crevices developed in Neoproterozoic andesites. Lethaia, 36:53-65.

Vinther, J. 2009. The canal system in sclerites of Lower Cambrian Sinosachites (Halkieriidae: Sachitida): significance for the molluscan affinities of the sachitids. Palaeontology, 52:689-712.

Vinther, J. and Nielsen, C. 2005. The Early Cambrian Halkieria is a mollusc. Zoologica Scripta, 34:81-89.
Waddell, B. and Pawlik, J.R. 2000a. Defenses of Caribbean sponges against invertebrate predators. I. Assays with hermit crabs. Marine Ecology Progress Series, 195:125-132.

Waddell, B. and Pawlik, J.R. 2000b. Defenses of Caribbean sponges against invertebrate predators. II. Assays with sea stars. Marine Ecology Progress Series, 195:133-144.

Wainwright, S.A., Biggs, W.D., Currey, J.D., and Gosline, J.M. 1976. Mechanical Design in Organisms. Edward Arnold, London.

Walcott, C.D. 1920. Cambrian geology and paleontology IV:6 - Middle Cambrian Spongiae. Smithsonian Miscellaneous Collections, 67:261-364.

Weissenfels, N. 1978. Bau und Funktion des Süßwasserschwammes Ephydatia fluviatilis L. (Porifera). V. Das Nadelskelet und seine Entstehung. Zoologisches Jahrbuch für Anatomie, 99:211-233.

Whittington, H.B. 1985. The Burgess Shale. Yale University Press, New Haven, Connecticut.

Wilkinson, C.R. and Garrone, R. 1980. Ultrastructure of siliceous spicules and microsclerocytes in the marine sponge, Neofibularia irata, new species. Journal of Morphology, 166:51-64.

Williams, A. and Holmer, L.E. 2002. Shell structure and inferred growth, functions and affinities of the sclerites of the problematic Micrina. Palaeontology, 45:845-873.

Wood, R.A. 1991. Non-spicular biomineralization in calcified demosponges., p. 322-340. In Reitner, J. and Keupp, H. (eds.), Fossil and Recent Sponges. Springer, Berlin.

Woodland, W. 1905. Studies in spicule formation. I. The development and structure of the spicules in Sycons: with remarks on the conformation, modes of disposition and evolution of spicules in calcareous sponges generally. Quarterly Journal of Microscopical Sciences, 49 NS:231-282.

Wrona, R. 2004. Cambrian microfossils from glacial erratics of King George Island, Antarctica. Acta Palaeontologica Polonica, 49:13-56.

Yochelson, E.L. 1993. Molluscan affinity of coeloscleritophorans. Lethaia, 26:47-48.

Zhao, Y., Zhu, M., Babcock, L.E., Yuan, J., Parsley, R.L., Peng, J., Yang, X., and Wang, Y. 2005. Kaili biota: a taphonomic window on diversification of metazoans from the basal Middle Cambrian: Guizhou, China. Acta Geologica Sinica, 79:751-765.

Zhuravleva, I.T. and Kordeh, K.B. 1955. Nakhodka gubki Chancelloria Walcott v otlozheniyakh nizhnego kembriya Sibiri. [Discovery of the sponge Chancelloria Walcott in the Lower Cambrian deposits of Siberia.]. Doklady AN SSSR, 104:474-477. (In Russian)

Ziegler, B. and Rietschel, S. 1970. Phylogenetic relationships of fossil calcisponges. Symposia of the Zoological Society of London, 25:23-40. 